University of Massachusetts Amherst

ScholarWorks@UMass Amherst

Masters Theses 1911 - February 2014

1973

\title{
Availability of an avoidance response as related to fear and anxiety
}

Jack Alexander Szpiler

University of Massachusetts Amherst

Follow this and additional works at: https://scholarworks.umass.edu/theses

Szpiler, Jack Alexander, "Availability of an avoidance response as related to fear and anxiety" (1973). Masters Theses 1911 - February 2014. 2021.

Retrieved from https://scholarworks.umass.edu/theses/2021

This thesis is brought to you for free and open access by ScholarWorks@UMass Amherst. It has been accepted for inclusion in Masters Theses 1911 - February 2014 by an authorized administrator of ScholarWorks@UMass Amherst. For more information, please contact scholarworks@library.umass.edu. 
FIVE COLLEGE : DEPOSITORY 
AVAILABILITY OF AN AVOIDANCE RESPONSE AS RELATED TO FEAR AND ANXIETY

A Thesis Presented

By

Jack Alexander Szpiler

Submitted to the Graduate School of the

University of Massachusetts in partial

fulfillment of the requirements for the degree of

MASTER OF SCIENCE

NOVEMBER 1973

DEPARTMENT OF PSYCHOLOGY 
ii

AVAILABILITY OF AN AVOIDANCE RESPONSE AS RELATED TO FEAR AND ANXIETY

A Thesis

By

Jack Alexander Szpiler

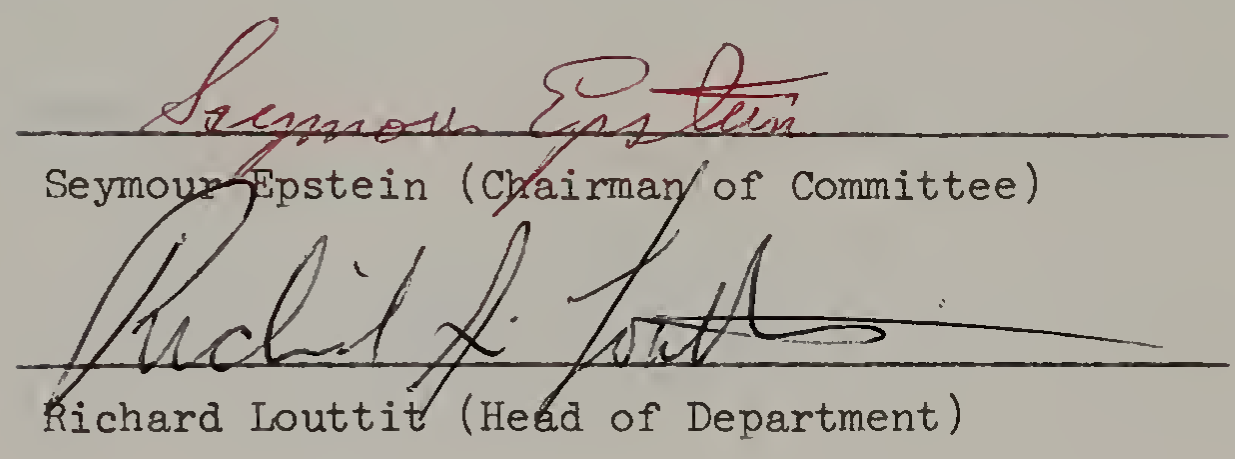

Patricia Wove

Patricia Wisocki (Member)

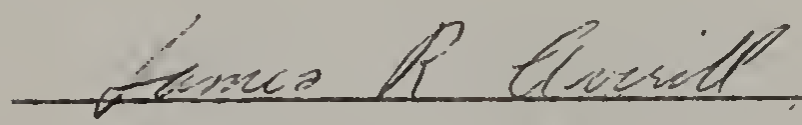

James R. Averill (Member)

November, 1973 


\section{ACKNOWLEDGMENTS}

I wish to thank the members of my committee Patricia Wisocki, Ph. D., and James Averill, Ph. D., for their professional advice and enduring patience. I would like to extend a special note of appreciation to my Chairman, Seymour Epstein, Ph. D., for his invaluable comments, his concern and his total involvement in this project. 


\section{TABLE OF CONTENTS}

INTRODUCTION

METHOD

Subjects

Apparatus

Procedure

Analysis of Data

RESULTS

Tapping Rate

Tonic Heart Rato

Heart Rate Variability

Phasic Heart Rate

Basal Skin Conductance

Specific GSRs

Adjective Check List
Scoring \& Data Reduction

1

2

3

3

3

4

5

6

6

8

12

12

15

21

29

31

36

SUMMARY

37

REFERENCES

39 


\section{LIST OF TABLES}

1. Summary of $F$ Values for Analysis of Variance of Heart Rate.

2. Summary of $F$ Values for Analysis of Variance of Basal Skin Conductance. 


\section{LIST OF FIGURES}

1. Mean tapping rate for practice trials, trial 1 and trial 6.

2. Mean Prestimulus Heart Rato for total count-up period pooled over trials.

3. Mean Phasic Heart Rato for total count-up period.

4. Mean Prestimulus Basal Skin Conductance for total count-up period pooled over trials.

5. Mean Prestimulus Basal Skin Conductance for total anticipatory period for 2 tapping groups.

6. Mean Stimulus Periods compared to each other for Basal Skin Conductance over total anticipatory period for all groups pooled over trials.

7. Mean Phasic GSR for total count-up period for all groups.

8. Mean number of Nonspecific GSRs over total count-up period for all groups pooled over trials.

9. Mean Stimulus Periods compared to each other for Nonspecific GSRs over total anticipatory period for all groups pooled over trials.

10. Mean Anxiety Scores for all groups as a function of time of testing. 
Based upon a number of studies on sport parachuting (e.g., Epstein \& Fenz, 1965: Fenz \& Epstein, 1967). Epstein has proposed that anxiety and fear can be differentiated in terms of available response tendencies (Epstein, 1967). Epstein believes that perception of threat induces a heightened state of arousal. This arousal is to be distinguished from both fear and anxiety, in that it is more basic than either emotion. Anxiety is defined as a "state" in which an individual experiences diffuse arousal, but is unable to direct this arousal into purposive action." Fear, on the other hand, is a "motivated state of directed avoidance" (Epstein, 1970).

According to Epstein. fear and anxiety often occur together, with the relative contribution of each depending upon the degree of which $\underline{S}$ is committed to a specific avoidance response. The present study was undertaken to test this hypothesis. Preliminary findings (Epstein \& Kling, 1970; Epstein, Solomon \& Brent, 1970; Katkin, 1965; Katkin, 1966) have found that nonspecific GSRs are a measure of diffuse anxiety. It was anticipated, therefore, that frequency of nonspecific GSRs might be a particularly effective physiological measure for discriminating between fear and anxiety. It was further anticipated that $\underline{\text { Ss }}$ could verbally distinguish between anxiety and fear, and, accordingly would endorse different adjectives in describing the experimentally induced states of fear and anxiety. This is based on a study (Tomazweski \& Epstein, 1970) involving self-ratings of emotions in every day life with the use of adjective check lists in which separate factors for anxiety and fear were found. 


\section{METHOD}

In this study a count-up paradigm was employed in which numbers on a counter advanced from 1 through 12 during each trial at 15 sec. intervals. There were six trials in all. Subjects in an Avoidance-Tapping Group were able to avoid shock (count 10) by tapping beyond a certain rate on a telegraph key between the numbers 8 and 10 . (As a simple motor response relying upon speed, finger tapping was selected as an avoidance response analogous to running from danger). According to Epstein this should be tantamount to a fear condition because there is a goal directed avoidance response. In a No-Avoidance Tapping Group Ss were also required to tap between the numbers 8 and 10, but were informed that their tapping would have no influence upon the receipt of shock, which would occur on the count of 10 on certain trials selected at random. They were asked to tap as rapidiy as possible, the ostensible purpose being to investigate the effect of motor activity on physiological reactions. This condition should provide an anxiety situation, since no response is available for coping with the shock. Subjects in a No-Tapping Group did not tap and were informed that they would receive a shock on the count of 10 on certain trials selected at random.

A yoked control design was used in which receipt of shock by Ss in the No-Avoidance-Tapping Group and the No-Tapping Group was yoked to $\underline{S s}$ in the Avoidance-Tapping Group. For $S$ s in the AvoidanceTapping Group, the second highest number of taps among 5 practice 
trials was taken as an initial criterion. In the first experimental trial S had to surpass this criterion in order to avoid a shock. On subsequent trials $\underline{S}$ had to surpass tapping speed on the immediately preceding trial in order to avoid a shock. Subjects were not informed of this procedure, but were led to believe they had to surpess a variable criterion in order to avoid being shocked. Subjects - Subjects were 60 male undergraduate volunteers at the University of Massachusetts who were randomly assigned to 3 equal groups. Subjects were solicited from several introductory Psychology courses and from posters advertising the study. Each $\underline{S}$ received either $\$ 2.00$ or, where appropriate, course credits for his time. Apparatus -- A Beckman Model RM Dynograph was used. Skin conductance was measured directly, using Beckman AG-AgCL electrodes $(1.7 \mathrm{~cm}$. diamater), $\mathrm{K}-\mathrm{Y}$ Surgical jelly as the contact medium, and a constant voltage source having an output of .5 volts (Lykken \& Venables, 1971). Heart rate was recorded from chest electrodes.

Shock level was set at 5 milliamps constant current. Shocks were of .5 seconds duration and were administored with a concentric disc electrode (Tursky, Watson \& O'Connell, 1965) and an AC electrostimulator.

Procedure - Upon entering the laboratory, Ss were required to complete an adjective check list ( $A C L$ ). The $A C L$, derived from a previous factor analytic study (Tomazewski \& Epstein, 1971), contained the following two scales: Anxiety (jittery, queasy, butterflies-instomach); and Fear (scared, frightened, panicky, terrified, threatened). 
These adjectives were embedded in a larger group of adjectives that will be examined in another paper. Each $\underline{S}$ was asked to check how well each adjective described his present feeling state. The adjective check list was completed at each of the following 9 times during the experiment: pre-instructions, post-instructions, after each of 6 trials and again immediately following a briof interview at the end of the experiment.

Following the initial completion of the ACL, each $\underline{S}$ was then placed in a sound-proof room. Skin conductance electrodes were attached to the palm of the non-preferred hand. The EKG electrodes were attached on opposite sides of the lower chest. The shock electrode was placed on the ventral side of the wrist of the non-preferred hand.

After calibrating the equipment in the adjacent control room and taking pre-experimental baseline messurements, E returned and presented $\underline{S}$ with a written sheet of instructions, which varied according to group. Upon reading the instructions, $\underline{S}$ was informed about the use of a shock stimulus and of his opportunity to withdraw from the experiment then, or at any later time during the experiment. Two Ss withdrew when informed of the shock. If $\underline{S}$ agreed to participate, $E$ presented the instructions again orally to eliminate any possibility of ambiguity. Following instructions, Ss completed the adjective check list again.

Analysis of Data -- The count-up paradigm provided distinct periods for analysis. These included the entire count-up period (count-up stimuli 1, 4, 7,8,9, 10, 12), an anticipatory period (count-up 
stimuli 1, 4, 7, 8, 9) an impact period (count-up stimulus 10), and a pre-tap period (count-up stimuli 1, 4, 7). A two factor repeated measures analysis of variance was performed, comprising two between and two within variables. There were 3 levels for groups and 2 levels

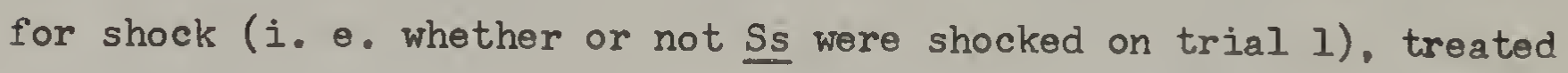

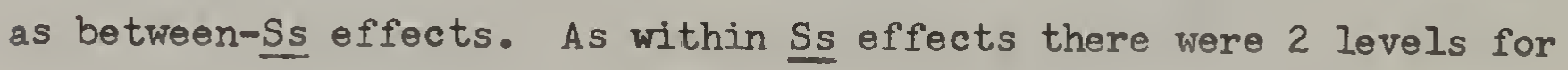
trials and varying levels for the stimuli in the count-up, depending upon whether the analysis was of the pre-tap period, anticipatory period, or the total count-up period, each of which were analysed separately. The trials analysed were of the first (trial 1) and the last(trial 6) trial. The time periods analysed for the Adjective Check List data were the following: pre-instructions, postinstructions, post trial 1, post trial 5 and post experiment. The time period, post trial 5, was examined for the ACL data rather than the time period, post trial 6, to make the subjective scale more comparable to the physiological measures that were examined in trial 6. Ratings obtained from an ACL given post trial 6, might be measuring Ss' reactions to the completion of the experiment rather than their reactions to a possible shock. Scoring and Data Reduction

Heart Rate -- Two scores were taken in measuring hoart rate: the highest beat within 5 seconds preceding stimulus onset, and the highest beat within the 5 seconds following stimulus onset. Change 
scores also were obtained by subtracting each prestimulus value from each poststimulus value.

Galvanic Skin Response -- A specific GSR was recorded if it was initiated between 1 to 3 seconds poststimulus onset. The magnitude of the specific GSR was obtained by taking the difference between the high point within a 1 through 7 second interval poststimulus onset and the low point preceding the high point within the same interval. Nonspecific GSRs -- Nonspecific GSRs were counted if they exceeded .5 micromhos during a 1 second interval and occurred within the count-up period from 3 seconds following stimulus onset to 1 second post onset of the next stimulus for a total interval of 13 seconds. Only frequency was tabulated.

Skin conductance and heart rate were also range corrected to adjust for individual reactivity (Lykken, Rose, Luther and Maley, 1966). Since the transformation produced no additional findings, these data are not presented.

\section{Results}

Tapping Rate -- Tapping rate for the two tapping groups was analysed by an analysis of variance which compared the means for the second highest number of taps during the practice trials and the means of trial 1 and trial 6. The analysis yielded a significant Conditions $x$ Trials interaction ( $F=11.33, \mathrm{~d} f=2 / 76, \mathrm{p}<.001$ ). According to the data presented in Figure 1 the No-Avoidance-Tapping Group had a relatively high tapping rate during the practice trials 
Avoidance-Tapping Group

No-Avoidance-Tapping Group

$-\ldots-\ldots$

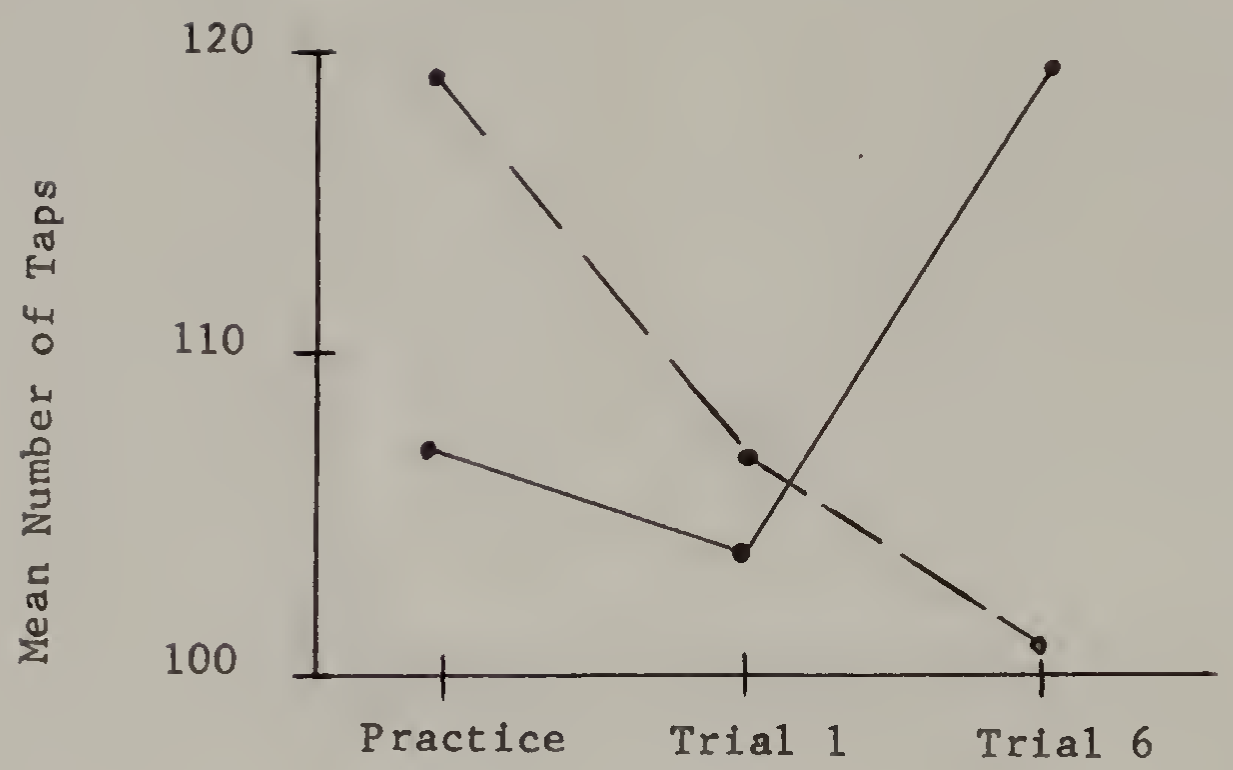

Figure 1. Mean tapping rate for practice trials, trial 1 and trial 6 . 
which decreased during the experiment. The Avoidance-Tapping Group exhibited a low rate of tapping during the practice trials (relative to the No-Avoidance-Tapping Group), which decreased slightly at trial $I$ and increased considerably during the experiment.

A t-test was done comparing the means for the practice trials of the No-Avoidance-Tapping Group (118.8) and of the Avoidance-Tapping Group (107.1). A $\underline{t}$ of -1.30 was obtained which, with 19 df. was not significant at the .05 level. A t-test was also done comparing the means at trial I of the No-Avoidance-Tapping Group (106.9) and of the Avoidance-Tapping Group (104.4), and it was found to be non-significant $(t=.28, d f=19,>.05)$. An additional $\underline{t}$-test showed that the mean tapping rate for the Avoidance-Tapping Group at trial 6 (119.75) was significantly greater than the mean tapping rate for the No-Avoidance-Tapping Group at trial 6 (100.45). A t of 2.28 was obtained which, with $19 \mathrm{df}$. was significant at the .05 level.

Tonic Heart Rate -- Separate analyses of variance were done for pre, post, and post minus pre stimulus measures for the entire count-up period $(1,4,7,8,9,10,12)$. Table 1 presents a summary of the F-Values for the three analyses of variance of heart rate. Table $I$ indicates a highly significant Conditions $\mathrm{x}$ Stimuli interaction for both pre- and poststimulus heart rate. Since poststimulus scores add no new information of interest to that provided by the prestimulus scores, only prestimulus means are plotted in Figure 2. Examining Figure 2 it can be seen that the overall form of the curves for the two tapping groups is similar. Both tapping groups exhibit 
TABLE 1

SUMMARY OF F VALUES FOR ANALYSIS OF

VARIANCE OF HEART RATE

\begin{tabular}{|c|c|c|c|c|c|c|}
\hline \multirow[b]{2}{*}{$\begin{array}{l}\text { Source of } \\
\text { Variance }\end{array}$} & \multicolumn{6}{|c|}{ Measure Analysed } \\
\hline & df & $\begin{array}{l}\text { Prestimulus } \\
\text { Heart Rate }\end{array}$ & $d f$ & $\begin{array}{l}\text { Postimulus } \\
\text { Heart Rate }\end{array}$ & $\mathrm{df}$ & $\begin{array}{l}\text { Change in } \\
\text { Heart Rate }\end{array}$ \\
\hline Groups-C & $\frac{2}{54}$ & $3.61 *$ & $-\frac{2}{54}$ & $4.38 *$ & $\frac{2}{54}$ & $4.11 *$ \\
\hline Shock on Tr\#I-P & $\frac{1}{54}$ & 1.09 & $\frac{7}{54}$ & 1 & $\frac{1}{54}$ & 2.46 \\
\hline Trial-T & $\frac{1}{54}$ & $12.85 * * *$ & $\frac{1}{54}$ & $17.75 * *$ & $\frac{*}{54}$ & 1 \\
\hline Stimuli-W & $\frac{6}{324}$ & $67.45 * * *$ & $\frac{6}{324}$ & $71.14 * *$ & $\frac{* 6}{324}$ & $21.46 * * *$ \\
\hline $\mathrm{CxP}$ & $-\frac{2}{54}$ & 1 & $\frac{2}{54}$ & 1 & $-\frac{2}{54}$ & 1 \\
\hline $\mathrm{CXT}$ & $\frac{2}{54}$ & 1.34 & $-\frac{2}{54}$ & 2.80 & $\frac{2}{54}$ & 1 \\
\hline $\mathrm{PXT}$ & $-\frac{1}{54}$ & 1.13 & $\frac{1}{54}$ & 1 & $\frac{1}{54}$ & 2.61 \\
\hline CxW & $\frac{12}{324}$ & $15.53 * * *$ & $-\frac{12}{54}$ & $10.06 *$ & $\frac{* 12}{54}$ & $2.80 * *$ \\
\hline PxWN & $\frac{6}{324}$ & 1 & $\frac{6}{324}$ & 1.49 & $\frac{6}{324}$ & 1.89 \\
\hline TXW & $\frac{6}{324}$ & 1.83 & $\frac{6}{324}$ & $3.49 *$ & $\frac{6}{324}$ & 1 \\
\hline $\mathrm{CXPXT}$ & $\frac{2}{54}$ & 2.05 & $\frac{2}{54}$ & $3.42 *$ & $\frac{2}{54}$ & 1 \\
\hline CXPXW & $\frac{12}{324}$ & 1 & $\frac{12}{324}$ & 1 & $\frac{12}{324}$ & 1.68 \\
\hline $\operatorname{CxT} x \mathrm{~N}$ & $\frac{12}{324}$ & 1.73 & $\frac{12}{324}$ & 1.27 & $\frac{12}{324}$ & 1.00 \\
\hline PxTXW & $\frac{6}{324}$ & 1 & $\frac{6}{324}$ & 1 & $\frac{6}{324}$ & 1 \\
\hline $\mathrm{CxPxT} \times \mathbb{N}$ & $\frac{12}{324}$ & 1 & $\frac{12}{324}$ & 1.07 & $\frac{12}{324}$ & 1.17 \\
\hline
\end{tabular}

\begin{tabular}{rll}
\hline$* \mathrm{p}$ & .05 \\
$* * \mathrm{p}$ & .01 \\
$* * \mathrm{p}$ & .001
\end{tabular}




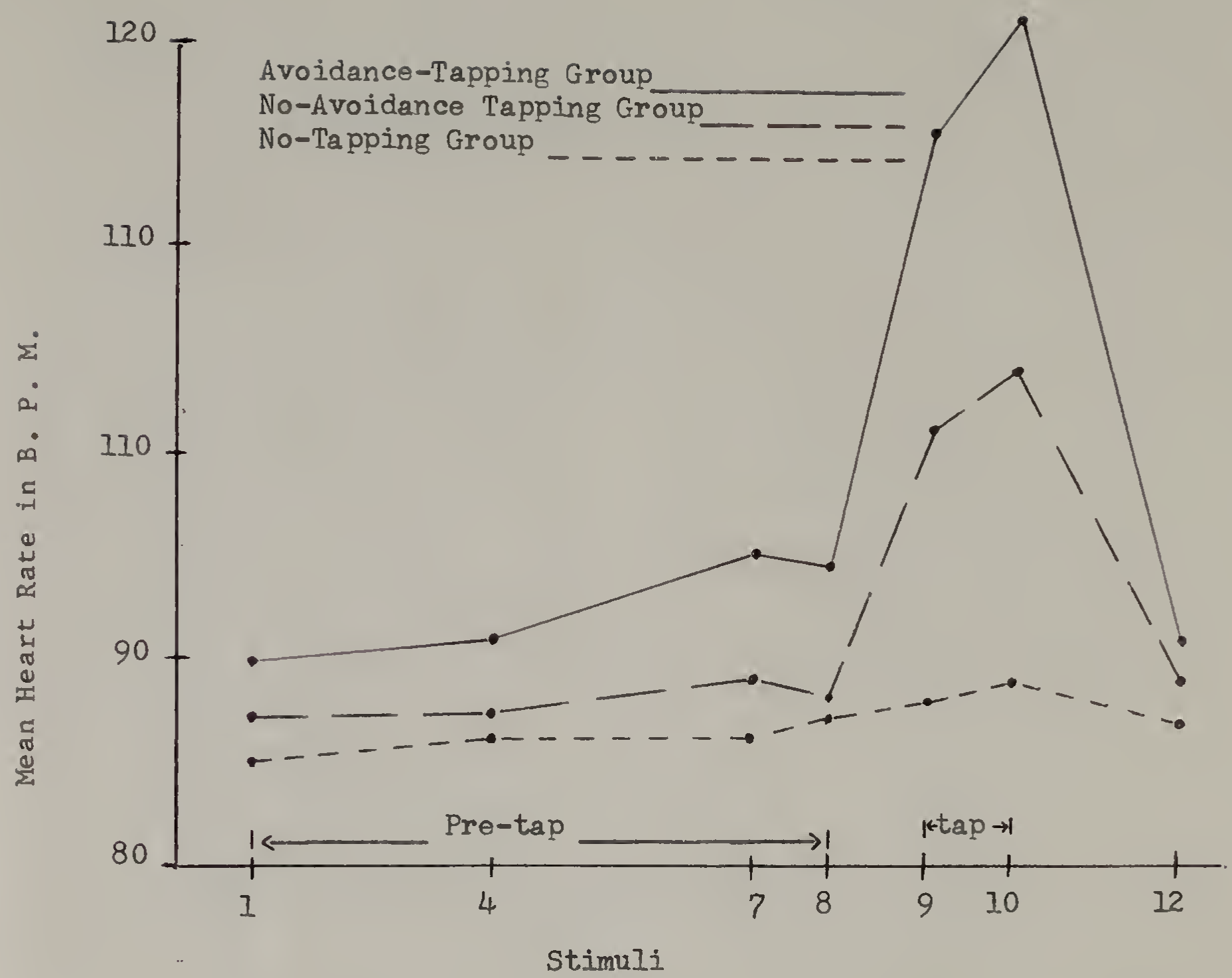

Figure 2. Mean Prestimulus Heart Rate for total count-up period pooled over trials. 
a rise to 7, a slight decrease at pre 8 and a marked acceleration during the tapping period from pre 9 to pre 10 followed by a marked deceleration to count 12. The curve for the No-Tapping Group shows only a slight rise during the tapping period. The greatest disparity among groups occurs during the tapping period, with the AvoidanceTapping Group having the highest heart rate, the No-Avoidance-Tapping Group having the next highest rate and the No-Tapping Group having the lowest heart rate.

Prestimulus means were also analysed for the anticipatory period alone $(1,4,7,8,9,10)$. A main effect was found for Conditions. The mean for the Avoidance-Tapping Group was 101.10, for the No-Avoidance-Tapping Group, 92.84, and for the No-Tapping Group, $87.07(F=4.60, d f=2 / 54, p<.05)$. A main effect was also found for Trials. The mean for Trial 1 was 95.62 , and the mean for Trial 6 was 91.71 $(F=11.95, \mathrm{~d} f=1 / 54, \mathrm{p}<.01$. There was also a main effect for Stimuli ( $F=63.94, d f=5 / 270, p<.001)$. These effects can be seen in Figure 2. A first order interaction for Conditions $x$ Stimuli $(F=15.17, \mathrm{~d} f=10 / 270, \mathrm{p}<.001)$ was produced. This interaction was described in the analysis of the total count-up period and can be seen in Figure 2.

In order to see if the two tapping groups differed from each other, an analysis of variance was done on the prestimulus measures for the anticipatory period, omitting the No-Tapping Group. The analysis produced a significant main effect for stimali ( $F=72.06$, $d f=5 / 180, p<.001)$. A main effect was also found for Trials. The 
mean for Trial 1 was 98.51 , and the mean for Trial 6 was 95.42 $(F=4.46, d f=1 / 36, p<.05)$. The analysis also produced a first order interaction for Conditions $x \operatorname{Stimuli}(F=5.20, d f=5 / 180, p .<.001)$, indicating that the two tapping groups did differ from each other. These effects can be seen in Figure 2.

An additional analysis was done for the prestimulus means for the pre-tap period $(1,4,7,8)$ to see if group differences occur during the period before tapping. No significant differences were found among groups.

Heart Rate Variability - In order to compare heart rate variability between the two tapping groups during the tapping perind, a one-way analysis of variance was performed. Since interest was in deviations around an increasing baseline, the analysis was performed on the standard error of estimates. Heart rate scores on which the standard error of estimates were done were the first beat 5 seconds post count 8 and every third beat thereafter, until 9 beats were recorded. The findings reveal a nonsignificant tendency for there to be greater heart rate variability in the No-Avoidance-Tapping Group than in the Avoidance-Tapping Group during the tapping period $(F=2.89$, $d f=2 / 38, p<.10)$

Phasic Heart Rate -- Change scores for heart rate (post minus pre) were analysed over the total count-up period for all groups. There was a main effect for Conditions. The mean for the AvoidanceTapping Group was 3.10, for the No-Avoidance-Tapping Group, 1.29, and for the No-Tapping Group, $2.19(F=4.11, d f=2 / 54, p<.05)$. A 
significant effect was also found for Stimuli. The means for Stimuli were as follows: Stimulus $1=1.81$; Stimulus $4=1.88$; Stimulus $7=2.89$; Stimulus $8=8.56$; Stimulus $9-3.37$; Stimulus $10=$ -0.13; Stimulus $12=-3.01(F=21.46, d f=6 / 324, p<.001) . A$ significant Conditions $x$ Stimuli interaction $(F=2.80, d f=12 / 324$, $p<.01$ ) was also found and is plotted in Figure 3. The data indicate that both tapping groups exhibit similar curves, which show a steep rise at Stimulus 8 , and a marked decrease to Stimulus 9. The NoTapping Group, however, does not show this effect. It should be noted that count 8 is the only stimulus for which a pre-tapping point is compared to a post-tapping point, and this accounts for the large increase in heart rate to count 8 for the tapping groups. It is noteworthy that the Avoidance-Tapping Group produces a greater reaction to count 8 than the No-Avoidance-Tapping Group.

Change scores were also analysed for the anticipatory period only. A main effect was produced for Conditions. The mean for the Avoidance-Tapping Group was 4.99, for the No-Avoidance-Tapping Group, 3.04, and for the No-Tapping Group, 3.08 ( $F=3.49, d f=2 / 54, p<.05)$. A main effect was also found for Stimuli ( $F=12.62, d f=4 / 216, p<.001)$. The Condition $x$ Stimuli interaction $(F=2.79, d f=8 / 216, p<.01)$ was also significant (see Figure 3).

An analysis of change in heart rate for the pre-tap period alone produced only a main effect for Shock. The mean for Shock on trial I was 1.33, while the mean for No-Shock on trial I was 3.06 $(F=6.15, d f=1 / 54, p<.05)$. 


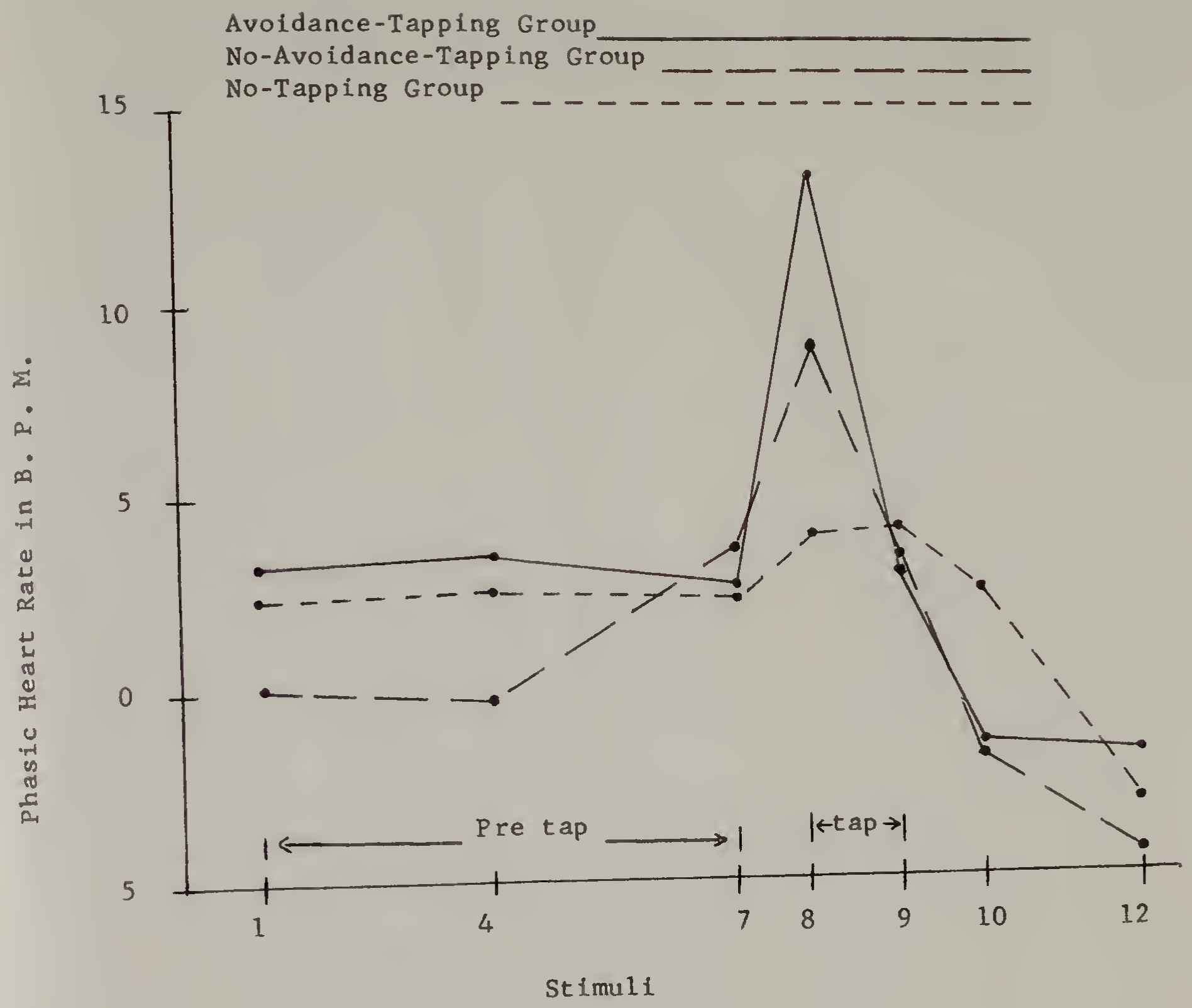

Figure 3. Mean Phasic Heart Rate for total count-up period. 
An analysis of change in heart rate for the impact period alone (post 10 minus pre 10) produced a main effect for Conditions. The mean for the Avoidance-Tapping Group was -1.48, for the No-Avoidance-Tapping group, -1.25 , and for the no-Tapping Group, $2.50(F=4.43, d f=2 / 54$. $p<.05)$.

\section{Basal Skin Conductance -- Separate analyses of variance were} done for pre, post and post minus pre stimulus measures for the total count-up dimension. Tablo 2 presents a summary of the F-Values for the three analyses of variance for basal skin conductance. In Table 2 it can be seen that there is a highly significant Conditions $x$ Stimuli interaction for both pre- and poststimulus basal skin conductance. Since poststimulus scores are confounded by the occurrence of specific GSRs, the prestimulus measures provide the better indicator of basal skin conductance, and are plotted in Figure 4. The data indicate that all groups show parallel flat curves up to count 7 . The groups begin to diverge at count 8 with both tapping groups exhibiting a marked rise from Stimulus 7 to 10, while the No-Tapping Group maintains a flat curve up to count 8 , and exhibits a marked rise only from Stimulus 9 to 10. The rise from pre-7 to pre -8 in the tapping groups indicates a reaction in anticipation of tapping. For prestimulus heart rate, however, as seen in Figure 2, a rise occurred from pre -4 to pre-7 and a decrease, suggestive of an attentive reaction, occurred from pre-7 to pre -8 for the tapping groups.

An analysis of variance was also done on the prestimulus means for the anticipatory period alone. A main effect was found for Trials. 
SUMMARY OF F VALUES FOR ANALYSES OF

VARIANCE OF BASAL SKIN CONDUCTANCE

\begin{tabular}{|c|c|c|c|c|c|c|}
\hline \multirow[b]{2}{*}{$\begin{array}{l}\text { Source of } \\
\text { Variance }\end{array}$} & \multirow[b]{2}{*}{$d f$} & \multicolumn{3}{|c|}{ Measure Analysed } & \multirow{2}{*}{\multicolumn{2}{|c|}{ Changes in }} \\
\hline & & $\begin{array}{l}\text { Prestimulus } \\
\text { Skin Conductance }\end{array}$ & $d f$ & $\begin{array}{l}\text { Postimulus } \\
\text { Skin Conductance }\end{array}$ & & \\
\hline Groups-C & $\frac{2}{54}$ & 1.52 & $\frac{2}{54}$ & 1.89 & $\frac{2}{54}$ & 1 \\
\hline $\begin{array}{l}\text { Shock on } \\
\text { Tr \#I-P }\end{array}$ & $\frac{1}{54}$ & 1 & $\frac{1}{54}$ & 1 & $\frac{1}{54}$ & 1 \\
\hline Trials-T & $\frac{1}{54}$ & $8.64 * *$ & $\frac{1}{54}$ & $8.24 * *$ & $\frac{1}{54}$ & 1 \\
\hline Stimuli-W & $\frac{6}{324}$ & $58.04 * * *$ & $\frac{6}{324}$ & $59.33 * * *$ & $\frac{6}{324}$ & $29.01 * * *$ \\
\hline $\operatorname{CxP}$ & $\frac{2}{54}$ & 1.13 & $\frac{2}{54}$ & 1.01 & $\frac{2}{54}$ & 1 \\
\hline $\operatorname{CxI}$ & $\frac{2}{54}$ & 1 & $\frac{2}{54}$ & 1 & $\frac{2}{54}$ & 1 \\
\hline $\mathrm{PXT}$ & $\frac{1}{54}$ & 1 & $\frac{1}{54}$ & 1 & $\frac{7}{54}$ & 1 \\
\hline Cxw & $\frac{12}{324}$ & $3.67 * * *$ & $\frac{12}{324}$ & $2.98 * * *$ & $\frac{12}{324}$ & $2.96 *$ \\
\hline Pxw & $\frac{6}{324}$ & 1.52 & $\frac{6}{324}$ & 1.97 & $\frac{6}{324}$ & 1.23 \\
\hline TxW & $\frac{6}{324}$ & $10.82 * * *$ & $\frac{6}{324}$ & $8.81 * * *$ & $\frac{6}{324}$ & $5.26 * * *$ \\
\hline CXPXT & $\frac{2}{54}$ & 1 & $\frac{2}{54}$ & 1 & $\frac{2}{54}$ & 1 \\
\hline CxPXW & $\frac{12}{324}$ & 1 & $\frac{12}{324}$ & 1 & $\frac{12}{324}$ & 1 \\
\hline CxTxW & $\frac{12}{324}$ & 1.60 & $\frac{12}{324}$ & 1.47 & $\frac{.12}{324}$ & $1.85 *$ \\
\hline PxIXW & $\frac{6}{324}$ & 1.94 & $\frac{6}{324}$ & 1 & $\frac{6}{324}$ & $4.54 * * *$ \\
\hline CxPxTXW & $\frac{12}{324}$ & 1.03 & $\frac{12}{324}$ & 1 & $\frac{12}{324}$ & 1 \\
\hline
\end{tabular}




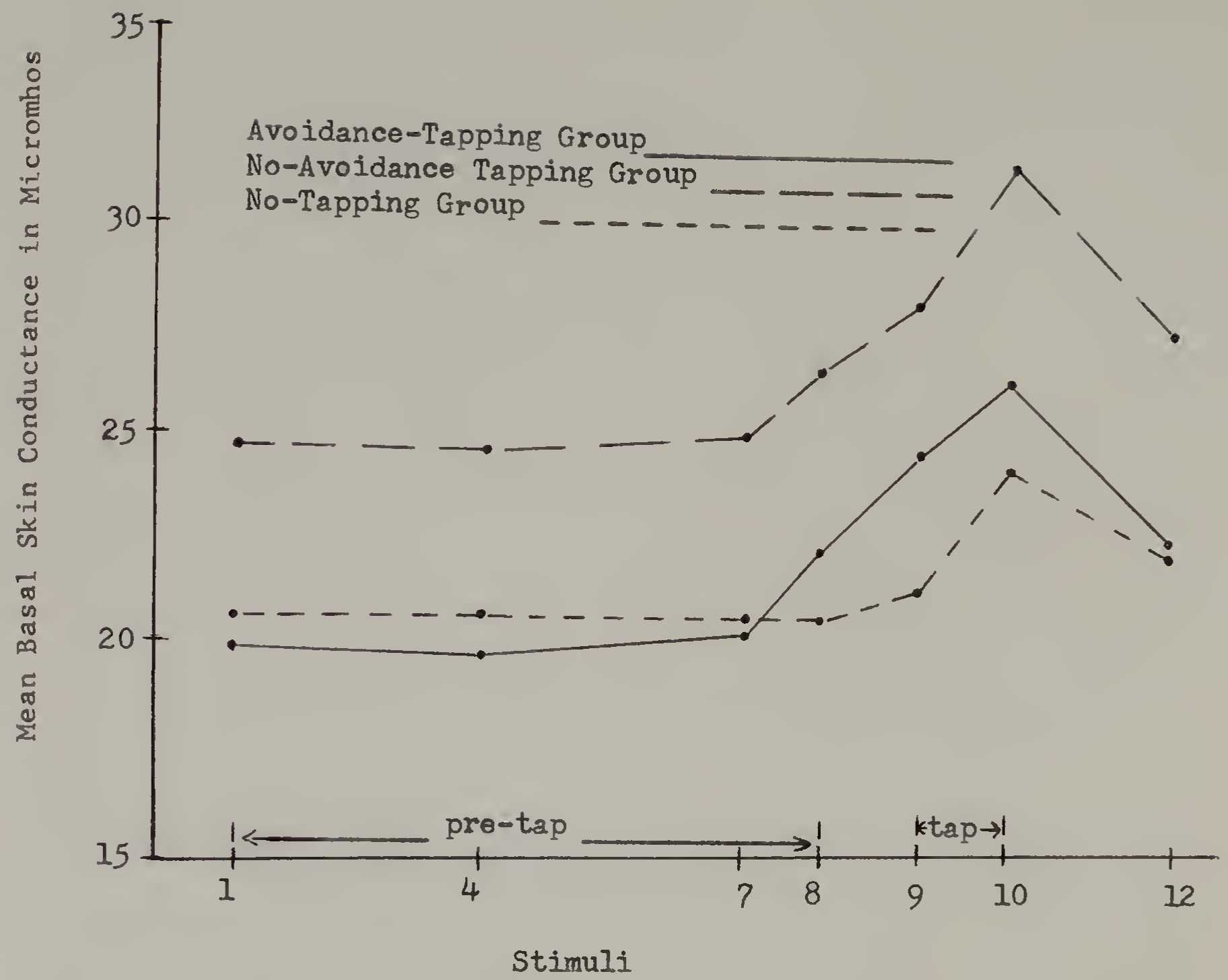

Figure 4. Mean Prestimulus Basal Skin Conductance for total count-up period pooled over trials. 
The mean for Trial 1 was 22.51, and the mean for Trial 6 was 24.40 $(F=8.77, d f=1 / 54, p<.01)$. There was also a main effect for stimuli $(F=67.23, d f=5 / 270, p<.001)$, which can be seen in Figure 4. A Conditions $x$ Stimuli interaction $(F=4.24, d f=10 / 270, p<.01)$ was also found. This interaction was described before in the analysis of the total count-up period (see Figure 4).

A separate analysis of variance of just the two tapping groups was done for the anticipatory period to see if the Conditions $x$ Stimuli interaction already reported was produced by the divergence of these groups from the No-Tapping Group. A main effect was obtained for Trials. The mean for Trial 1 was 23.56, while the mean for Trial 6 was $25.44(F=4.18, d f=1 / 36, p<.05)$. A main effect was observed for Stimuli $(F=48.93, \mathrm{df}=5 / 180, \mathrm{p} .<001)$. The effects for Stimuli can be seen in Figure 5. A three way interaction for Conditions $\mathbf{x}$ Stimuli $x$ Trials $(F=2.54, d f=5 / 180, p<.05)$ was also found. A plot of this interaction can be seen in Figure 5. Both groups exhibit a relatively flat curve up to count 7 , then begin a rise preceding the tapping period and extending through it for both trials 1 and 6 . The Conditions $\mathrm{x}$ Stimuli $\mathrm{x}$ Trials interaction is produced by the AvoidanceTapping Group exhibiting a greater increase during the tapping period from trials 1 to 6 than the No-Avoidance-Tapping Group. This is consistent with the increased tapping rate of the Avoidance-Tapping Group on trial 6.

A separate analysis of variance was done on the prestimulus means for the pre-tap period for all groups to see if group differences 
Mean Basal Skin Conductance in Micromhos

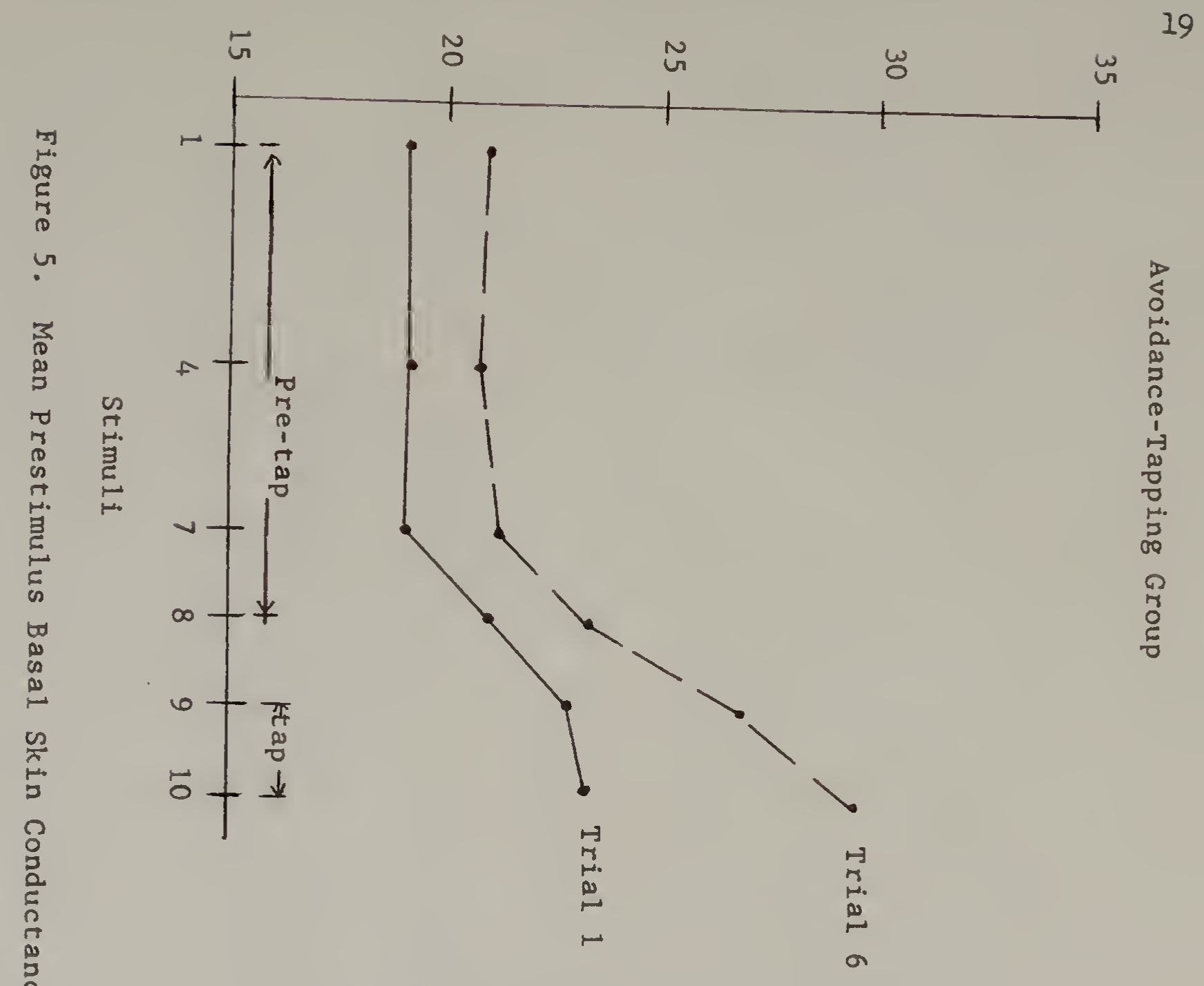

Mean Basal Skin Conductance in Micromhos

rit

7
0
1
0

2

?

ח.

䒘

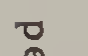

ind

a

$n$
0
$n$

$N$

2)

뭉.

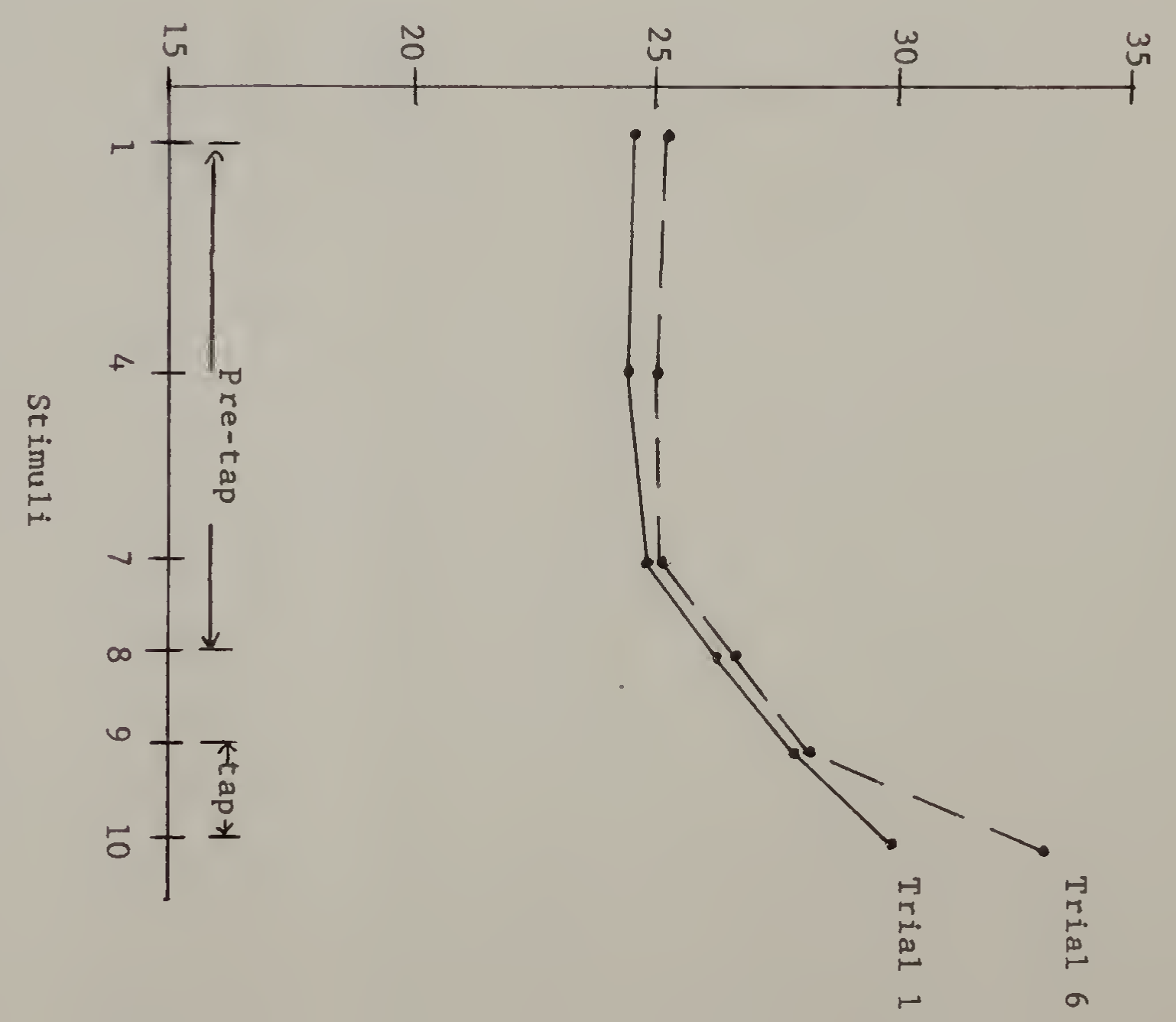

$z$
0
1
0
0
0
0
0
0
3
0
0
1
1
0
0
0
0
0
0
0
0
0
5
0 
were manifest before the tapping period. A main effect was produced for Stimuli $(F=17.97, d f=3 / 162, p<.001)$. These effects can be seen in Figure 4. A main effect was also found for Trials. The mean for Trial 1 was 21.53. and the mean for Trial 6 was $22.76 \quad(F=4.36$, $d f=1 / 54, p<.05)$. A Conditions $x$ Stimuli interaction $(F=5.26$, $d f=6 / 162, p<.001)$ was also found which indicates that group differences emerged before the tapping period. This interaction has been described before in the analysis of the total count-up period and can be seen in Figure 4.

A subsequent analysis was done on the pre-tap period omitting the No-Tapping Group to see if the two tapping groups differed from each other. The analysis yielded a highly significant main effect for Stimuli ( $F=20.81, d f=3 / 108, p<.001$ ), and a third order intersction for Conditions $x$ Stimuli $x$ Trials $(F=3.51, d f=3 / 108, p<.05)$ indicating that the two tapping groups differed from each other in the pretap period (see Figure 5).

An analysis of variance was also performed on the pooled stimulus periods compared to each other for all groups. These periods were early pre-tap $(1,4)$, pre-tap $(7,8)$ and tapping $(9,10)$ periods. The analysis produced a main effect for Trials. The mean for Trial 1 was 22.51, and the mean for Trial 6 was 24.40 ( $F=8.77, d f=1 / 54, p<.01$ ). A main effect was also found for Stimuli. The mean for the early pre-tap period was 21.80 , the mean for the pre-tap period was 22.49 . and the mean for the tap period was 26.07 ( $F=69.49, \mathrm{df}=2 / 108, \mathrm{p}<.001$ ). A Conditions $x$ Stimuli interaction $(F=4.23, d f=4 / 108, p<.01)$ was 
also found. A plot of this interaction can be seen in Figure 6. The data indicate that the overall form of the curves for the two tapping groups is similar. Both tapping groups exhibit an increase in the pre-tap period $(7,8)$ and a greater increase during the tapping period $(9,10)$. The curve for the No-Tapping Group, however, shows a slight decrease during the pre-tap period followed by a rise during the tapping period.

Specific GSRs -- Specific GSRs were analysed for the total count-up dimension. The analysis produced a main effect for Stimuli $(F=26.86, d f=4 / 26, p<.001)$. This effect can be seen in Figure ?. A first order interaction for Conditions $x$ Stimuli $(F=2.96, d f=12 / 324$. $\mathrm{p}<.001$ ), and a 3-way interaction, Conditions $\mathrm{x}$ Stimuli $\mathrm{x}$ Trials $(F=1.85, d f=12 / 324, p<.05)$ were also found. These effects can be seen in Figure 7. It can be seen from Figure 7 that the curves for both tapping groups are similar in several respects. Both tapping groups exhibit a fall from stimuli 1 to 4 and then a rise to stimulus 8, which marks the onset of tapping, and a marked fall to count 9 on both trials 1 and 6 . As was noted in the data for change in heart rate, count 8 is the only one that compares a post-tap to a pre-tap reaction, which can be expected to produce a large GSR. This explains the much greater reaction to stimulus 8 than to stimulus 9. Of particular interest in view of the Conditions $x$ Stimuli $x$ Trials interaction is that the three groups exhibit a differential rise in GSR in the pre-tap period during the counts 4 to 7 from trials 1 to 6. The Avoidance-Tapping Group shows a steeper slope in trial 


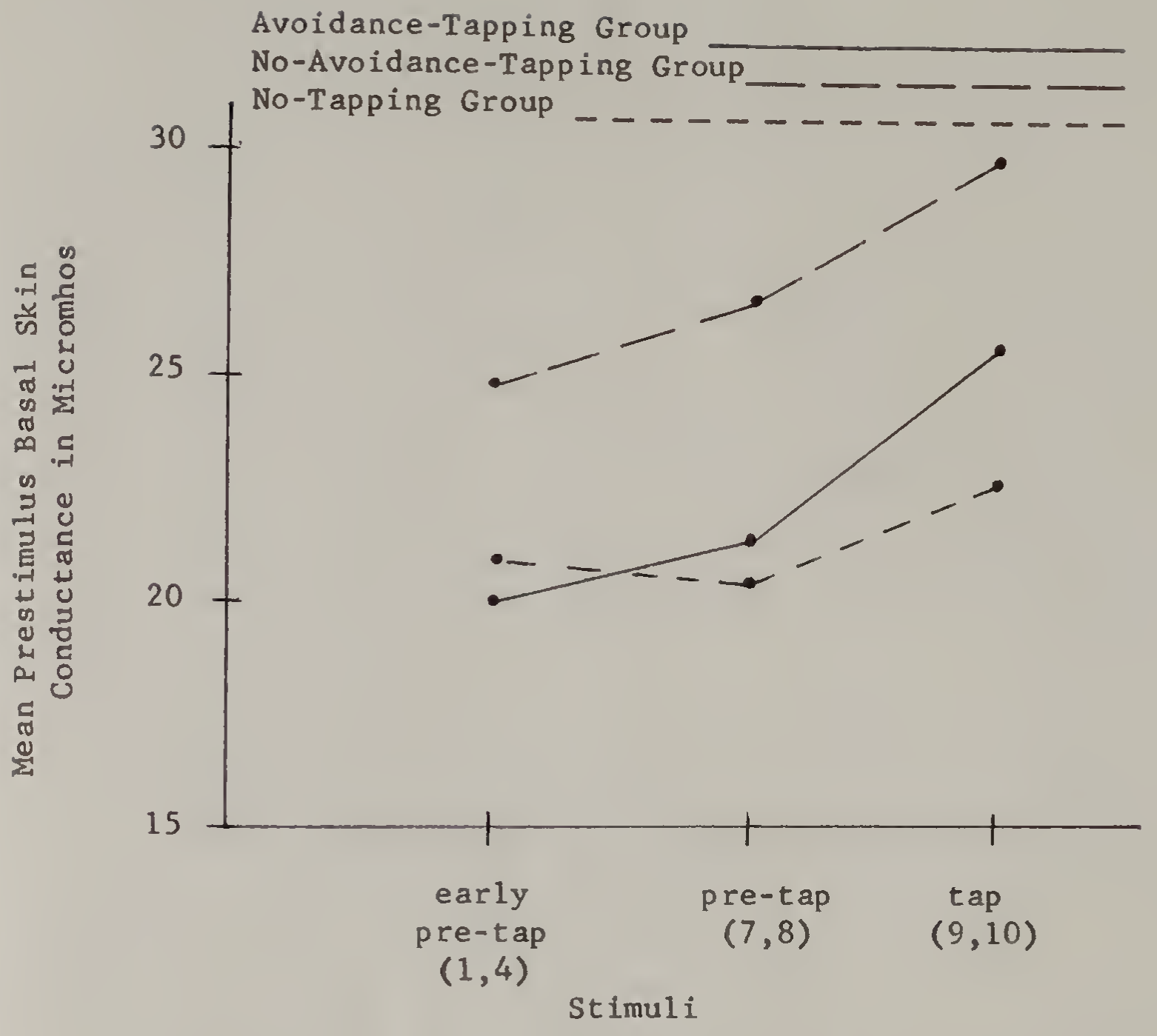

Figure 6. Mean Stimulus Periods compared to each other for Basal Skin Conductance over total anticipatory period for all groups pooled over trials. 
GSR in Micromhos

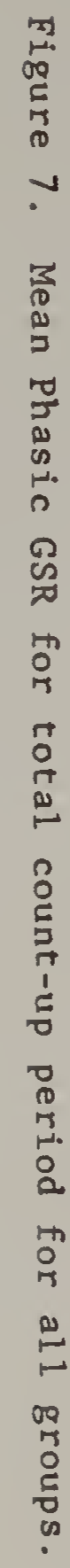
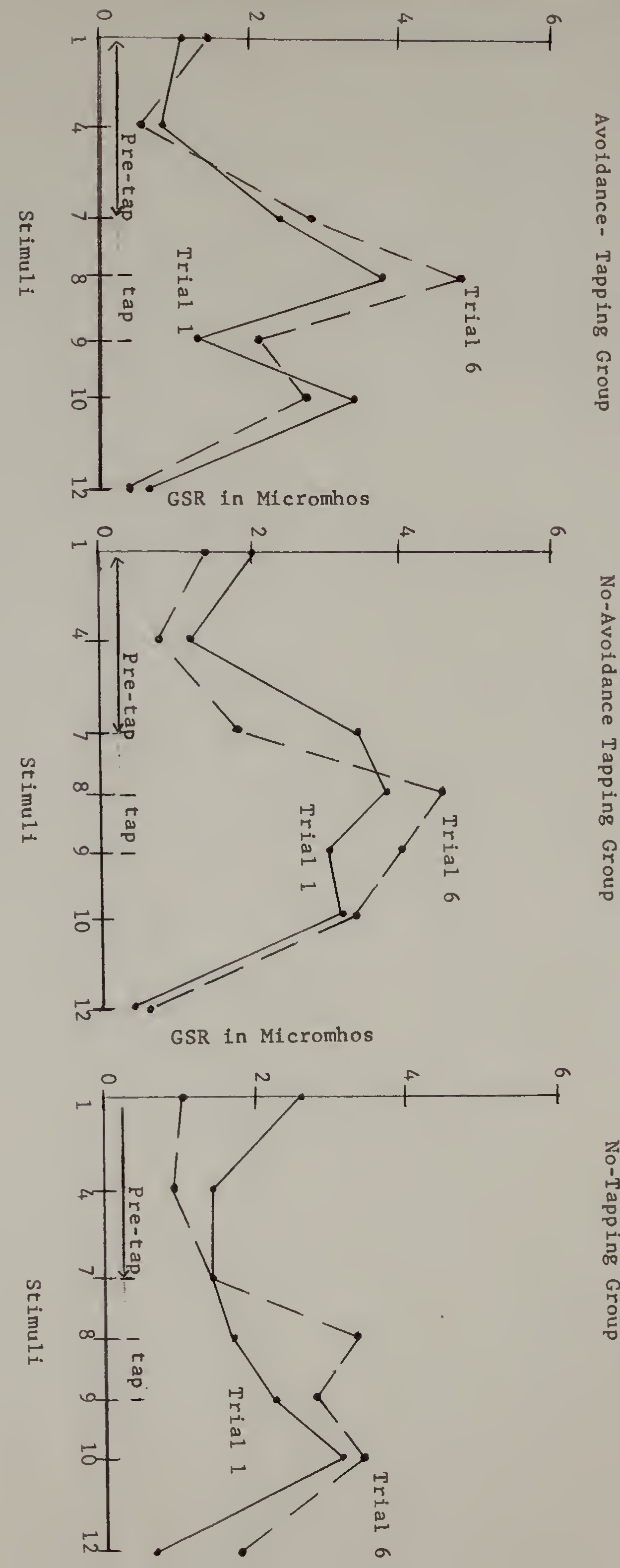

$z$
0
1
1
0
0
0
0.
5
0
0
5
0
0
0 
6 than in trial 1, while the No-Avoidance-Tapping Group shows a decrease in slope from trials 1 to 6 . This is consistent with the view that the Avoidance-Tapping Group is becoming increasingly motivated over trials. It is notoworthy that the difference precedes tapping, and therefore can not be accounted for by tapping rates.

Specific GSRs were also analysed for the anticipatory period alone. A main effect was found for Stimuli ( $F=26.86, d f=4 / 216$. $p<.001)$. A first order interaction for Conditions $x$ Stimuli $(F=3.80$, $d f=8 / 216, p<.001$ ) was also found. These effects can be seen in Figure 7 .

An analysis of the pre-tap period alone was done for all groups to see if differences among groups occurred during the pre-tap period for specific GSRs. Main effects were found for Stimuli ( $F=23.21$, $d f=2 / 108, p<.001)$ and for Trials. The mean for Trial 1 was 1.82 , while the mean for Trial 6 was 1.35 ( $F=8.10, \mathrm{df}=1 / 54, \mathrm{p}<.01)$. Interactions for Conditions $x$ Trials ( $F=3.67, d f=2 / 54, p<.05)$, Conditions $x$ Stimuli $(F=5.13, d f=4 / 108, p<.001)$, and Conditions $x$ Stimuli $x$ Trials $(F=2.71, d f=4 / 108, p<.05)$ were also produced ( see Figure ?).

An analysis of the impact period (post 10 minus pre 10) produced no significant differences among groups.

Nonspecific GSRs -- An analysis of variance was performed over the total count-up dimension for nonspecific GSRs. There was a significant main effect for Conditions. The mean for the AvoidanceTapping Group was 1.18, for the No-Avoidance-Tapping Group, 1.59. and 
for the No-Tapping Group,1.44 ( $F=5.28, d f=2 / 54, p<.001)$. A very significant main effect was also found for Stimuli ( $F=46.54, d f=6 / 324$, $p<.001$ ). These effects can be seen in Figure 8 . First order interactions for Conditions $x$ Shock $(F=6.57, d f=2 / 54, p<.01)$ and Conditions $x$ Stimuli $(F=2.49, d f=12 / 324, p<.01)$ were also found. The Conditions $x$ Stimuli interaction can be seen in Figure 8 . All groups are similar up to the onset of tapping, and exhibit a gradient of increasing nonspecific GSRs. The groups spread out during the tapping period, with the No-Avoidance-Tapping Group being highest and the Avoidance-Tapping Group being lowest.

An additional analysis of the anticipatory period alone produced a main effect for Conditions. The mean for the Avoidance-Tapping Group was 1.39, for the No-Avoidance-Tapping Group, 1.87, and for the NoTapping Group 1.54, $(F=4.88, d f=2 / 54, p<.05)$. A main effect for Stimuli ( $F=48.78, d f=4 / 216, p<.001$ ) was also found. There was also a Conditions $x$ stimuli interaction $(F=2.23, d f=8 / 216, p<.05)$. These effects can be seen in Figure 8.

A subsequent analysis was done for nonspecific GSRs during the pre-tap period. No significant differences were found among groups. An analysis of variance was also performed on pooled stimulus periods compared to each other for all groups. These periods included an early pre-tap period $(1,4)$, a pre-tap period (7) and the tapping period $(8,9)$. A main effect was found for Conditions. The mean for the Avoidance-Tapping Group was 1.46, for the No-Avoidance-Tapping Group, 1.86, and for the No-Tapping Group, 1.54 ( $F=3.85, d f=2 / 54$, $p<.05)$. A main effect for Stimuli was also found. The mean for the 


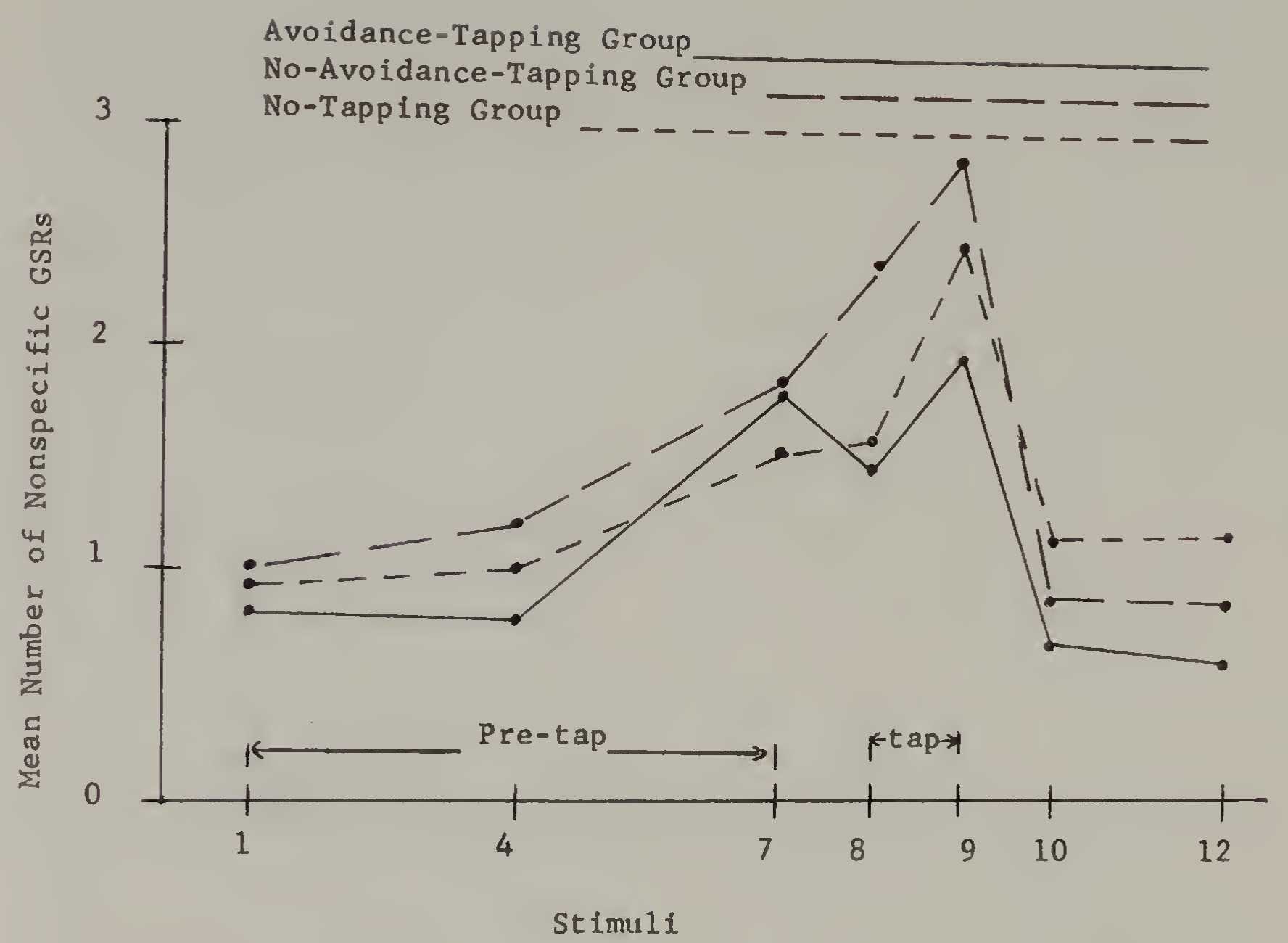

Figure 8. Mean number of Nonspecific GSRs over total count-up period for all groups pooled over trials. 
early pre-tap period was 0.97, for the pre-tap period, 1.74 and for the tapping period, 2.15 ( $F=71.07, d f=2 / 108, p<.001)$. A significant Conditions $x$ Stimuli interaction was also produced $(F=4.02, d f=4 / 108$, $p<.01)$. The data in Figure 9 indicate that the No-Avoidance-Tapping Group and the No-Tapping Group exhibit a marked increase in number of nonspecific GSRs during the pre-tap and tapping periods. The AvoidanceTapping Group, however, shows a marked increase in number of nonspecific GSRs during the pre-tap period, but shows a decrease during the tapping period. It is noteworthy that among the three groups, the AvoidanceTapping Group exhibited the fewest number of nonspecific GSRs during the tapping period.

\section{Adjective Chock List -- An analysis of variance on the 3} anxiety words (jittery, queasy, butterflies-in-stomach), revealed a main effect for Adjectives. The mean for jittery was 0.60 , for queasy, 0.35, and for butterflies-in-stomach, 0.50 ( $F=10.77$, $d f=2 / 108, p<.001)$. A main effect was also produced for Trials $(F=28.34, d f=4 / 216, p<.001)$, which can be seen in Figure 10. A significant Conditions $x$ Trials $(F=2.25, d f=8 / 216, p<.05)$ interaction was also found and is plotted in Figure 10. As can be noted in Figure 10, all groups report an increase in feelings of anxiety following instructions. The Avoidance-Tapping Group produces the least increase, and also has a lower score than the other groups on trial 1.

An analysis of variance on the 5 fear adjectives (scared, threatened, panicky, frightened, terrified) produced a main effect 


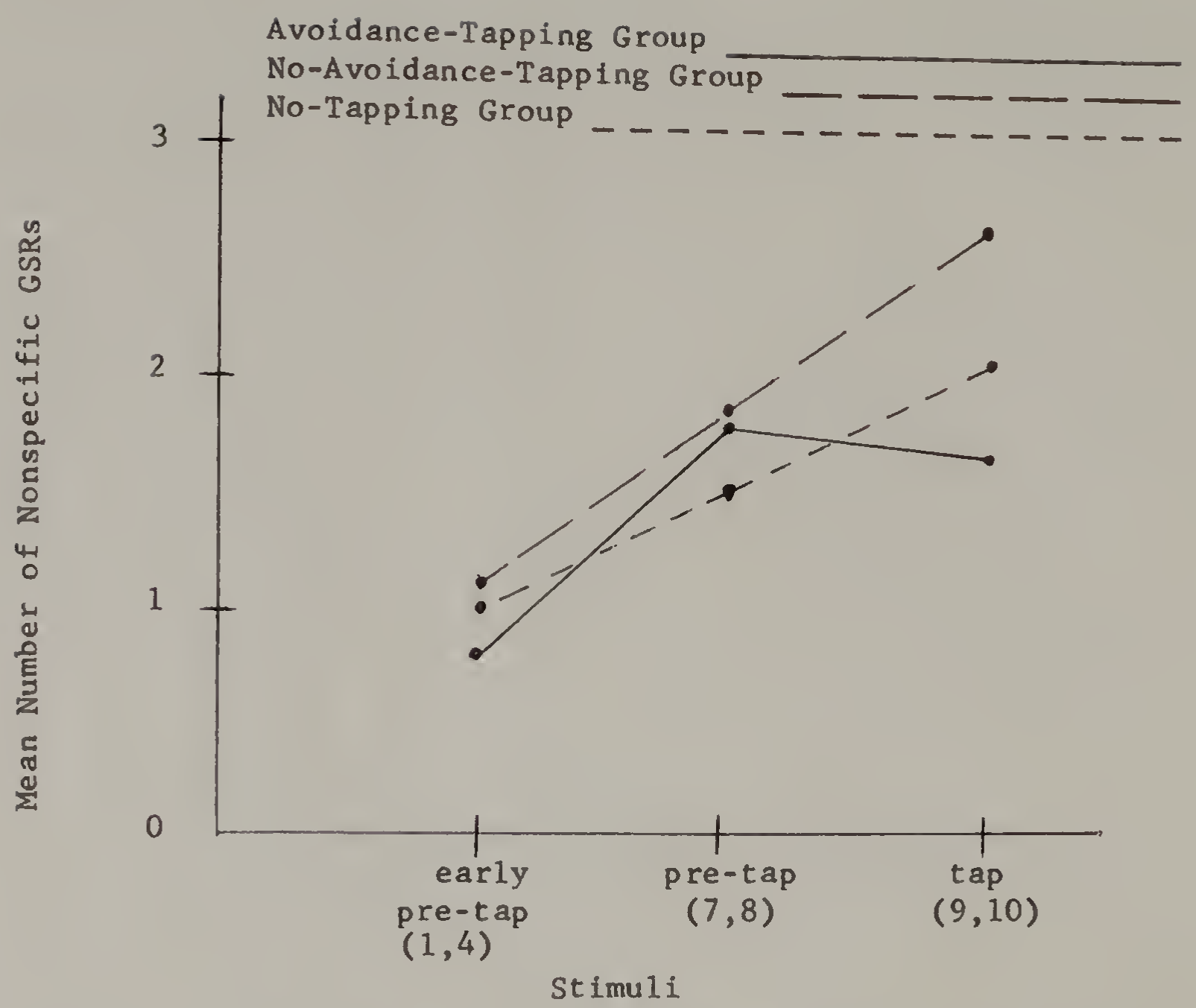

Figure 9. Mean Stimulus periods compared to each other for Nonspecific GSRs over total anticipatory period for all groups pooled over trials. 


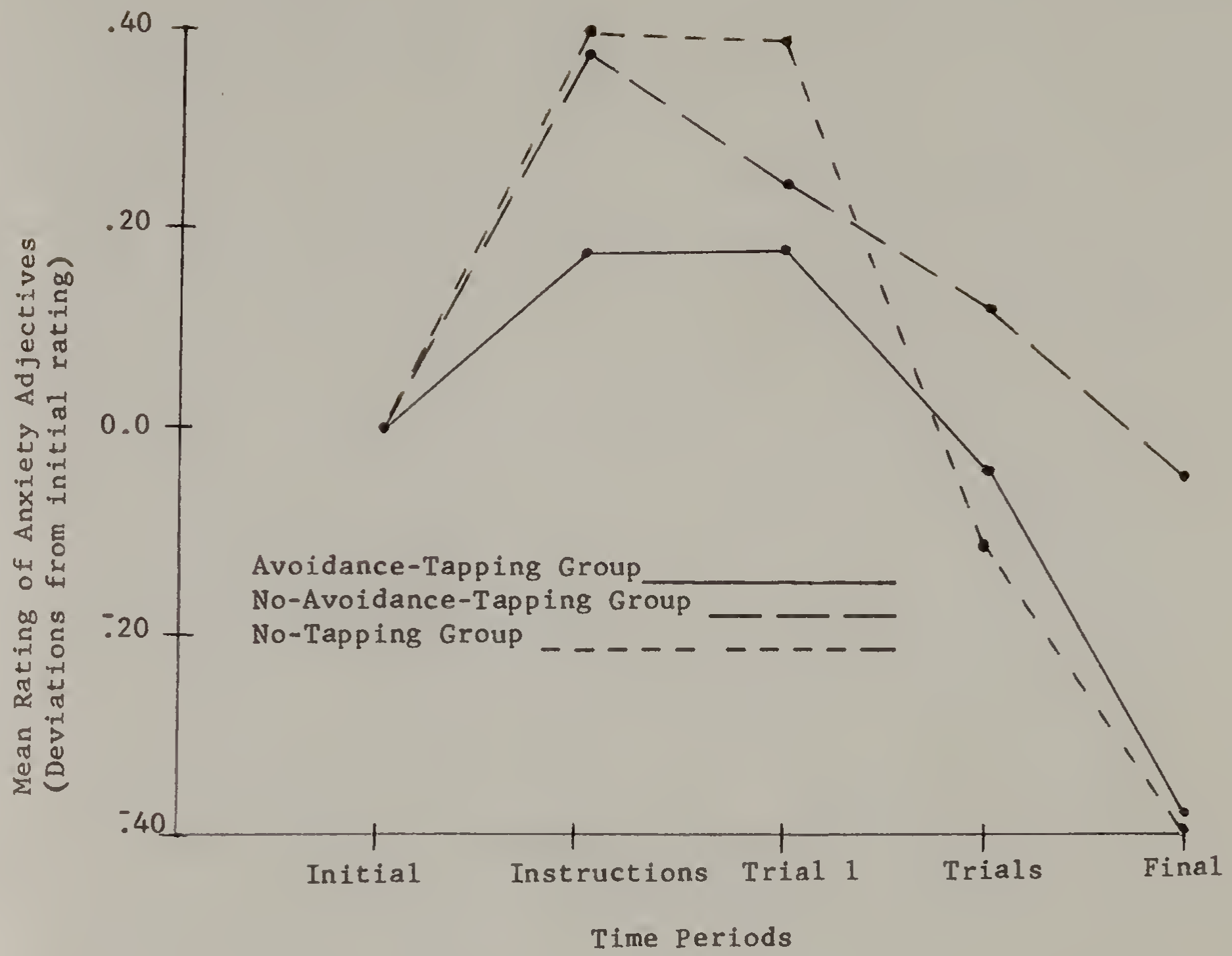

Figure 10. Mean Anxiety Scores for all groups as a function of time of testing. 
for Adjectives. The mean for scared was 0.34, for threatened, 0.25 . for panicky, 0.16, for frightened, 0.28, and for terrified, 0.11 $(F=8.79, d f=4 / 216, p<.001)$. There was also a main effect for Trials. The mean for pre-instructions was 0.20 , for post instructions, 0.38 , for trial 1, 0.35, for trial 5, 0.18, and for final, 0.03 $(F=17.17, d f=4 / 216, p<.001)$. There was no significant effect associated with groups. 


\section{DISCUSSION}

It was hypothesized that anxiety and fear could be differentiated physiologically and subjectively, and that this would be dependent upon the degree to which a response is available for coping with a threat. It was anticipated that when subjects aro placed in a situation where shock is imminent and no escape is possible (NoAvoidance-Tapping Group) these subjects would manifest a greater frequency of nonspecific GSRs than subjects who were placed in a situation in which shock could be avoided (Avoidance-Tapping Group). It was also anticipated Ss could verbally distinguish between anxiety and fear and that when subjects are threatened with shock and are unable to avoid it they will rate "anxiety" adjectives as more applicable to their situation than "fear" adjectives and will exhibit the reverse when in a position of being able to avoid the shock. The results support the hypothesis that anxiety defined in these terms is a state of nonspecific, diffuse arousal, while fear is a motivated state of directed avoidance.

The anticipatory period to a stressful event is a significant time for a subject. since it is at this time that he must elicit coping mechanisms in his repertoire if he is to deal effectively with a threat. It is during this period that arousal is known to vary as a function of an effective coping response (Iazarus, Averill \& Opton, 1970).

In this study, an Avoidance-Tapping Group which had an effective 
avoidance response, unlike a No-Avoidance-Tapping Group which had an ineffective response and a No-Tapping Group which had no response at all. In examining the data for heart rate, it can be seen that a marked increase occurred during the tapping period for both tapping groups, while the No-Tapping Group did not exhibit such an increase. The motoric effect of tapping appears to have elevated the heart rate levels for the two tapping groups during the tapping period, but it was not the only source of variance. An analysis of just the two tapping groups for the total anticipatory period produced a significant Conditions $x$ Stimuli interaction suggesting that the steeper rise for the Avoidance-Tapping Group during the tapping period was produced by the motoric effect of tapping, and by the heightened motivation to avoid the shocks. In other words, perhaps the Avoidance-Tapping Group became more involved in the tapping task, because it had an opportunity to avoid a threat. This is also supported by the results for tapping rate. It can be seen in Figure $I$ that the AvoidanceTapping Group's tapping rate increased markedly throughout the experiment, whereas the No-Avoidance-Tapping Group's rate of tapping decreased steadily over trials.

The data for basal skin conductance also illustrates that arousal increased greatly during the tapping period for both tapping groups, but not for the No-Tapping Group. Once again, as was noted in the data for heart rate, arousal appears to have increased during the tapping period partially as a function of the tapping response. An analysis of just the two tapping groups for the total 
anticipatory period produced a significant difference between the two tapping groups for basal skin conductance. It seems that basal skin conductance is also a measure of increased motivation as shown by Figure 5. There is some support for this observation when one examines the degree to which trial 6 is greater than trial 1 during the pre-tap period but particularly during the tapping period for the Avoidance-Tapping Group than for the No-Avoidance-Tapping Group.

Both tapping groups exhibited a sharp acceleration throughout the tapping period for heart rate and basal skin conductance, but the rise for basal skin conductance initiated at count 7. which precedes the onset of tapping, suggesting that both tapping groups underwent a readiness to tap. This is supported by a pre-tap analysis for basal skin conductance, but not for heart rate, indicating that group differences emerged before the tapping period, as indicated by basal skin conductance. It may not have appeared for heart rate, however, because it was cancelled out by anticipatory deceleration immediately preceding onset of tapping. According to the results of this experiment, there is physiological arousal associated with a readiness to perform a response, regardless of whether or not it is an effective coping response. The mere anticipation of performing an act which may serve as an avoidance response or merely as a distracting response appears sufficient to increase arousal.

While the findings for heart rate and basal skin conductance suggest an increase in tension for both tapping groups during the tapping period, the data for nonspecific GSRs suggest a decrease in 
anxiety for the Avoidance-Tapping Group, as manifested by a reduced number of nonspecific GSRs over the entire anticipatory period, and particularly during the tapping period. This finding is further supported by the tendency for heart rate variability to be greater for the No-Avoidance-Tapping Group than for the Avoidance-Tapping Group. The question may be raised as to whether the findings for nonspecific GSR are merely artifactual. That is, since the AvoidanceTapping Group also exhibits a lower basal conductance level during this same period, there may be a direct correspondence between basal level and frequency of nonspecific GSRs. However, examination of Figures 6 and 9 indicate that this is not the case. The data in Figure 6 shows that both tapping groups exhibited a marked increase in basal level throughout the entire anticipatory period. The data in Figure 9 , however, indicates that the No-Avoidance-Tapping Group produced a steady increase in the number of nonspecific GSRs throughout the anticipatory period, while the Avoidance-Tapping Group exhibited an increase in nonspecific GSRs during the pre-tap period but a decrease during the tapping period. These findings support Epstein's hypothesis that anxiety and fear vary as a function of the degree to which a response is available for coping with a threat.

An analysis of the 3 anxiety adjectives by themselves produced a significant Conditions $x$ Trials interaction, which indicated that Ss reported an increase in feelings of anxiety when first informed of a threat. Furthermore, the interaction suggests that an inverse relationship exists between the amount of anxiety reported when in- 
itially informed of a threat and one's perceived ability to cope with the threat. This is supported by the smaller increase in reporting feelings of anxiety for the Avoidance-Tapping Group as compared to the other two groups.

An analysis of the 5 fear adjectives by themselves produced no significant group effects.

The anxiety words were consistenly rated as more descriptive of Ss feelings than the fear words. It may be that since the factors were derived from descriptions of real life situations that adjectives such as "terrified" and "panicky" are not applicable in the laboratory, since subjects are aware that no life and death danger is at hand.

The results support Epstein's hypothesis that anxiety is a state of nonspecific, diffuse arousal, while fear is a motivated state of directed avoidance. This was confirmed physiologically by the frequency of nonspecific GSRs and a nonsignificant tendency for there to be greater heart rate variability in the No-Avoidance-Tapping Group than in the Avoidance-Tapping Group during the tapping period and subjectively by the anxiety adjectives, but not by the fear adjectives. 


\section{SUMMARY}

This study sought to establish physiological and subjective differences between anxiety and fear. Sixty Ss were randomly assigned to three equal groups. An Avoidance-Tapping Group was able to avoid a shock by tapping rapidly, a kind of "running away" with the fingers, so to speak. A No-Avoidance-Tapping Group was encouraged to make the same response, but it did not prevent shock. Subjects in a No-Tapping Group did not have any response to perform, nor could they avoid shock. The results support the hypothesis that anxiety is a state of nonspecific, diffuse arousal, while fear is a motivated state of directed avoidance. Specifically, the No-Avoidance-Tapping Group reported more anxiety, exhibited a greater frequency of nonspecific GSR, and showed more variability in heart rate than did the Avoidance-Tapping Group. 


\section{References}

Epstein, S. "Toward a unified theory of anxiety." In B. A. Maher (Ed.), Progress in Experimental Personality Research, Vol. 4 New York: Academic Press, 1967. pp. 1-89.

Epstein, S. "The nature of anxiety with emphasis upon its relationship to expectancy." In C. D. Spielberger, Anxiety: Current Trends in Theory and Research. Academic Press, in press. (Presented at Symposium on Anxiety, Tallahassee, Florida, 4/1970).

Epstein, S., and Fenz,W. D. "Steepness of approach and avoidance gradients in humans as a function of experience: Theory and experiment." Journal of Experimental Psychology, 1965, 70, $1-12$.

Epstein, S., and Kling, J. S. "Reactivity during anticipation and impact of an unavoidable noxious stimulus as a function of time ambiguity." (unpublished study, 1970).

Epstein, S., Solomon, G., and Brent, G. "The effect of the anticipation and impact of an unavoidable noxious stimulus upon motor performance, autonomic arousal, and ratings of stimulus intensity." (unpublished study, 1970).

Fenz, W. D., and Epstein,S. "Gradients of physiological arousal of experienced and novice parachutists as a function of an approaching jump." Psychosomatic Medicine, 1967, 29, 33-51.

Katkin. E. S. "The Relationship between a measure of transitory anxiety and spontaneous autonomic activity." Journal of Abnormal Psychology, 1966, 71. No. 2, 142-146.

Katkin, E. S. "Relationship between manifest anxiety and two indices of autonomic response to stress." Journal of Personality and Social Psychology, $1965,2, \frac{2}{324-333 .}$

Lazarus, R. S., Averill, J.R., and Opton, E. M. Jr. "Towards a cognitive theory of emotion." In M. Arnold (Ed.). Third International Symposium on Feelings and Emotions. New York: Academic Press, 1970. 
Lykken, D. T., Rose, R., Luther, B., and Maley, M. "Correcting psychophysiological measures for individual differences in range." Psychological Bulletin, 1966, 66, 481-484.

Lykken, D. T., and Venables, P. H. "Direct measurement of skin conductance: A proposal for standardization." Psychophysiology, 1971, 8, 656-672.

Tomaszewski, G., and Epstein, S. "Discrimination between fear and anxiety as revealed in self reports of real-life experience." (unpublished study, 1970).

Tursky, B., Watson, P. H., and O'Connell, B. N. "A concentric shock electrode for pain stimulation." Psychophysiology, $1965,1,296$. 
APPENDIX A

Results for all Dependent Measures for the total count-up dimension for all groups. 
Mean Heart Rate in B. P. M.
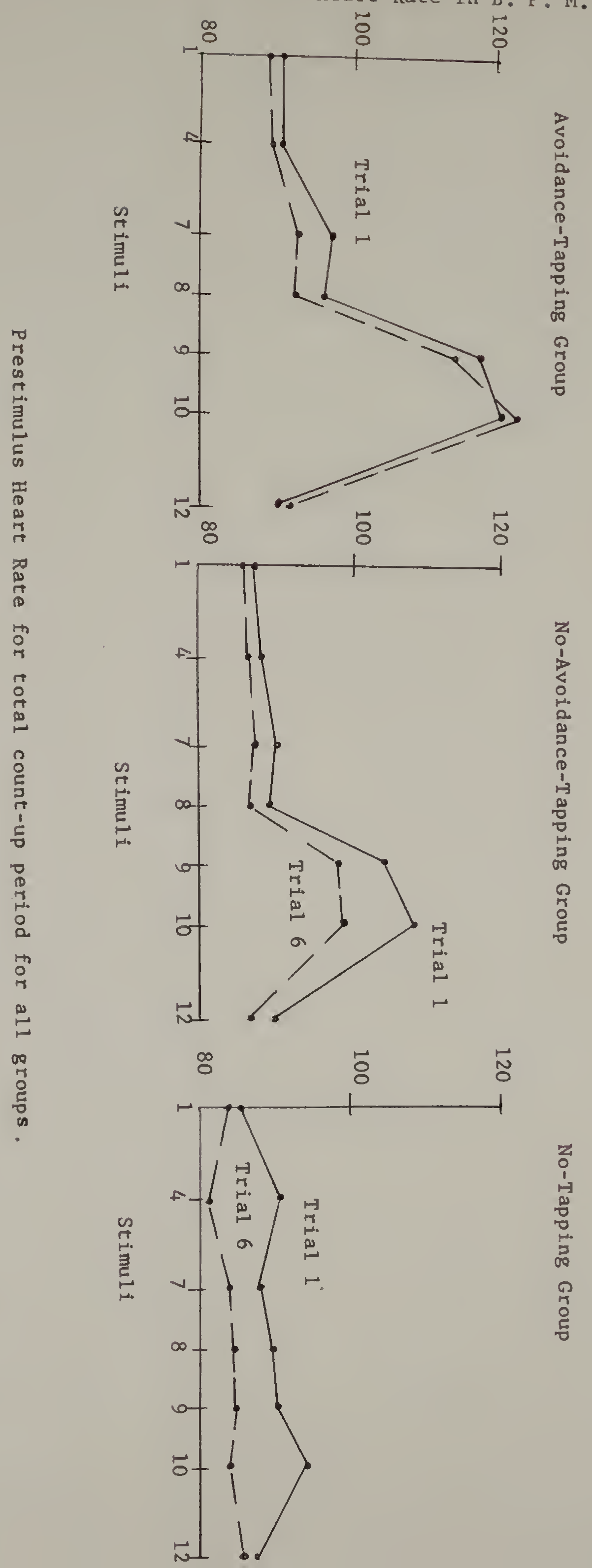


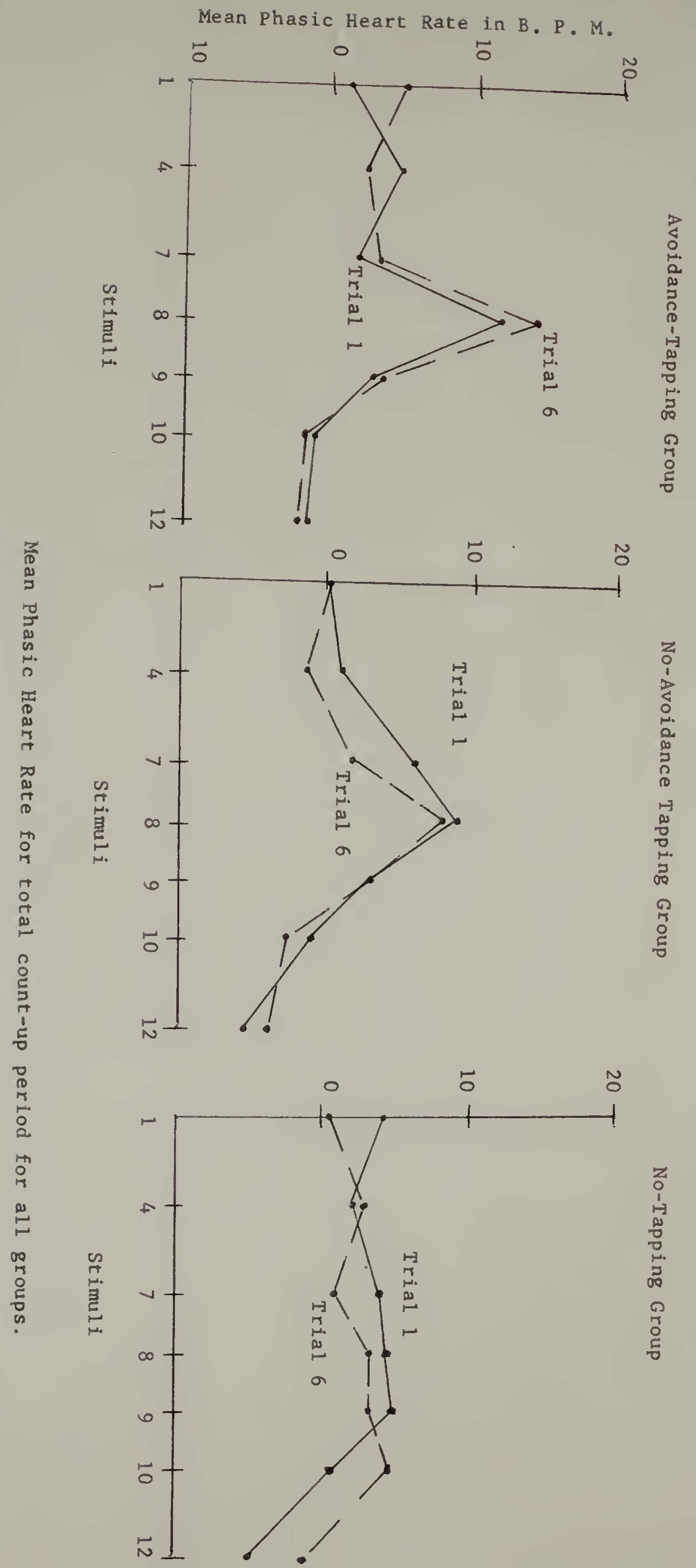




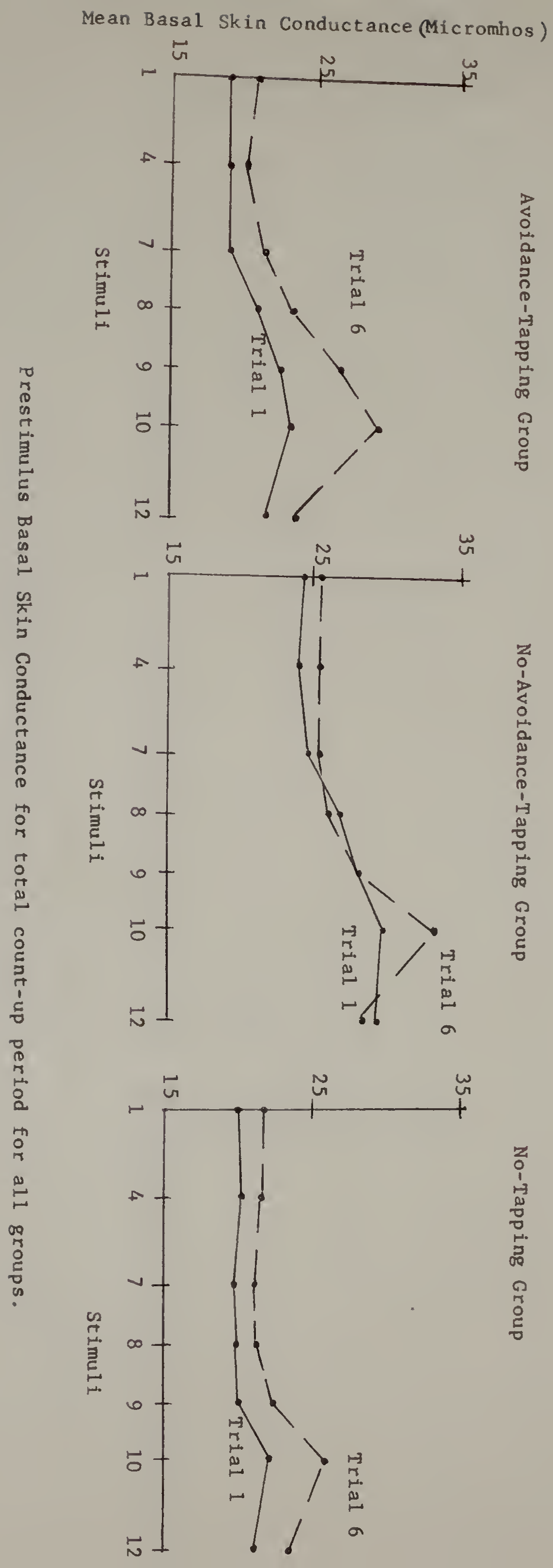




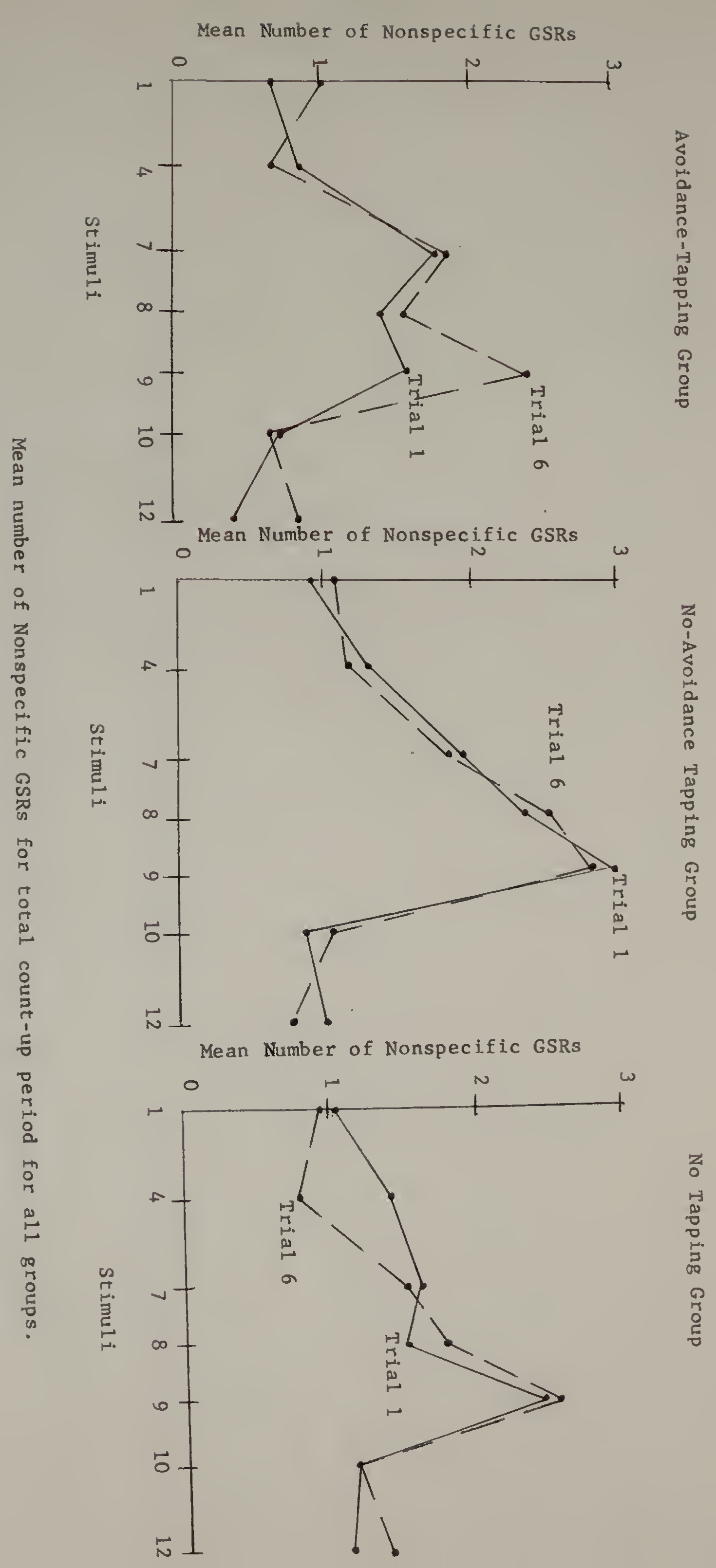


APPENDIX B

Example of Self Rating Forms Used in this Experiment. 
Please check how well each adjective describes your present feelings.

Not at All Slightly Hoderately Definitely hopeless

at-ease

scared

calm

irritated

blocked

jittery

threatened

worried

keyed-up

frustrated

ponicky

queasy

angry

frightened

annoyed

on-edge

terrified

troubled

insecure

relaxed

tense

helpless

but terflles-in-stomach

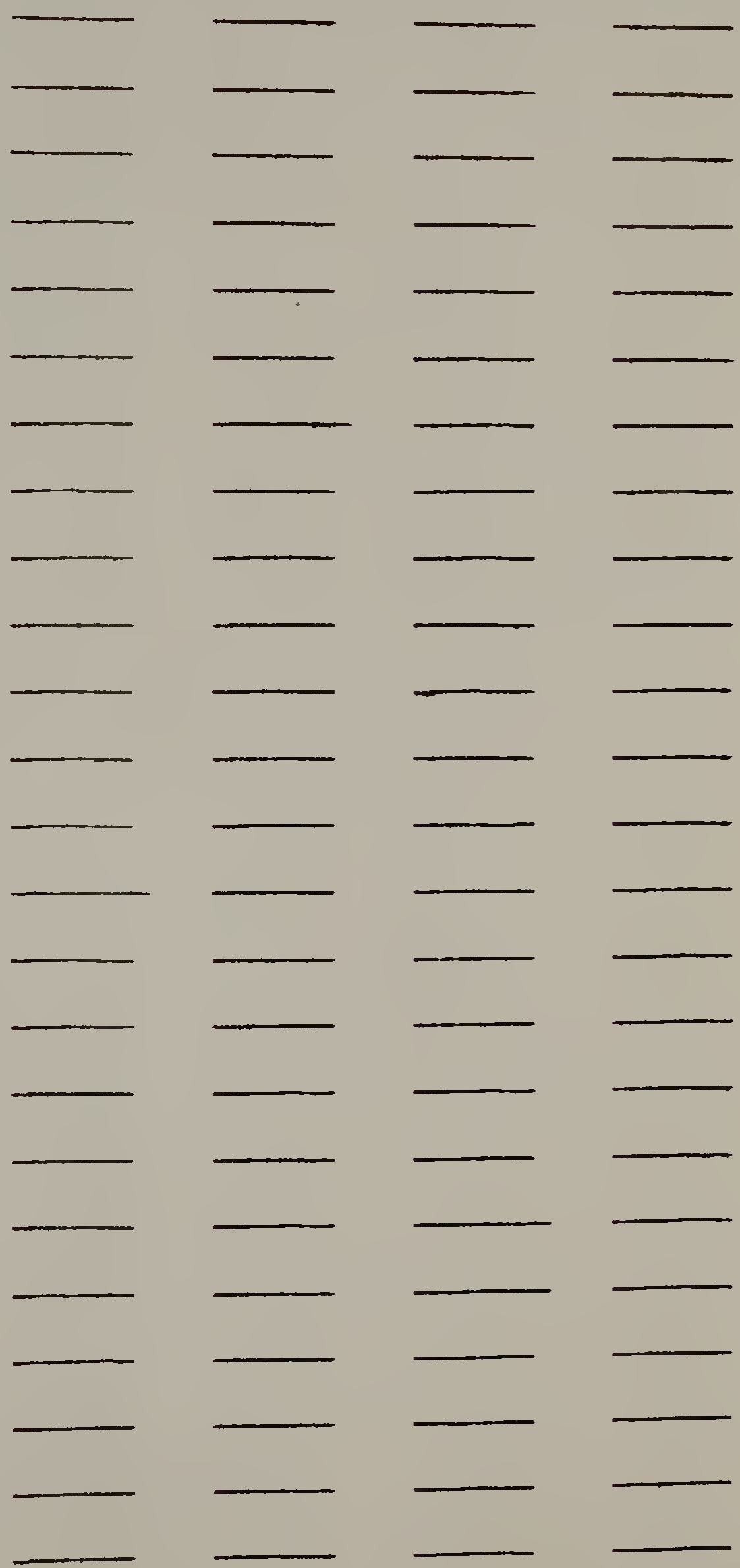


APPENDIX C

Printouts for all Analyses of Variance Performed. 



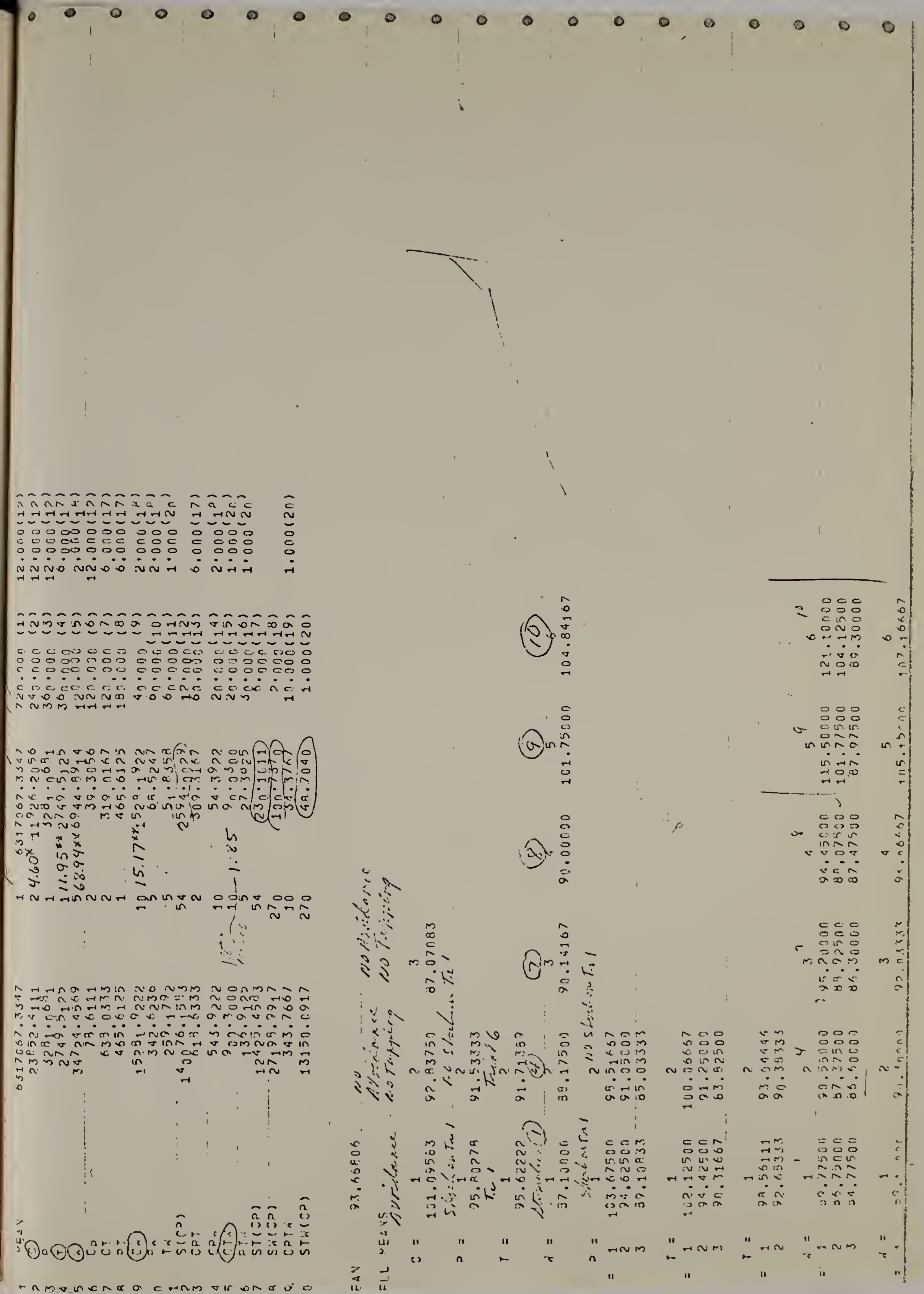




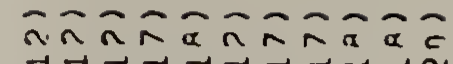

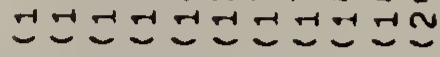 0000000000

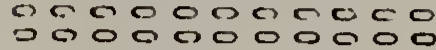 nininoninoning

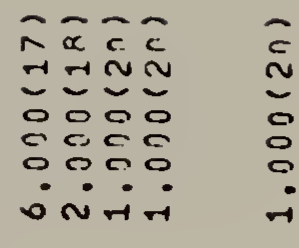
, 1

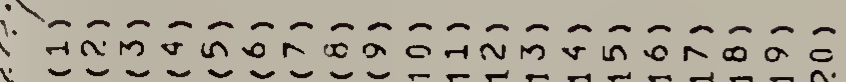

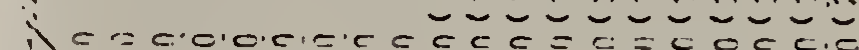

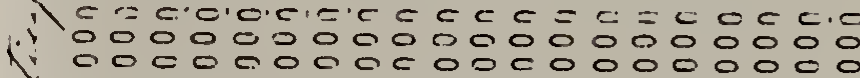

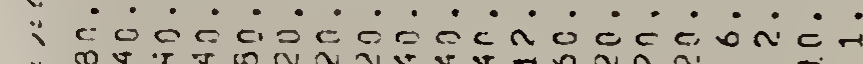

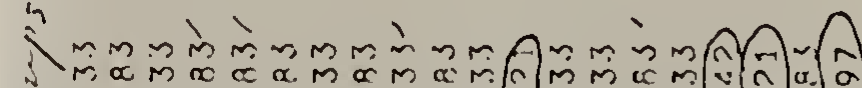

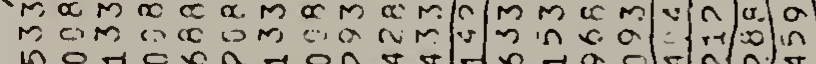
a

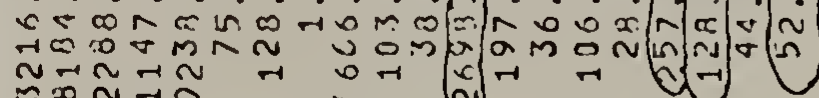

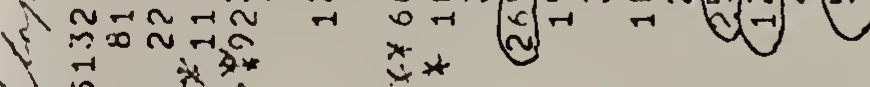

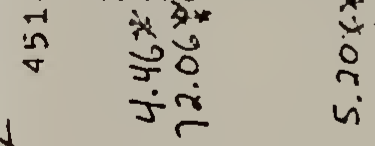

hyhyinhy hin

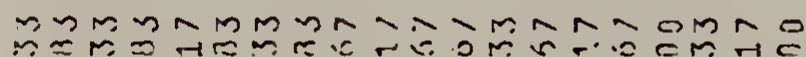

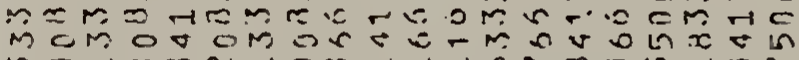
-

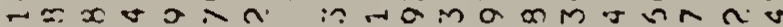

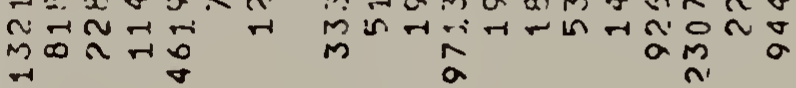
in

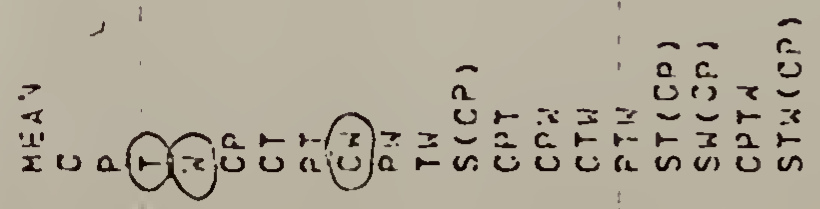

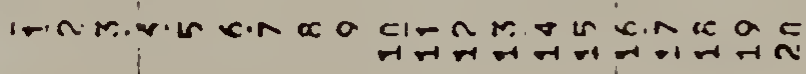

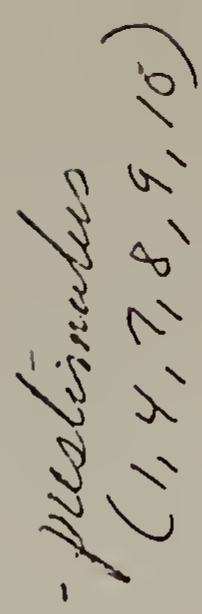

N

1.
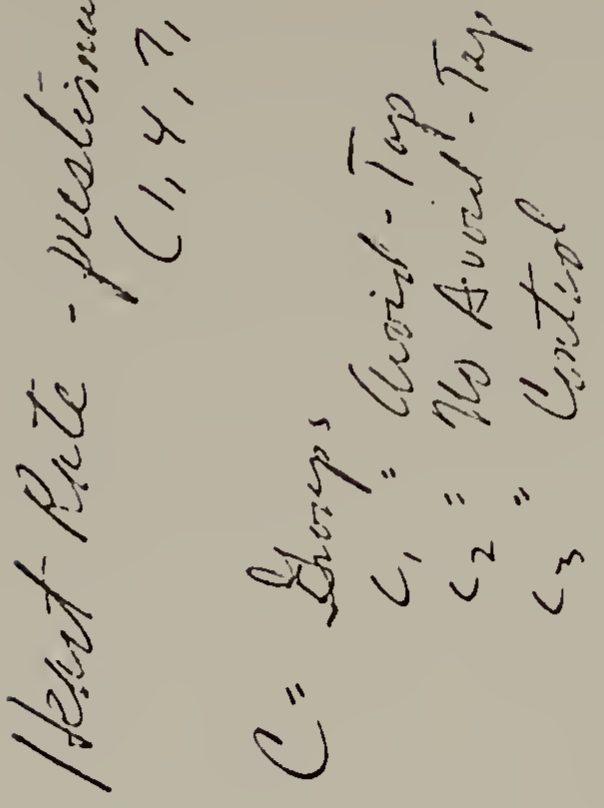

$\sqrt{3}$

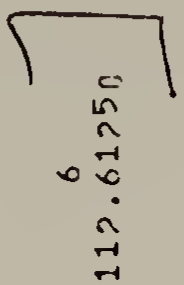

$\sum_{1}^{1}$

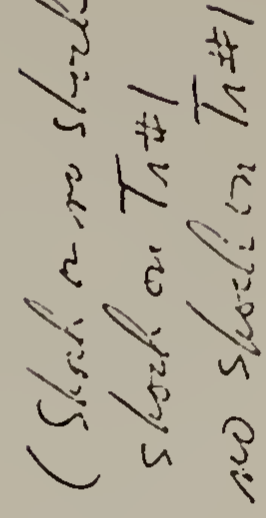

ई
ई

$a^{11}$

n'

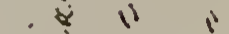

说N

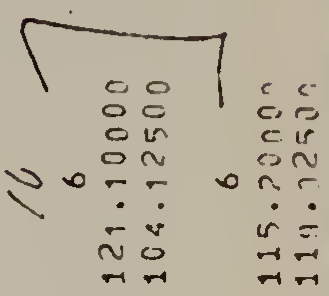

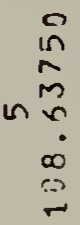

$\underset{\substack{0 \\ \stackrel{i}{n}}}{\stackrel{a}{a}}$

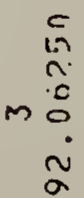

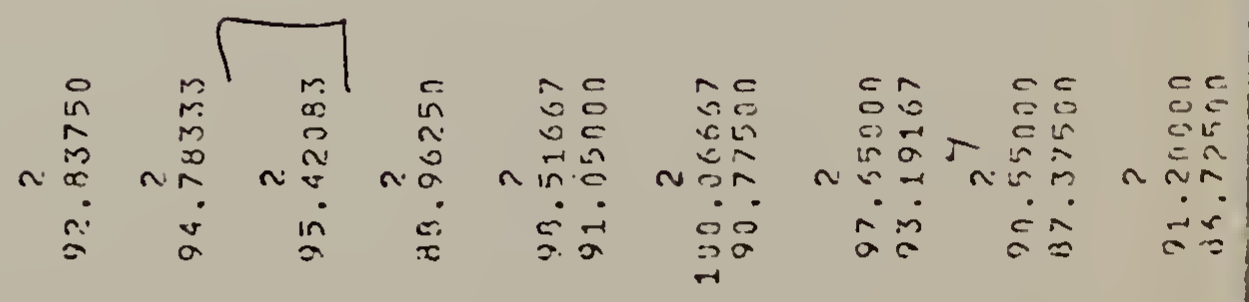

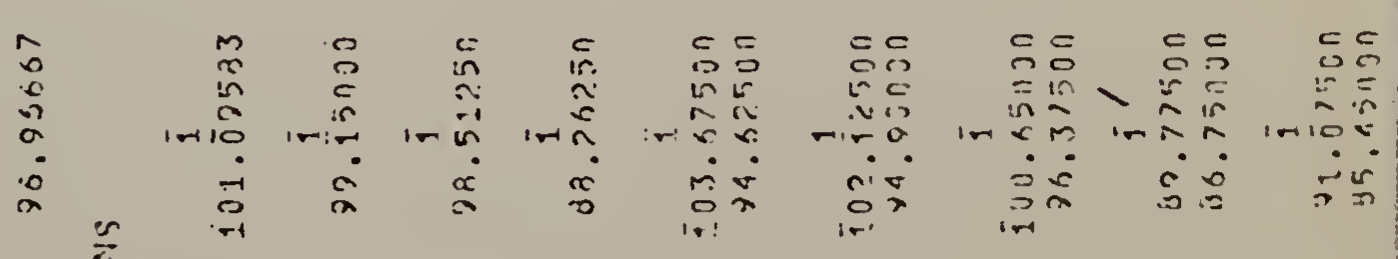
$\frac{2}{3}$ 


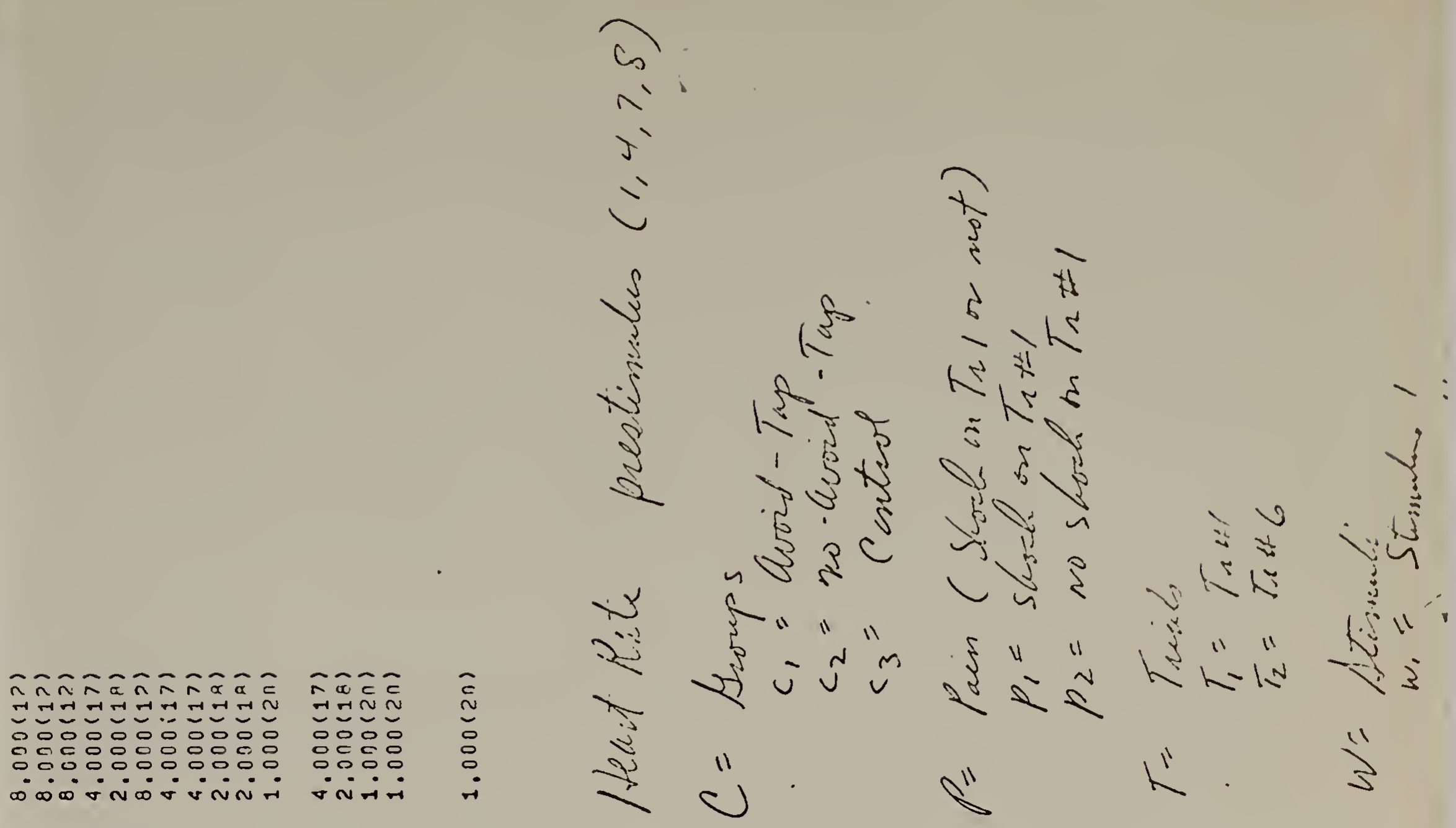

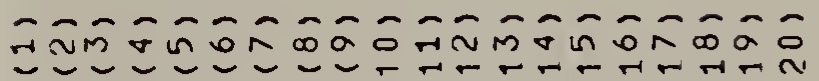

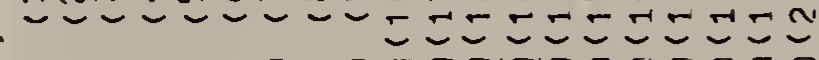

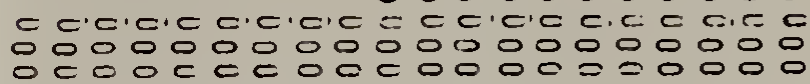

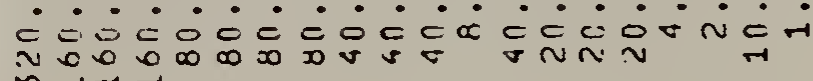
iि नन न

zำn

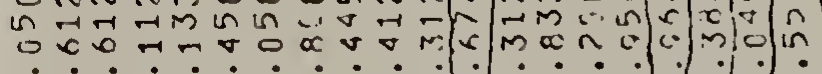

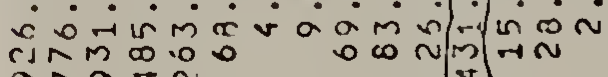

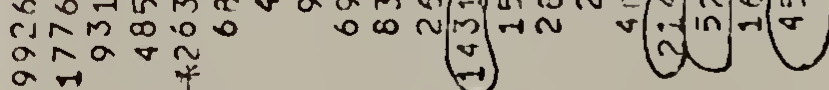
in

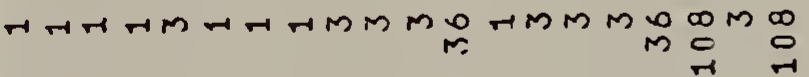

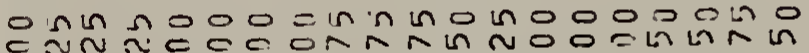
in

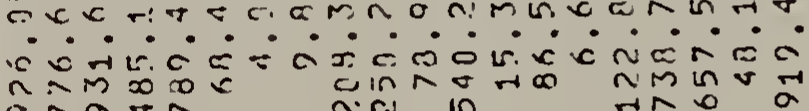

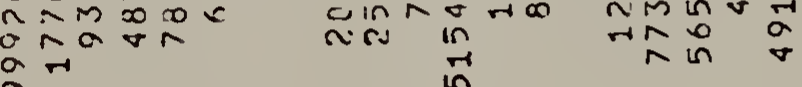
in

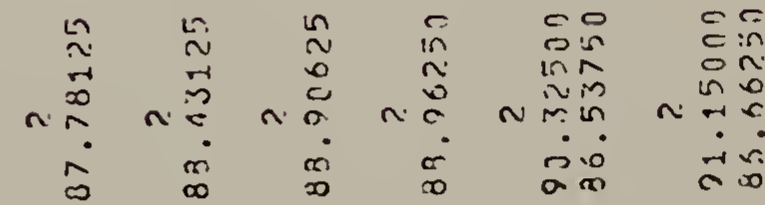
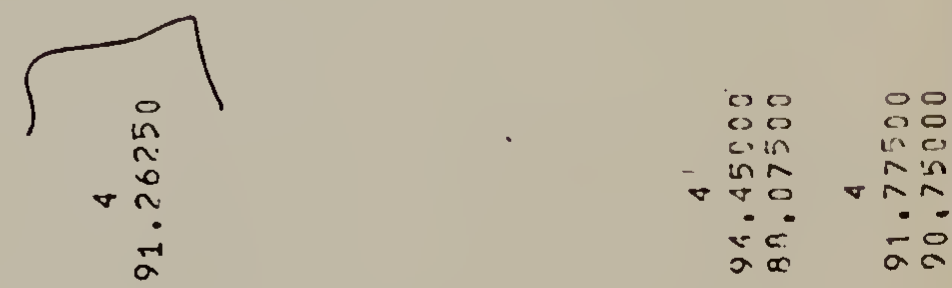

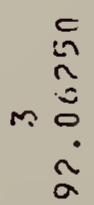

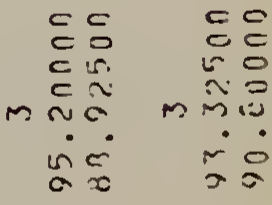

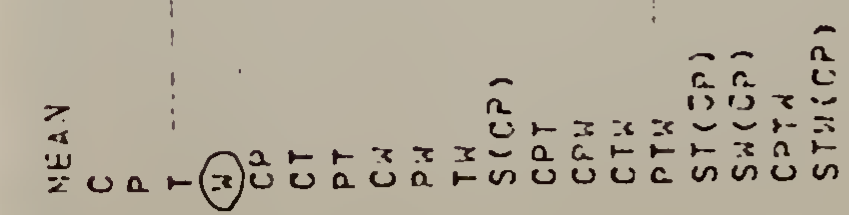

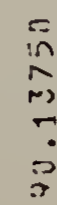

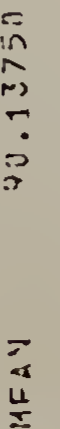

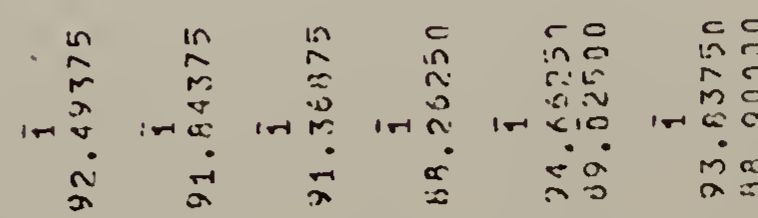

$\stackrel{2}{2}$

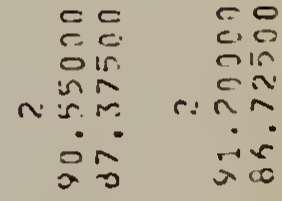

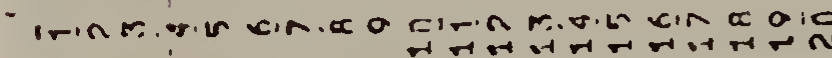

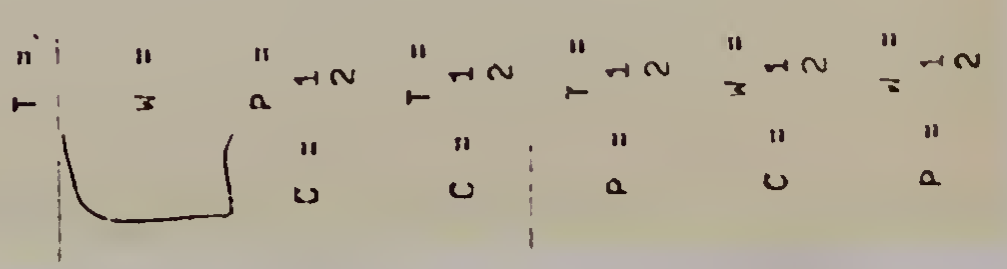




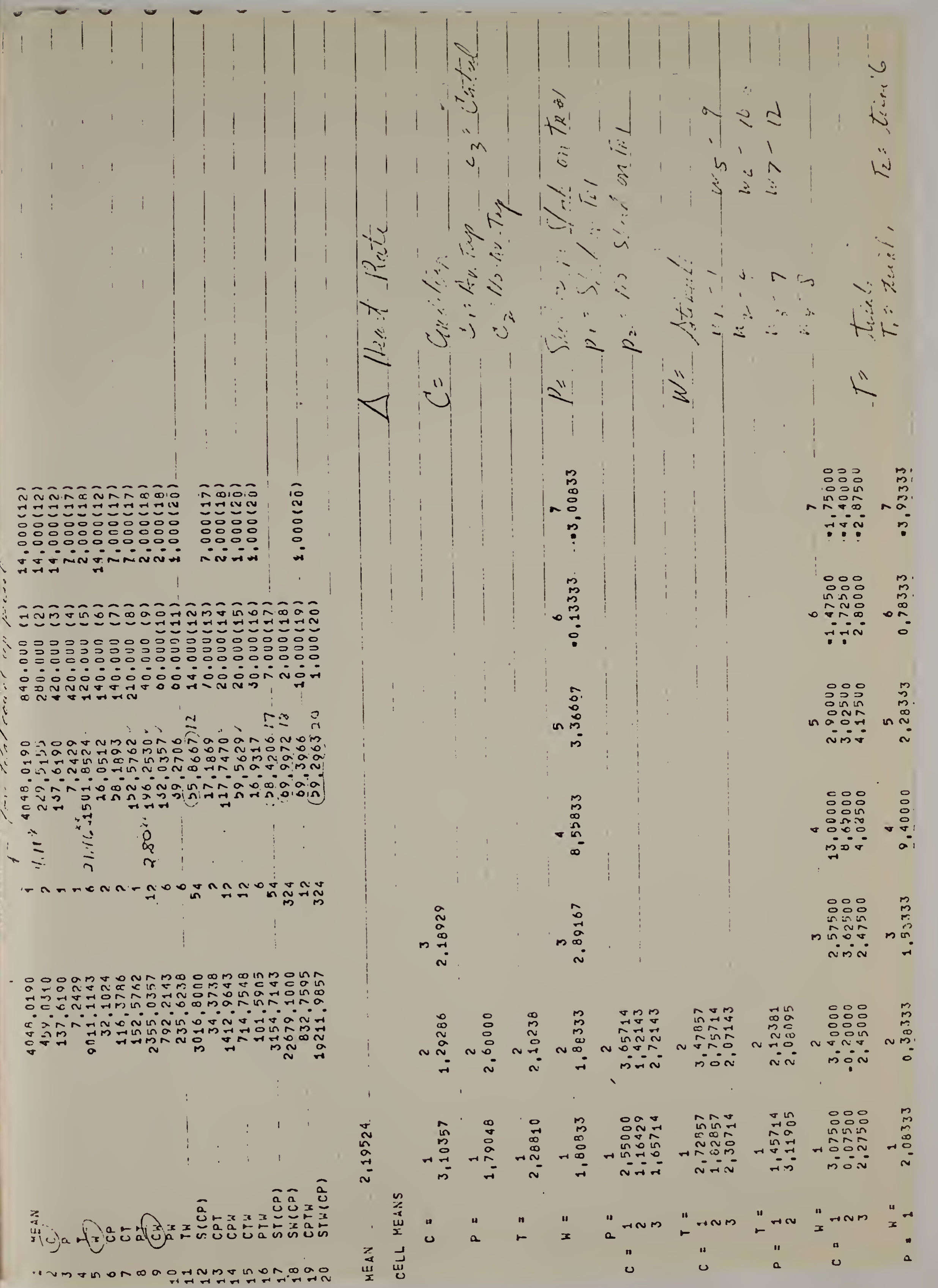




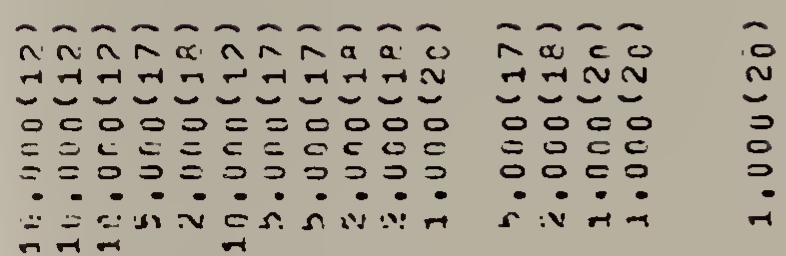

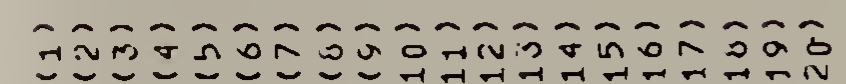

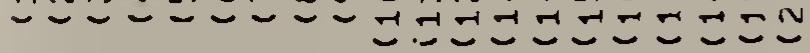

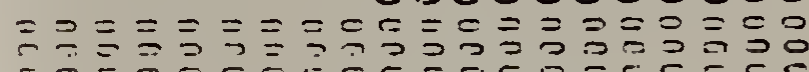

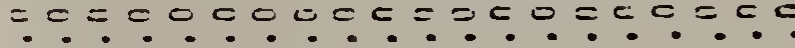

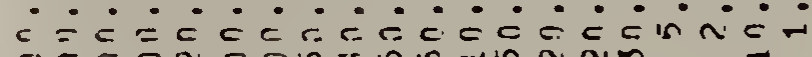

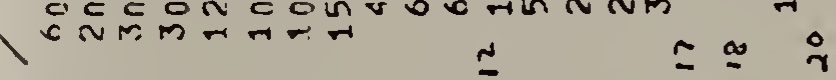

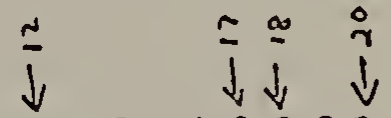

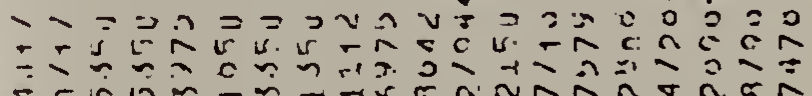

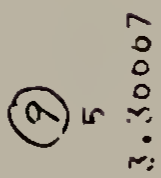

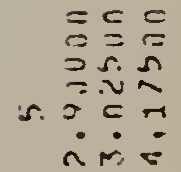

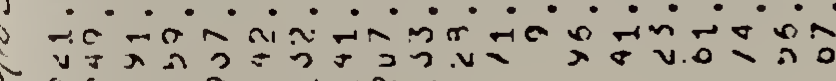

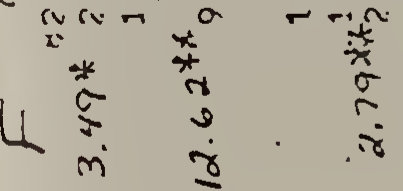

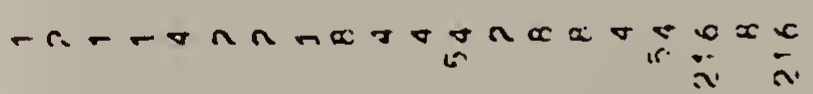

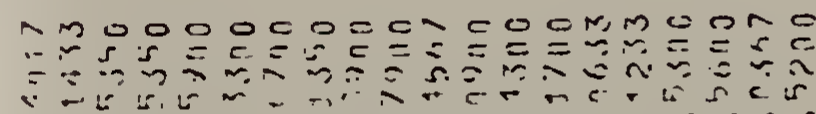
$\because \because \because \because \because \because \because \therefore)$ a

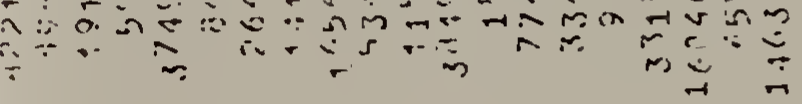

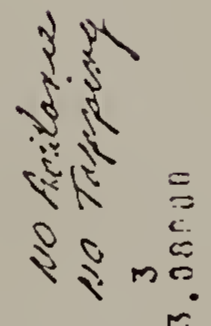<smiles>CC(=O)C1CCCC1</smiles>

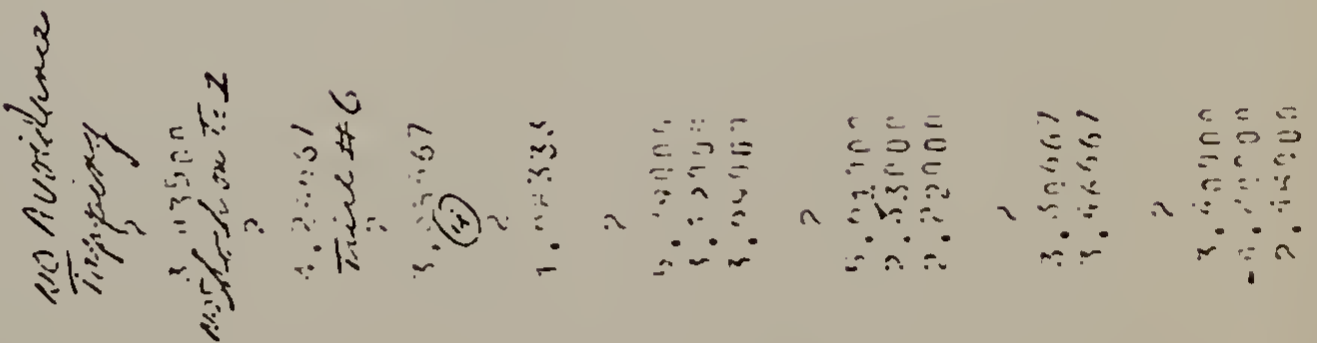

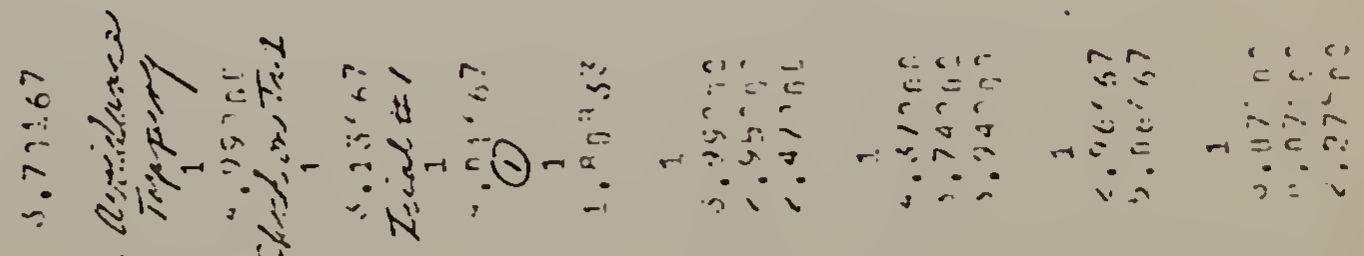
等

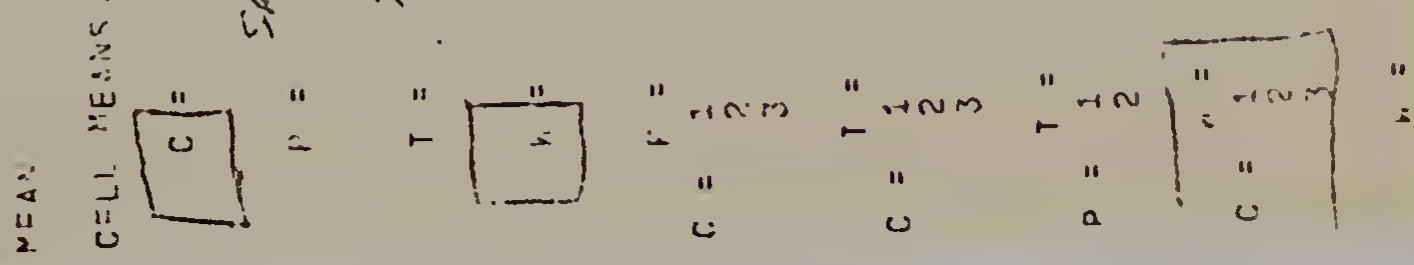





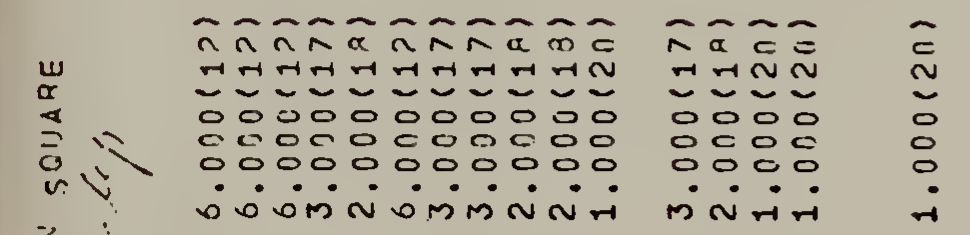

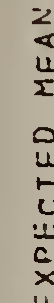
(i)

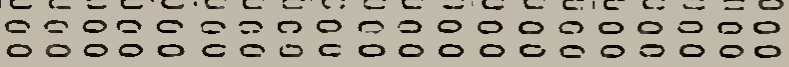
u icióc स joñ

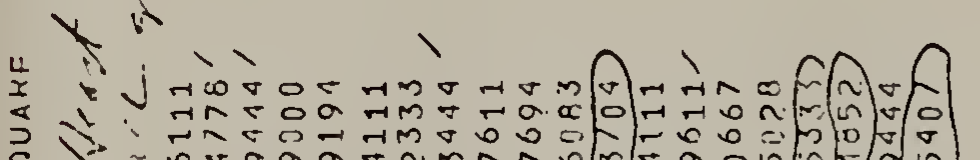
is

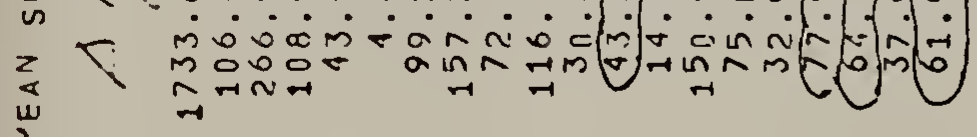
$\stackrel{c}{c} 4 \stackrel{*}{\frac{*}{j}}$

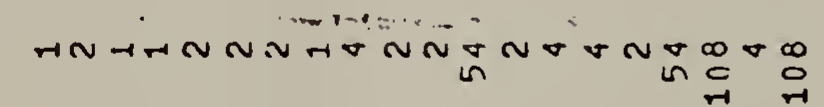
7.

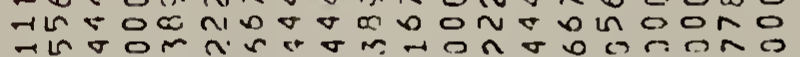

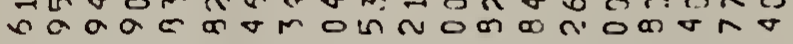
mind jo

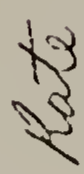

t $\nabla$<smiles>c1ccccc1</smiles>

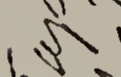<smiles>[AlH2]</smiles>

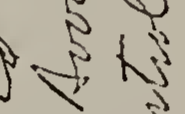
3 $2+\frac{1}{2}$

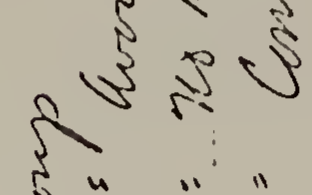
$\int^{\prime \prime} v^{\prime \prime} v^{\prime \prime} v^{\prime \prime}$

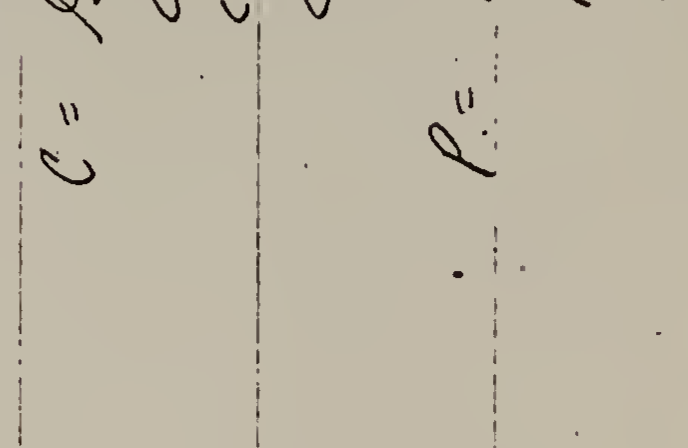<smiles>C1=Cc2ncnc1n2</smiles>

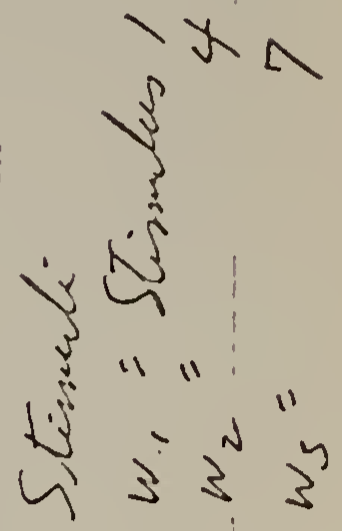

11

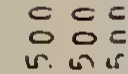

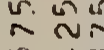

$\therefore \dot{n}$

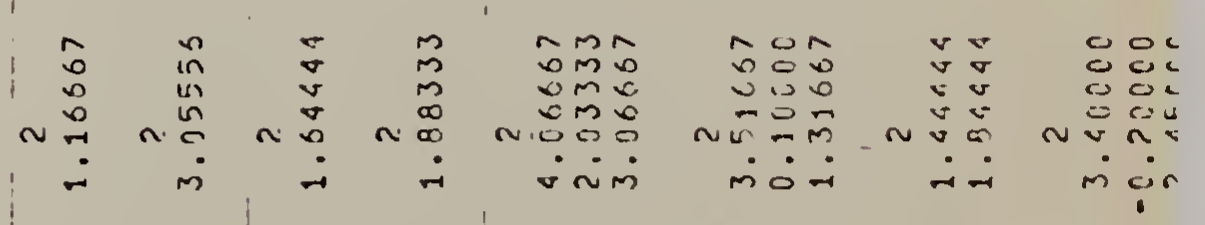
>

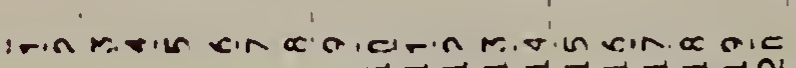

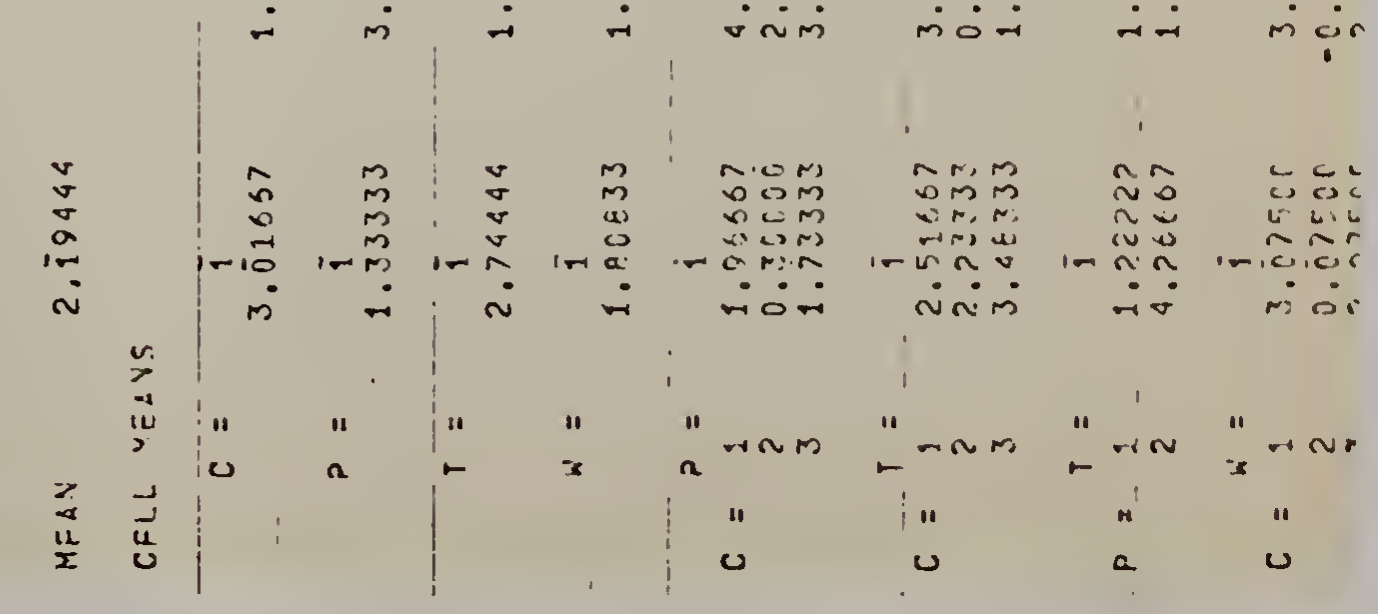




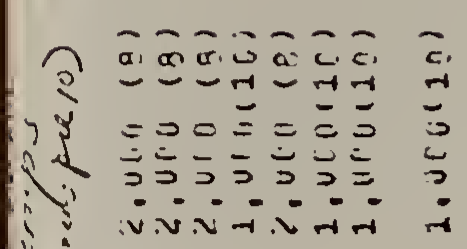
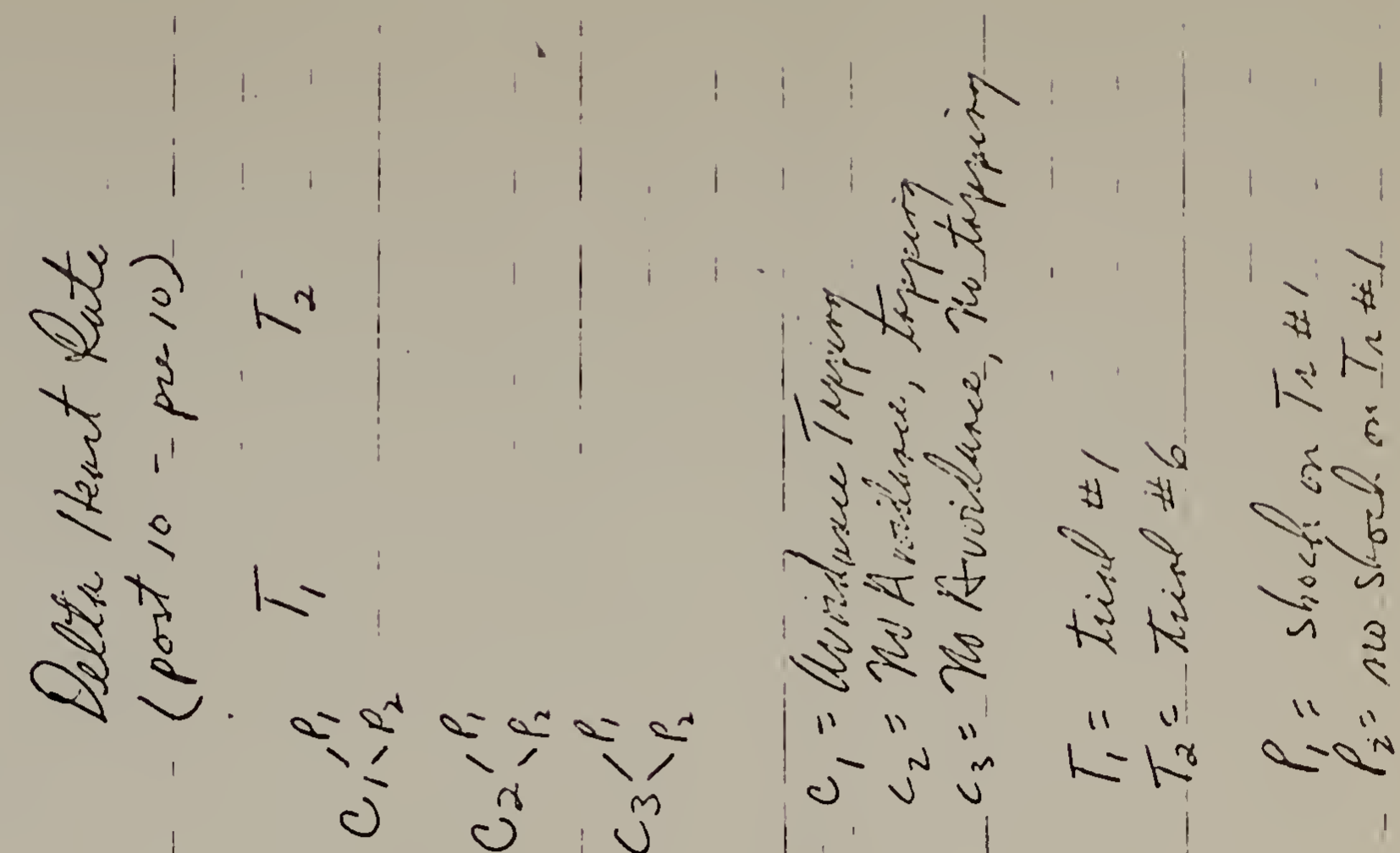

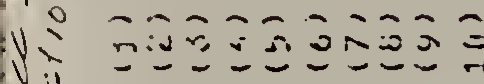

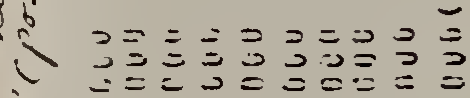

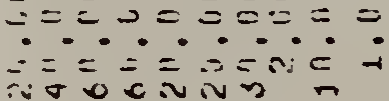

से

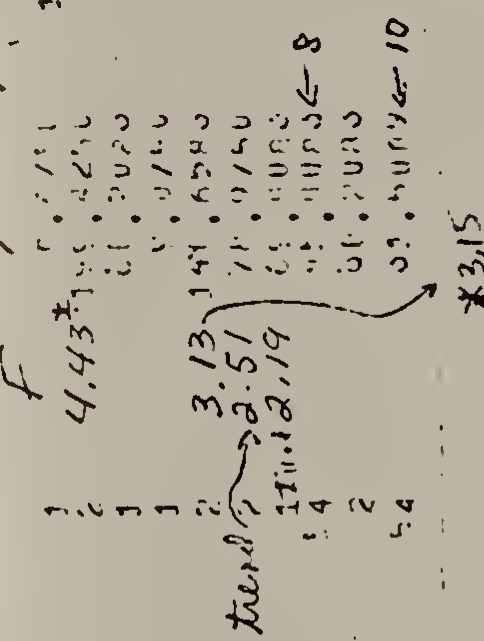

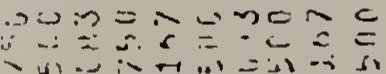

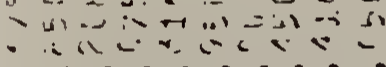

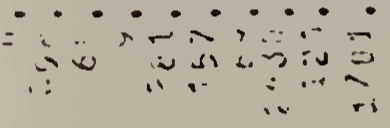

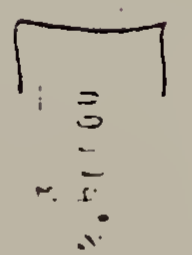

$\left|\frac{5}{3}\right|$
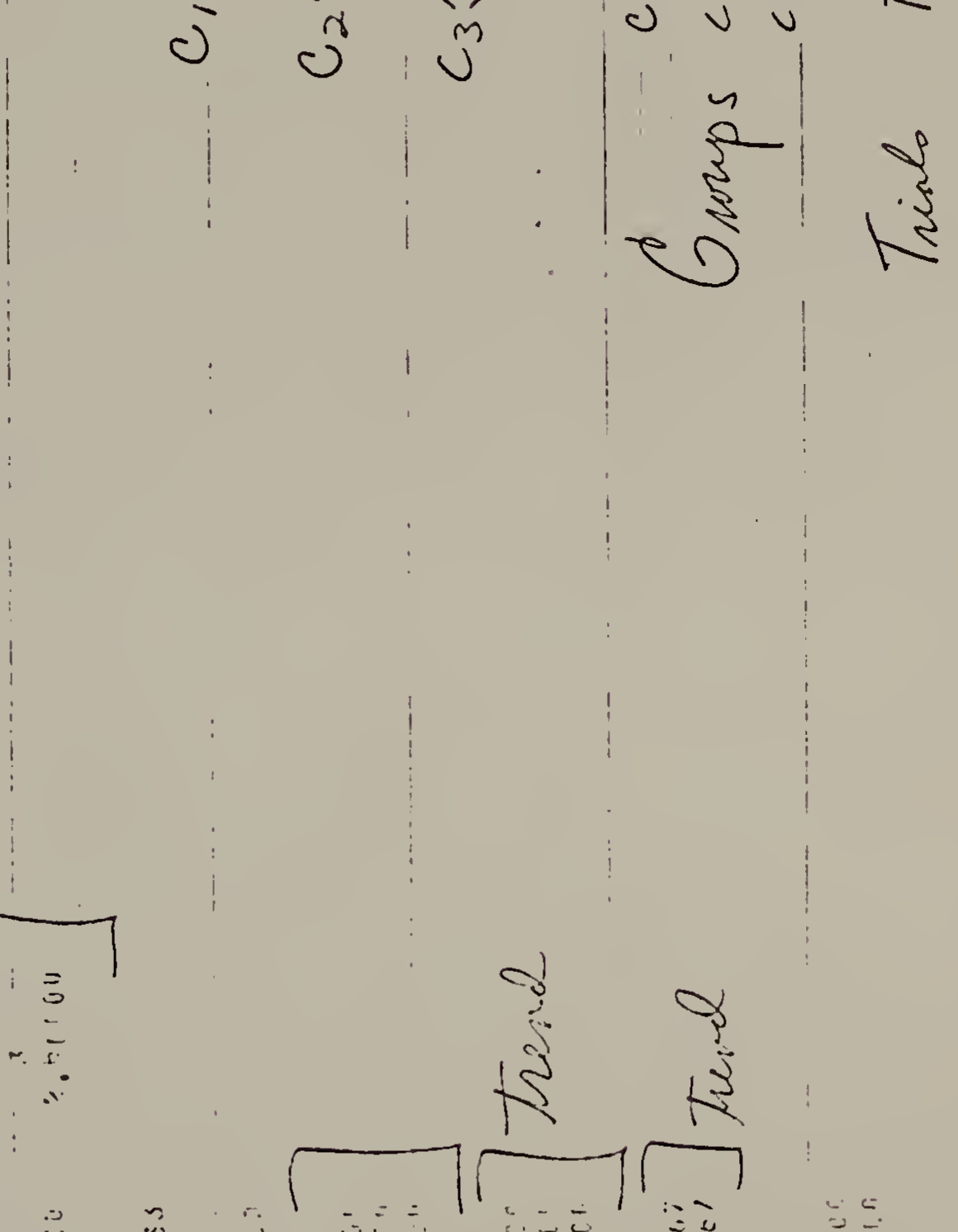

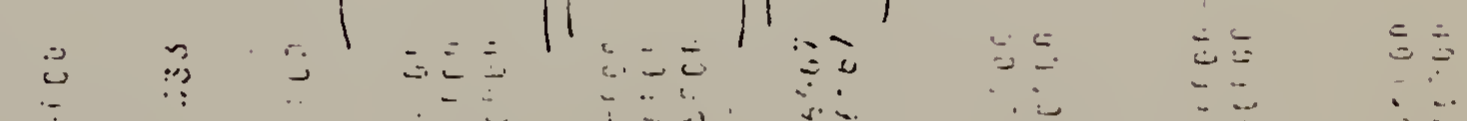

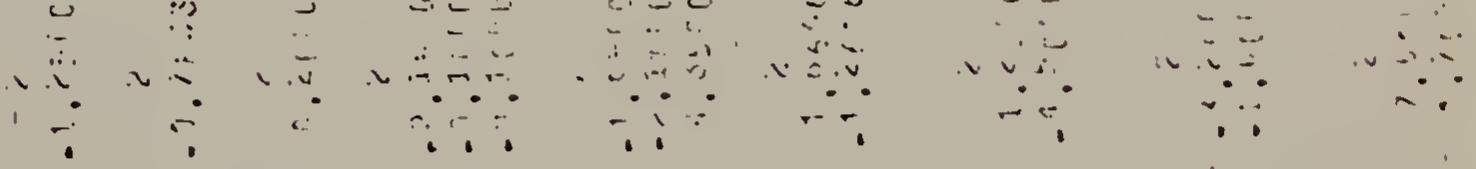

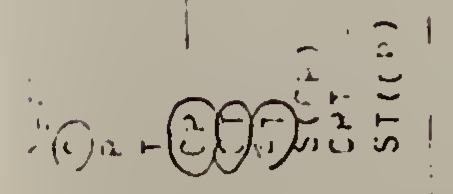

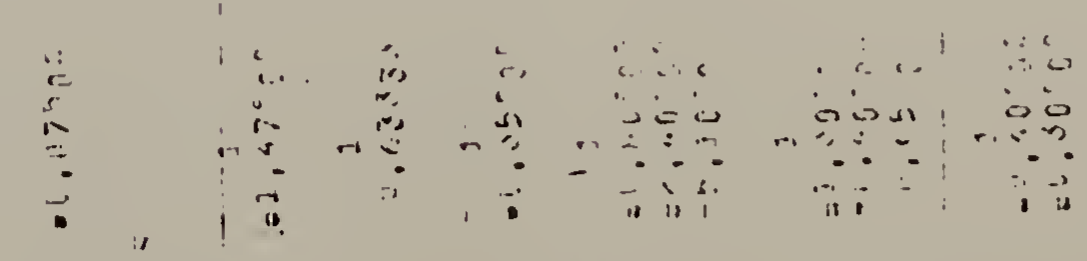
anderaces

is

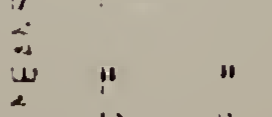

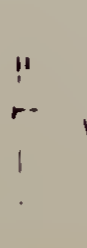
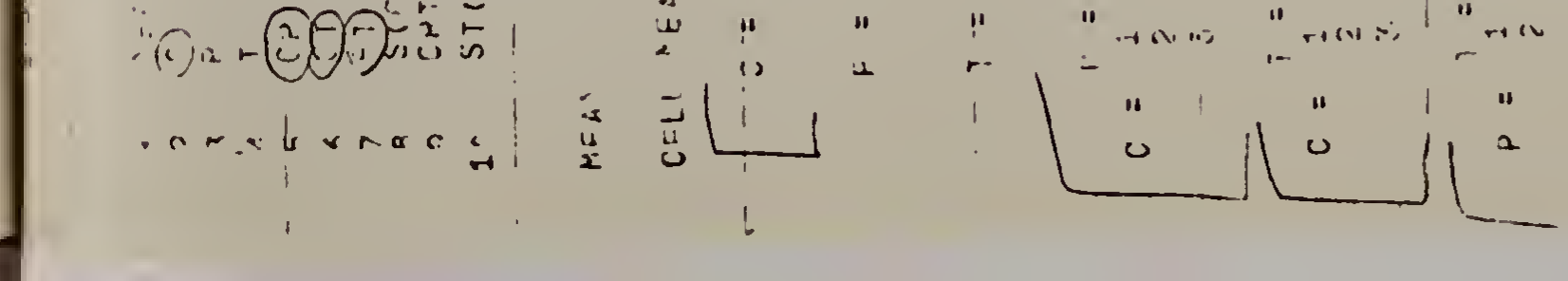




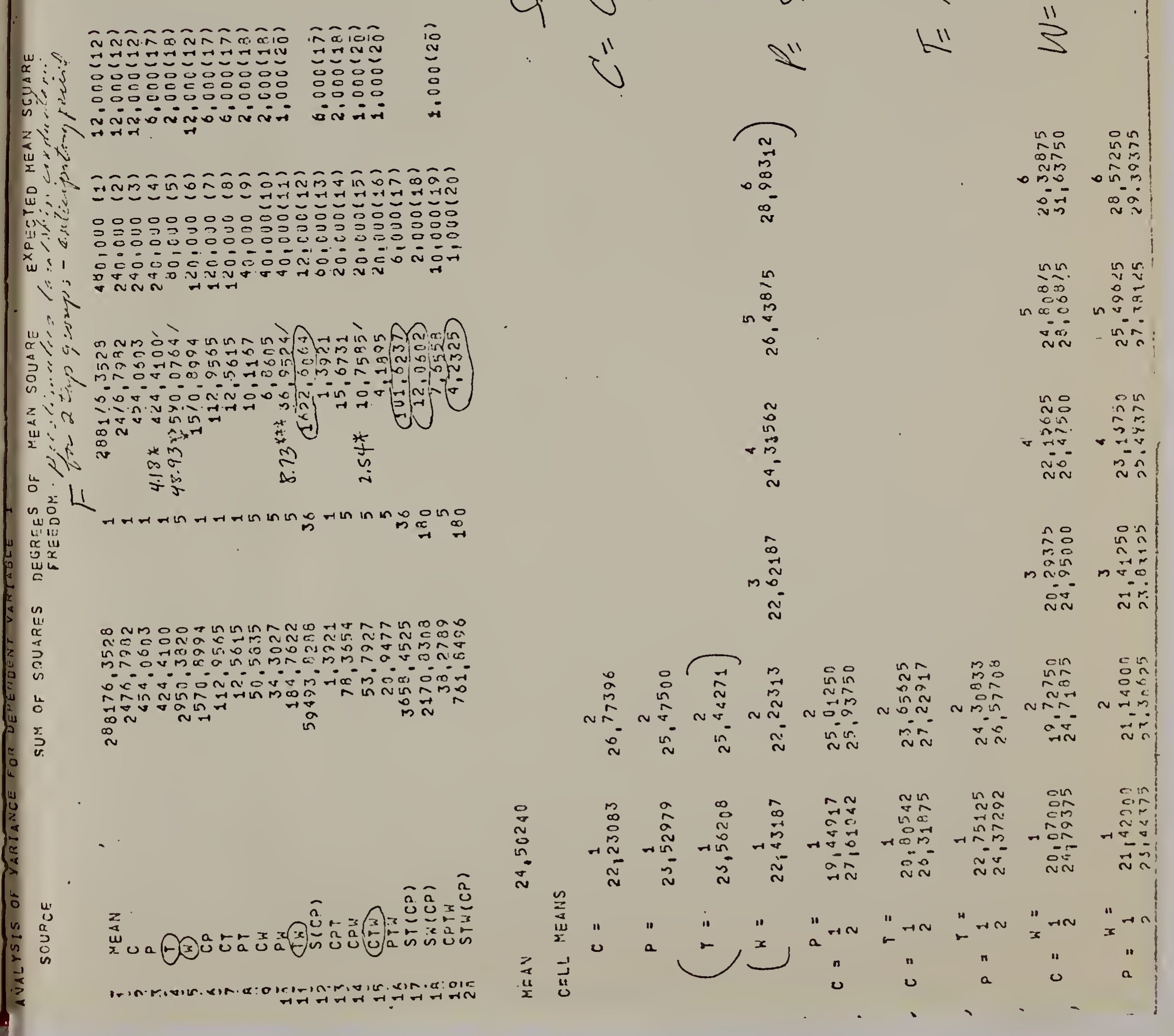




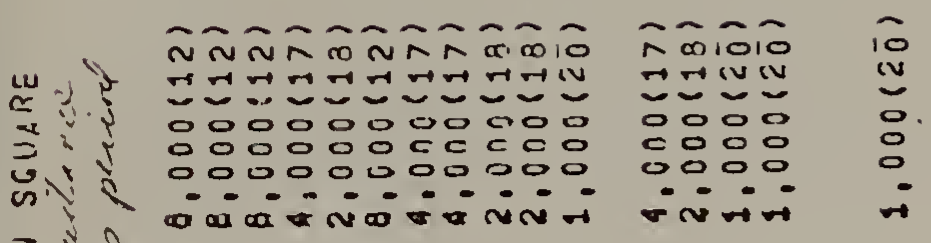

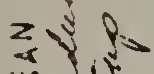

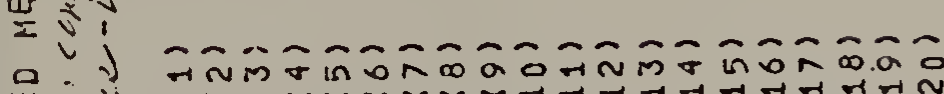

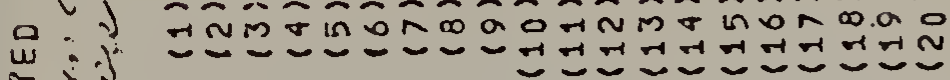
ㄴ. 시

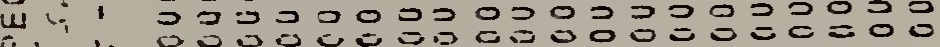
x) " W रु

世

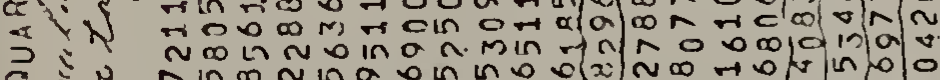

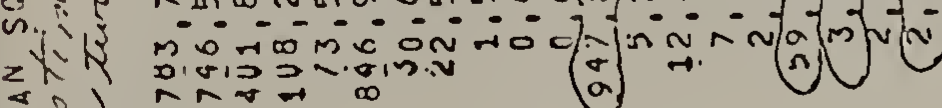

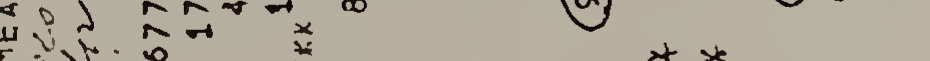

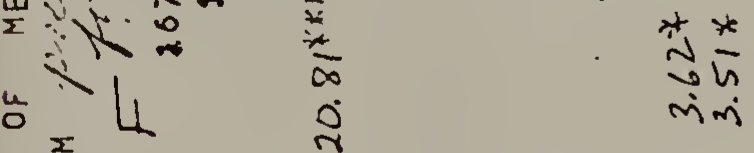

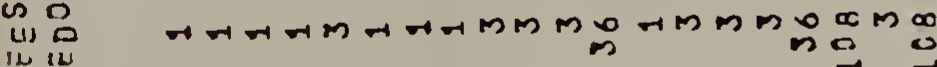
党

는

i1!

HLn thm

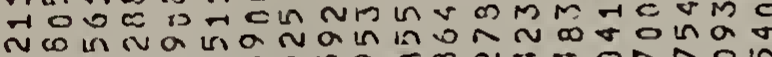
$\sim$ in $N$ is

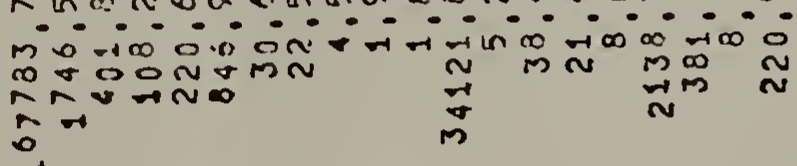
苂 $\stackrel{\sum}{\rightrightarrows}$

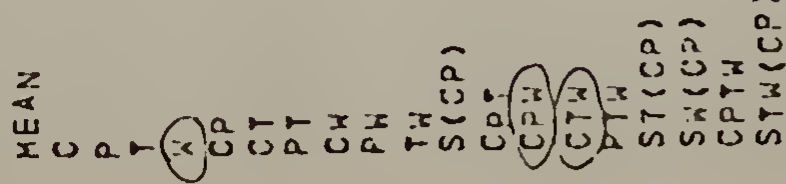

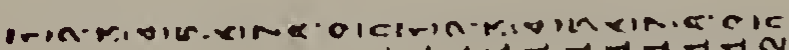

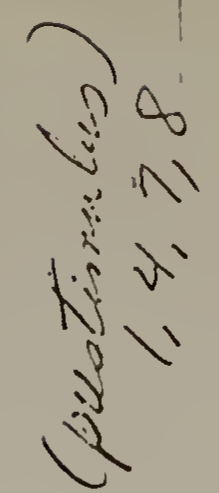<smiles>[AsH2]</smiles>

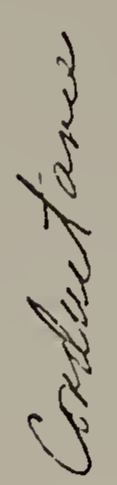

$\sum^{2}$<smiles>C1CCCCC1</smiles>

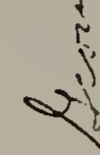
11 S<smiles>C=[V]=CC=C(C)C</smiles>

$\bullet$<smiles>[V]=[V]</smiles>

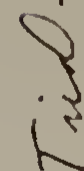<smiles>C1=CC=C1</smiles>

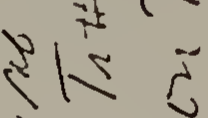

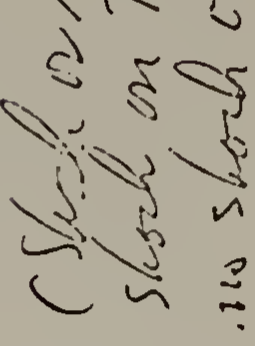

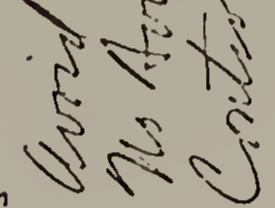
$-\sqrt{\prime \prime} v^{m}$

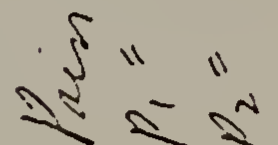
\& :<smiles>CC1CC1</smiles>

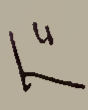




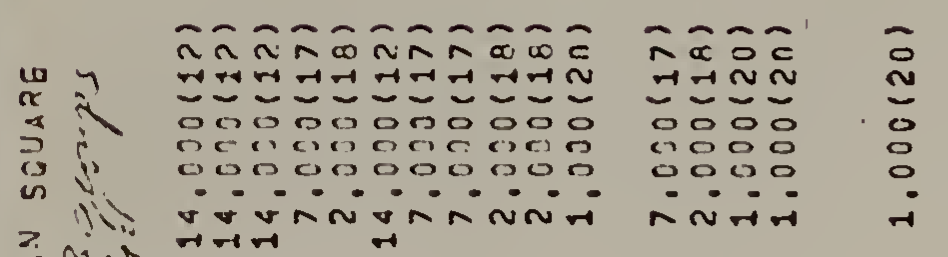

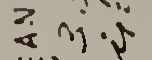

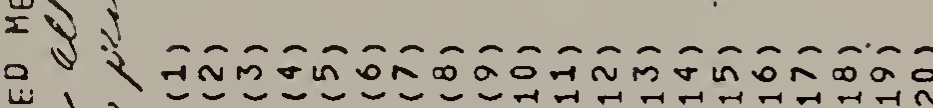

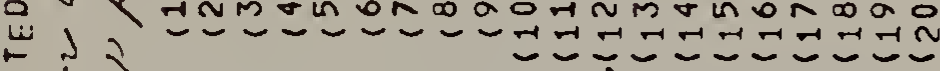
ت m

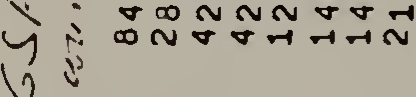

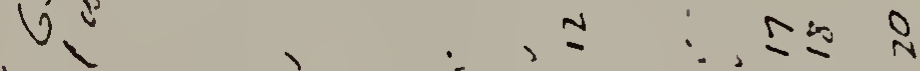
㟧㠃 似

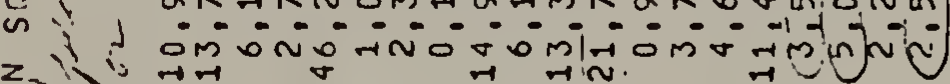

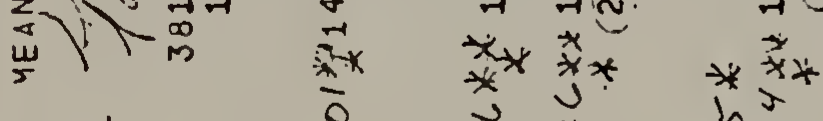

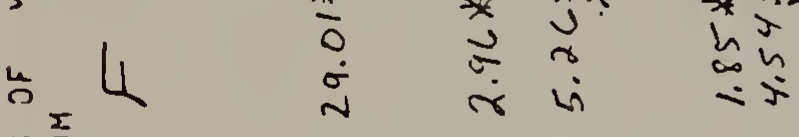

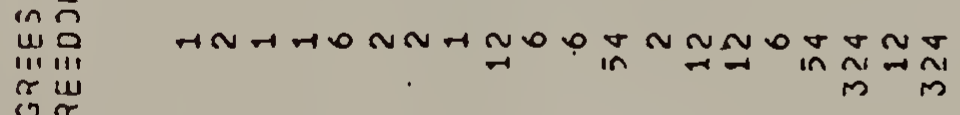
象些

in

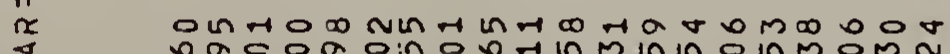

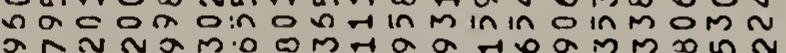

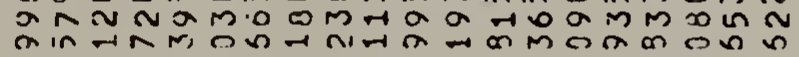

\& क

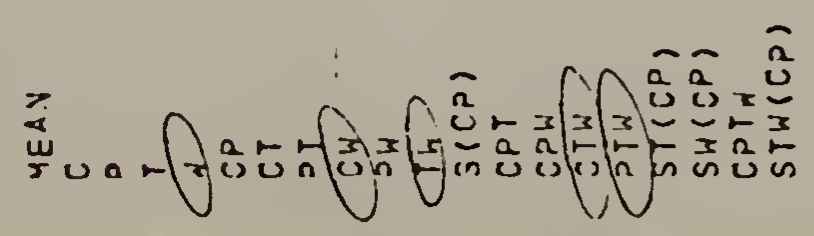

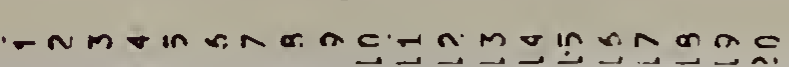

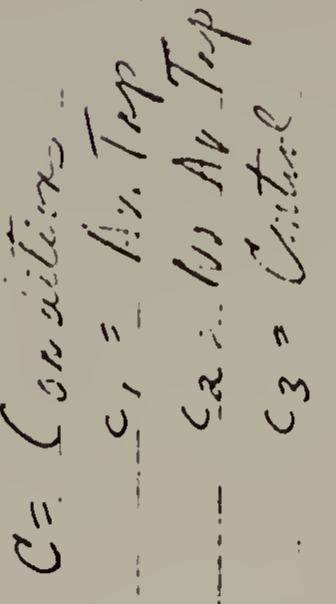

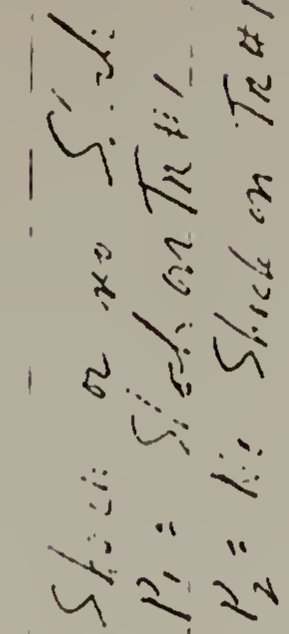

his ?

11

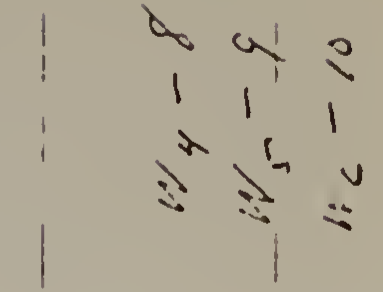

$h^{\prime \prime}$

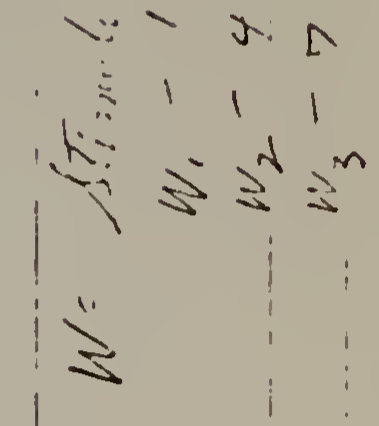

$\stackrel{n=1}{\simeq} \Perp$

$\rightarrow \infty \infty$

in in

वंध्य

in

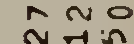

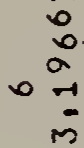

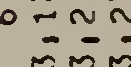

$\underset{n}{\stackrel{n}{a}}$

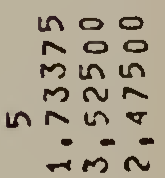

0
0
0
0
0
in

$\ln \operatorname{in} 0$

$\sin 2$

oin $\infty$

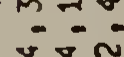

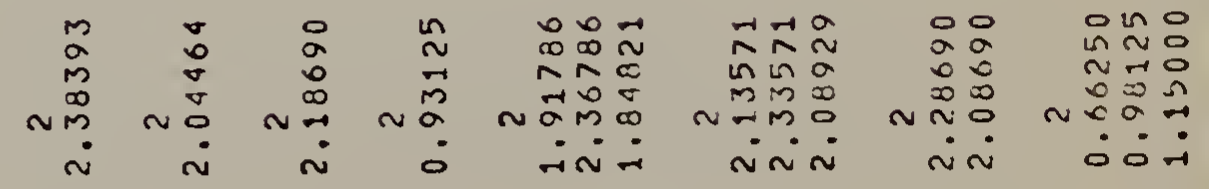

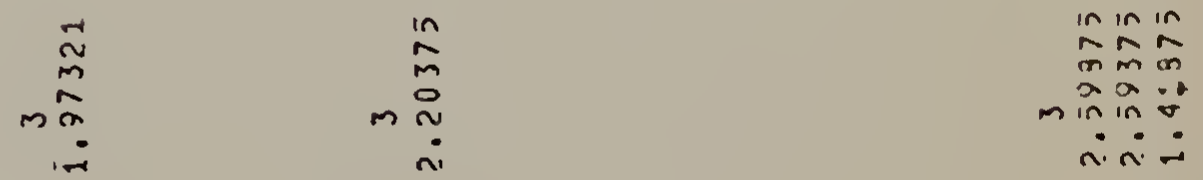




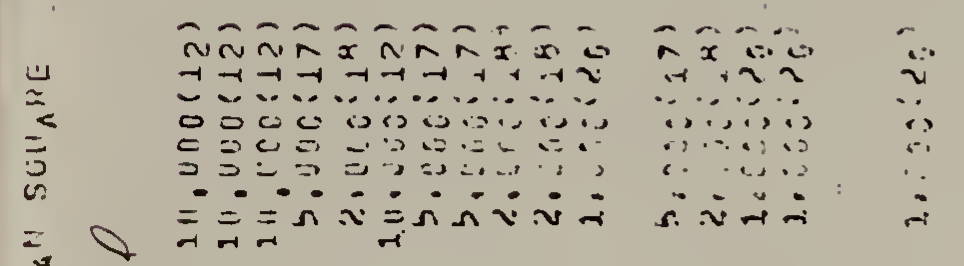

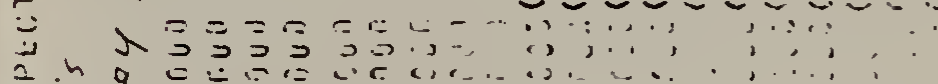

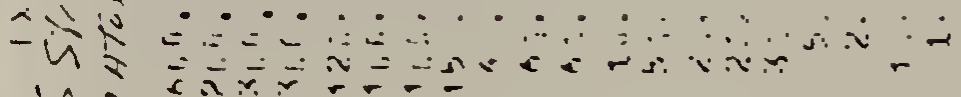

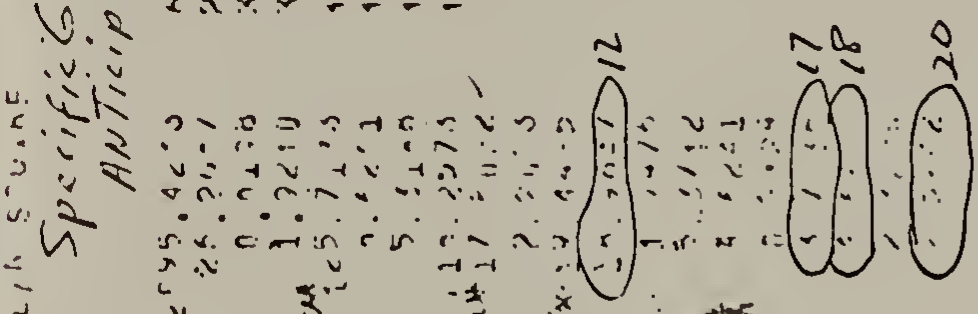

$\sigma \quad \frac{a}{\hat{\alpha}}$

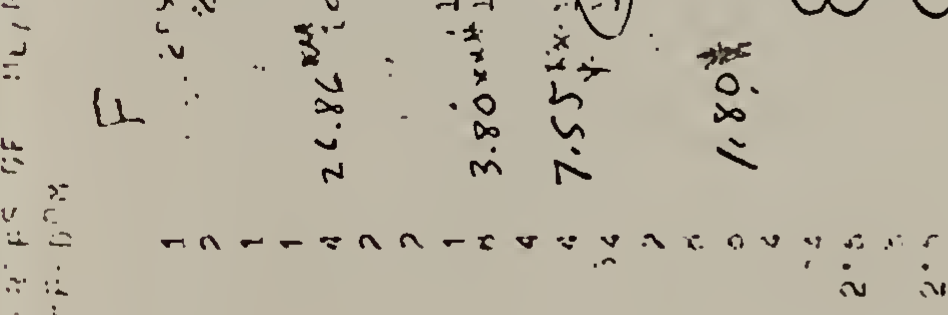

2

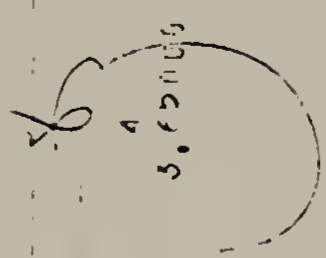

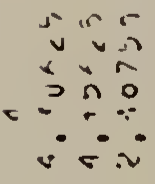

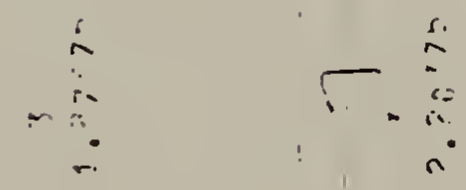

돈

$\therefore \therefore$

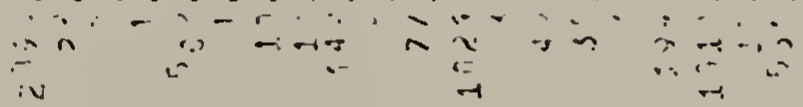

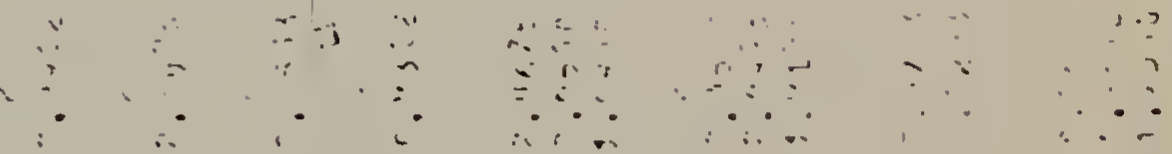

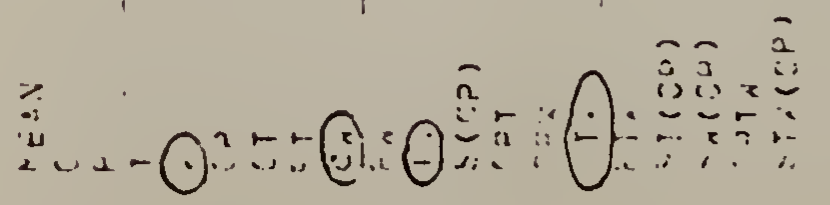

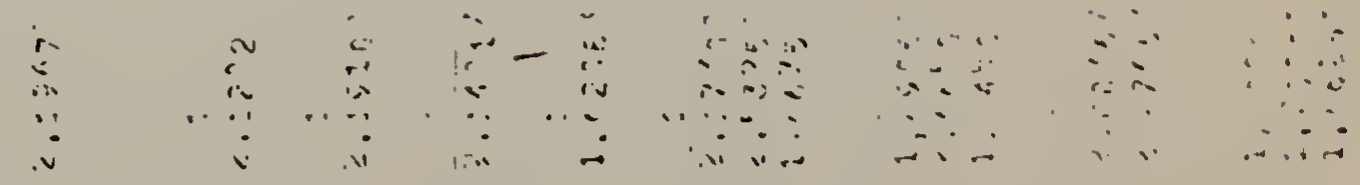

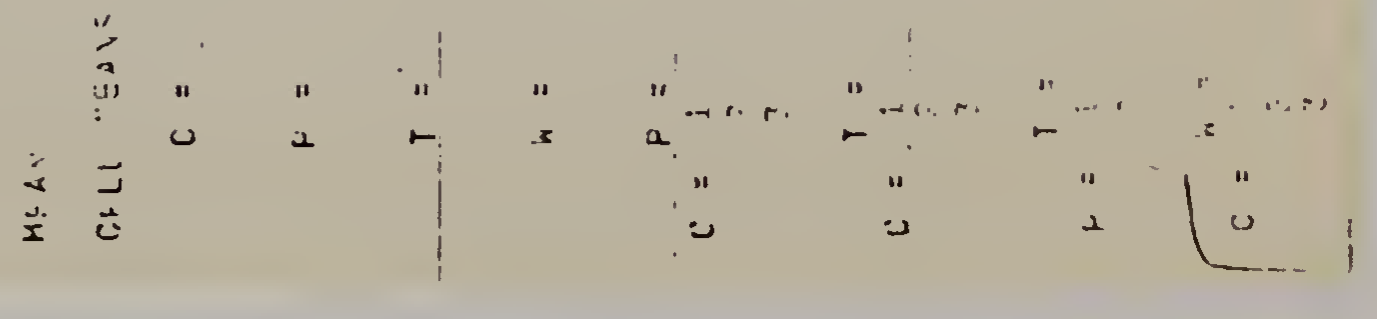




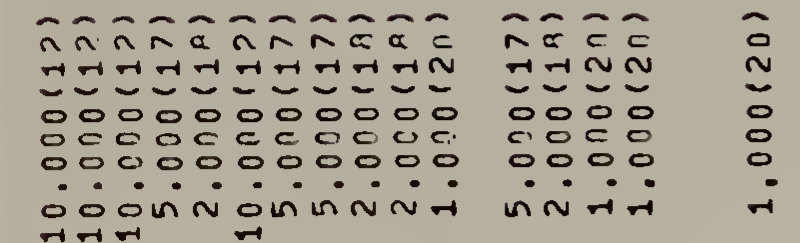

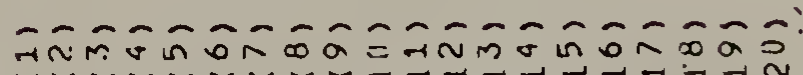

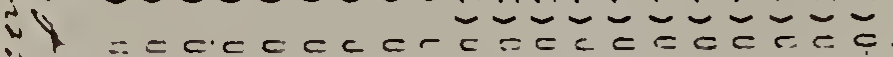

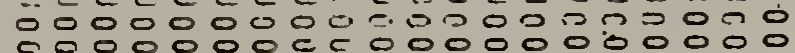

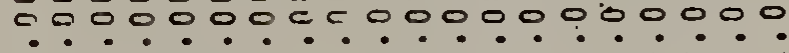

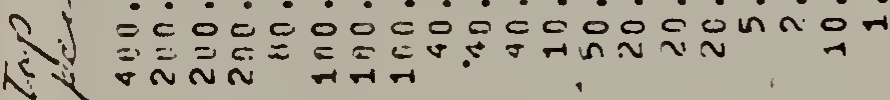

Nin

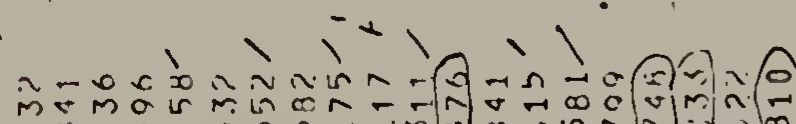

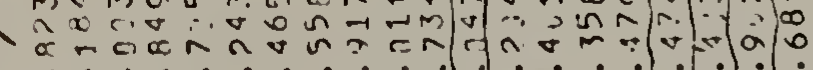

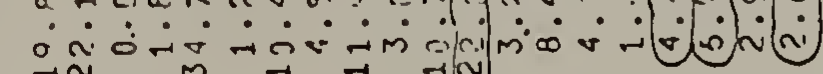

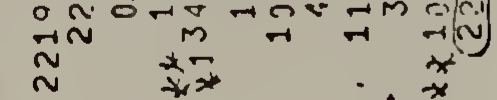

4

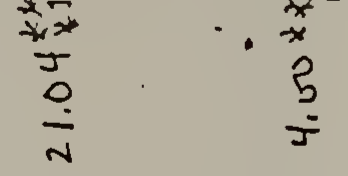

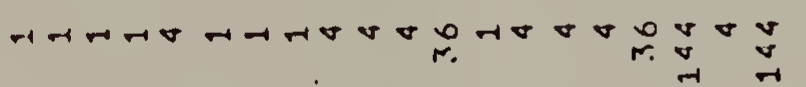

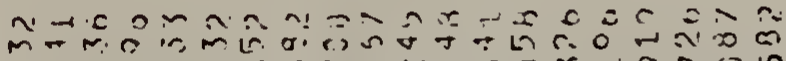

mx $x=0$

柋

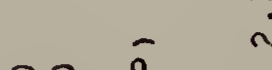

$\Rightarrow \quad \hat{2}+\hat{n} \dot{n} \hat{n}=0$

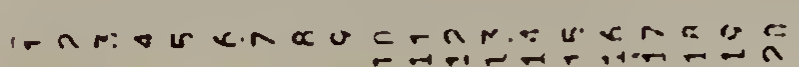

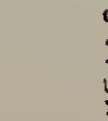

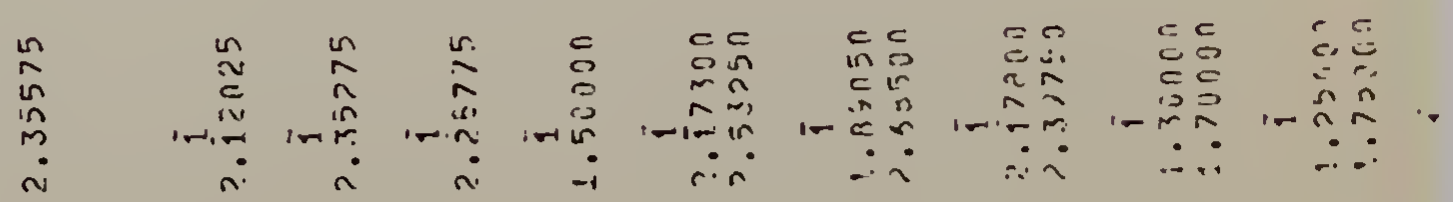

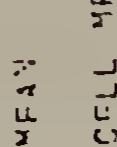
s.

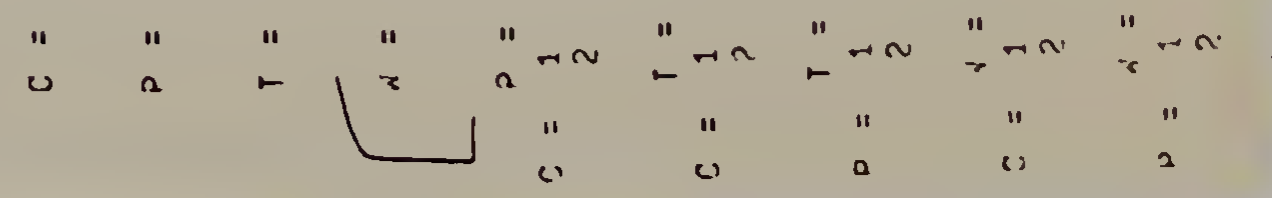

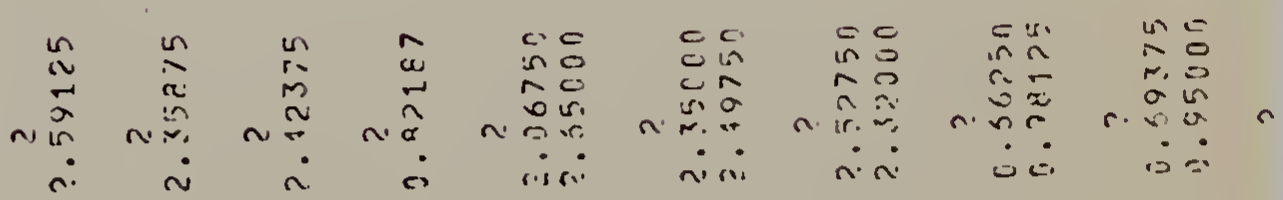




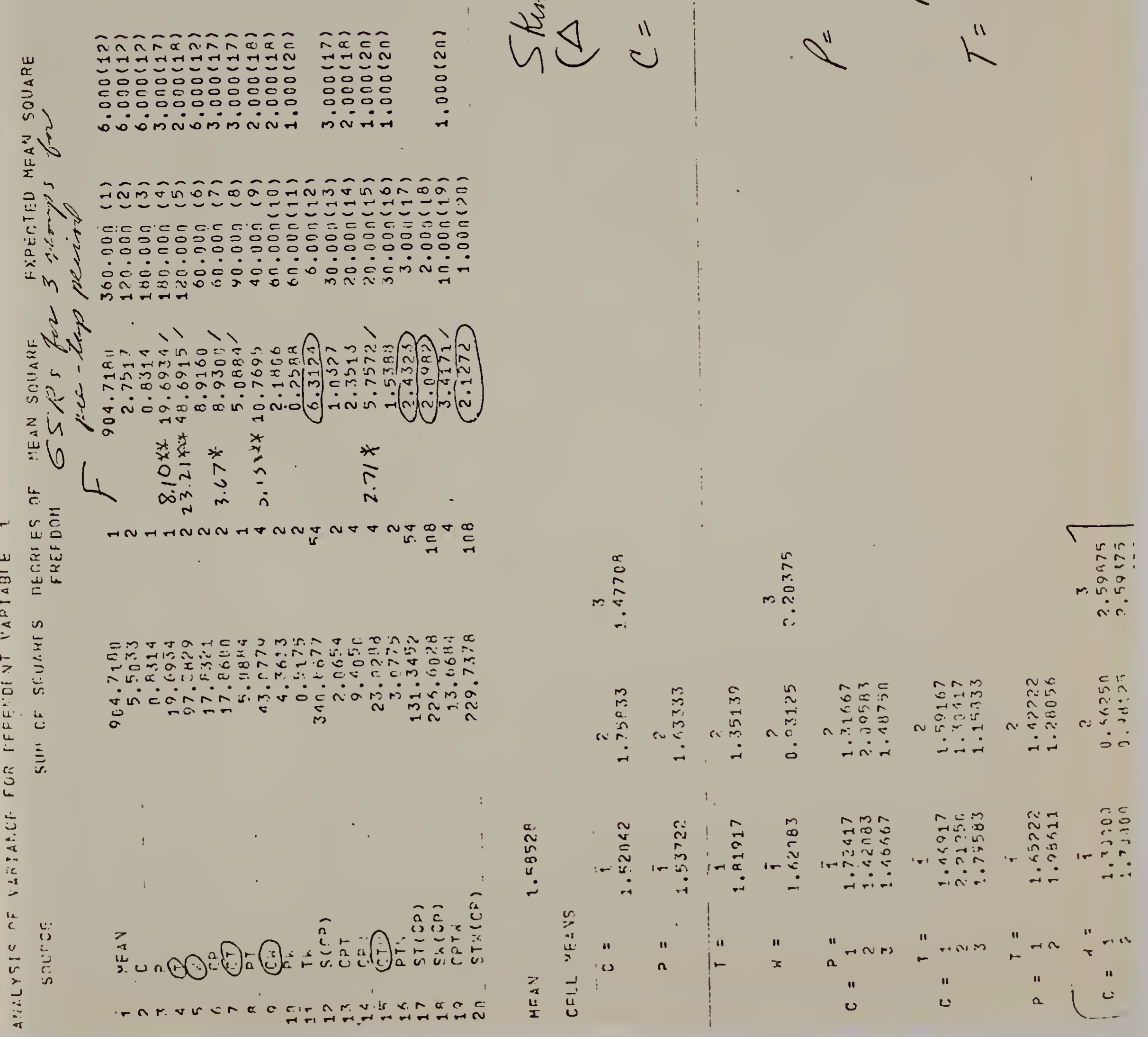





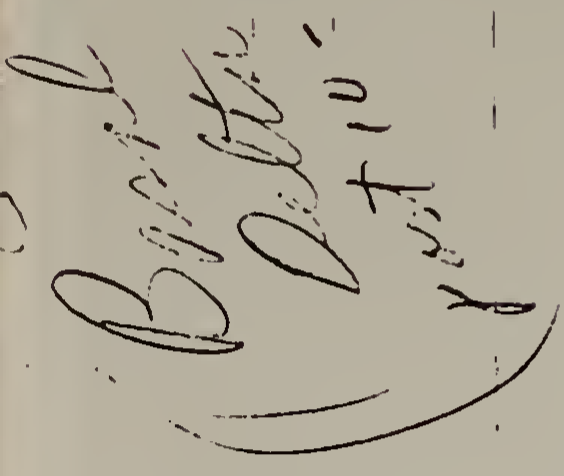

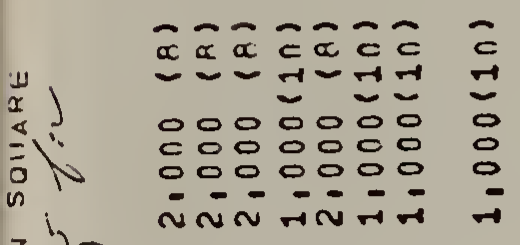

करण

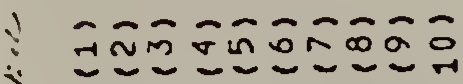

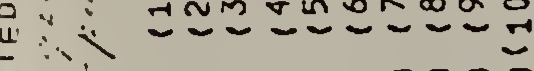

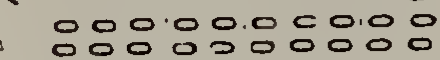

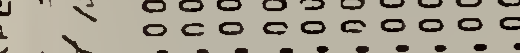

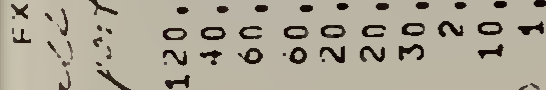

党

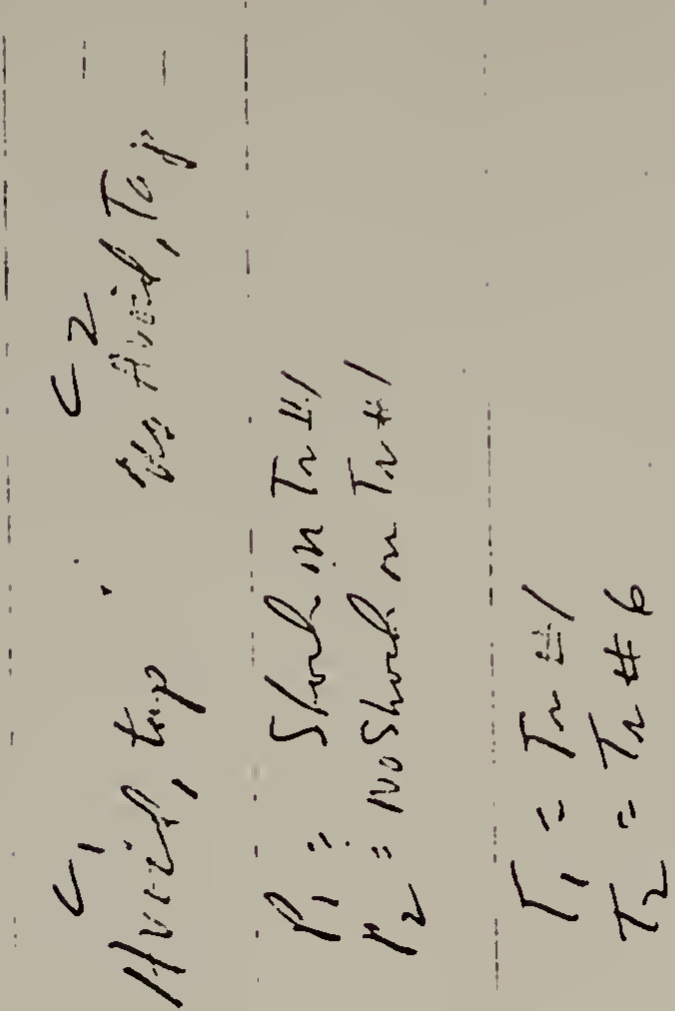

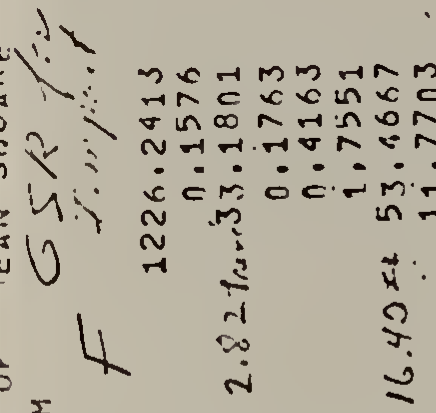

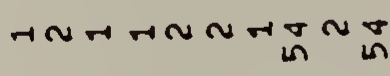

matmann. nn

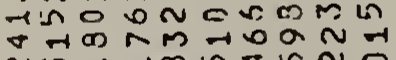

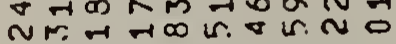

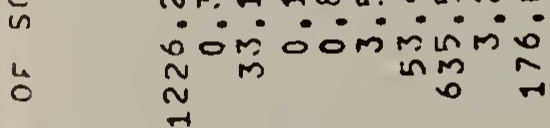

m $\stackrel{\circ}{\circ}$ in

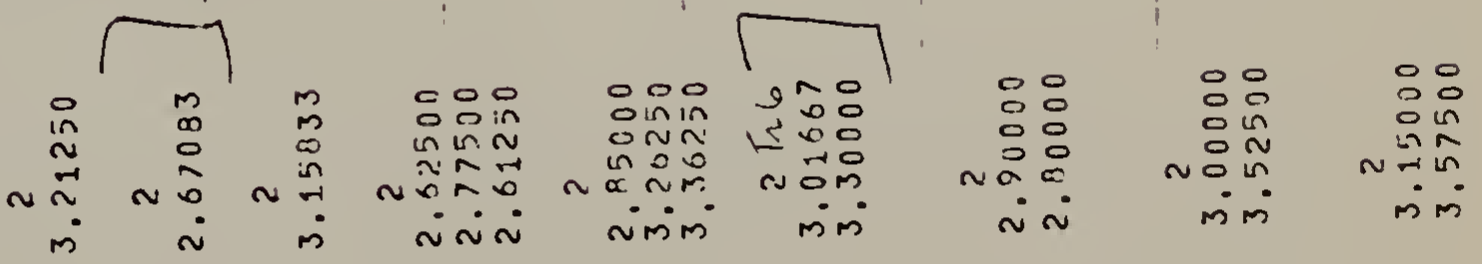

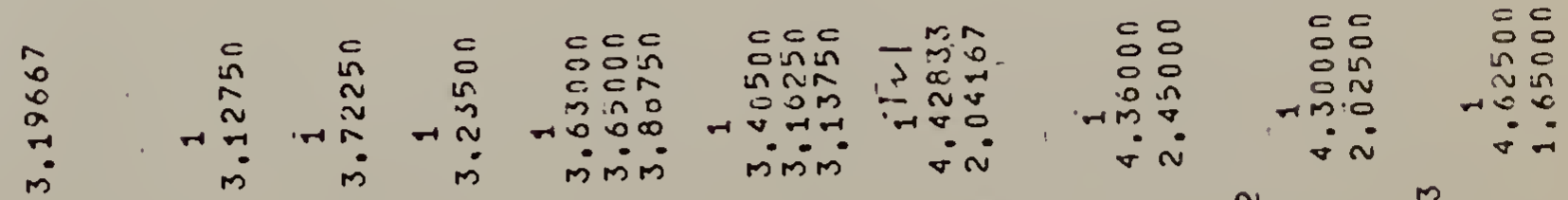

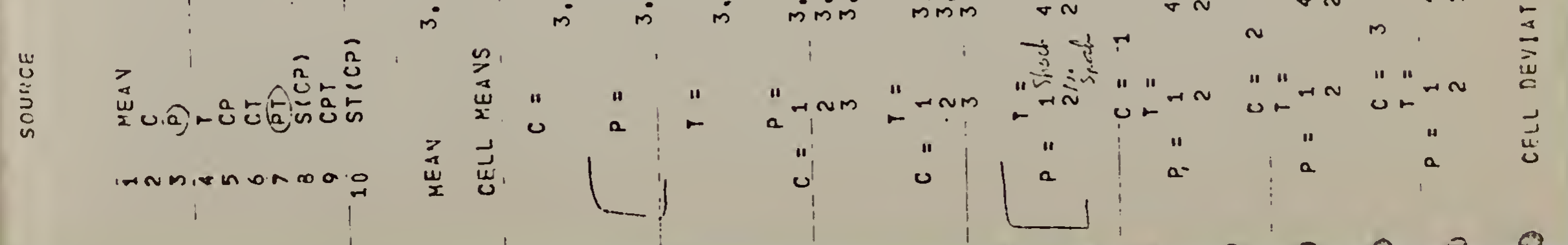




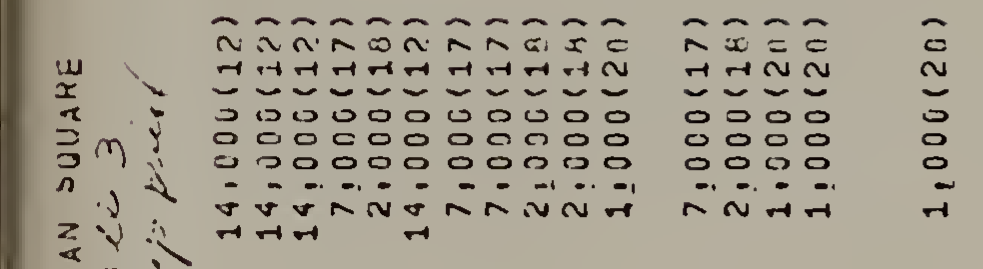

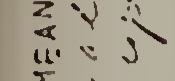

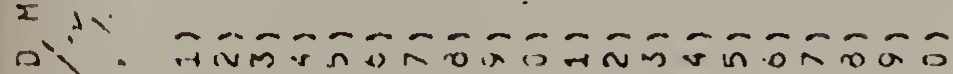

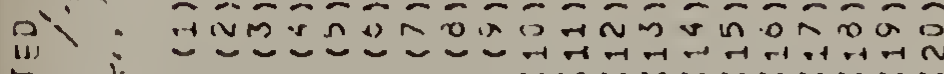

U : 出

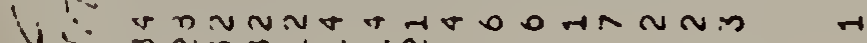

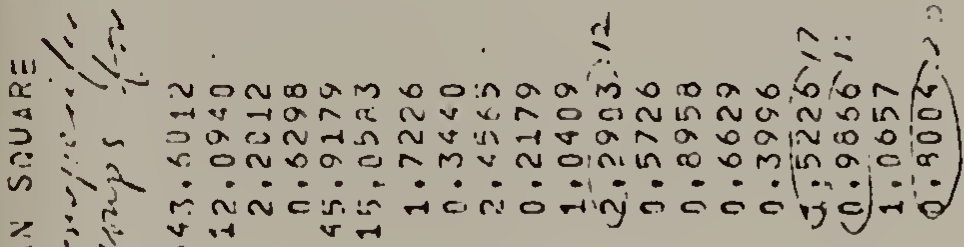

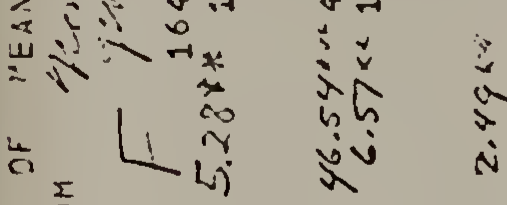

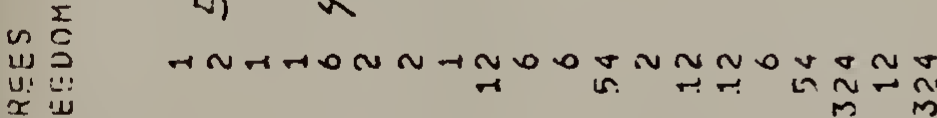

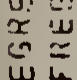

$\stackrel{w}{c}$

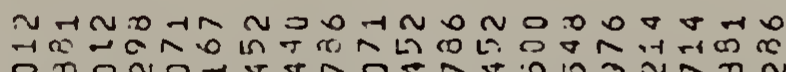

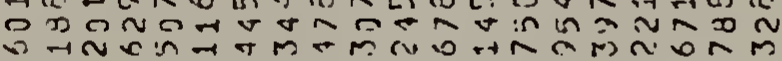

L $\quad$ v

$\sum_{i n}^{5}$

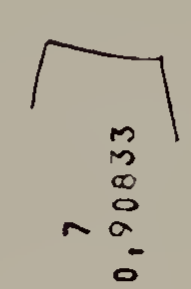

$m$
$m$
$\pi$
0
0
0

$\ln \underset{\substack{m \\ \infty}}{\substack{\infty \\ \sim}}$

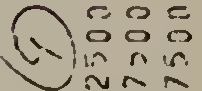

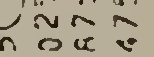
ini

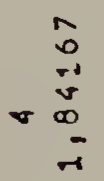

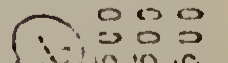

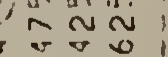

नखिये

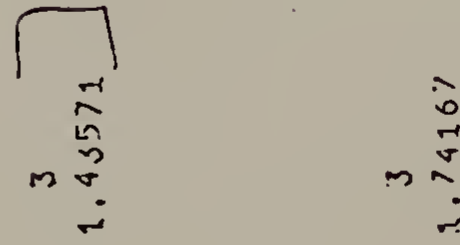

(n)

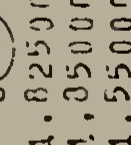

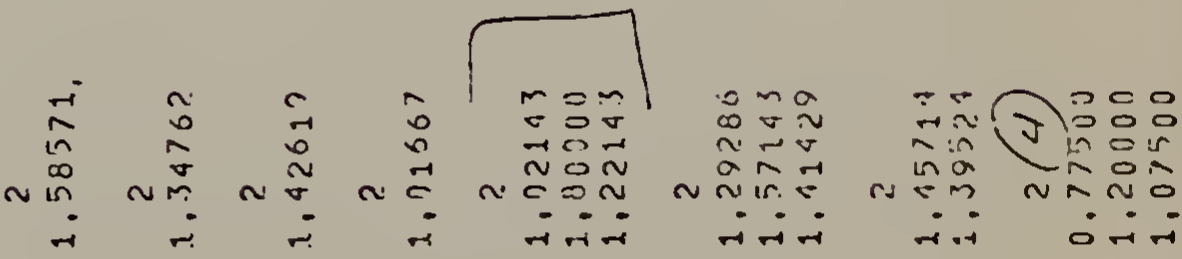

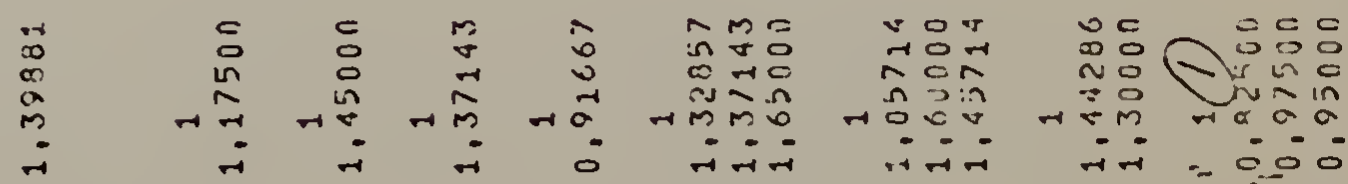

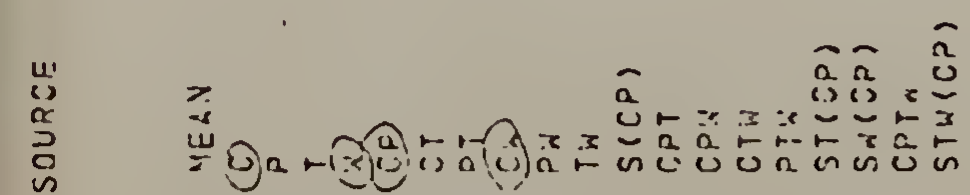
z

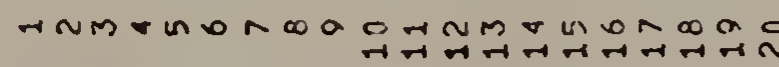




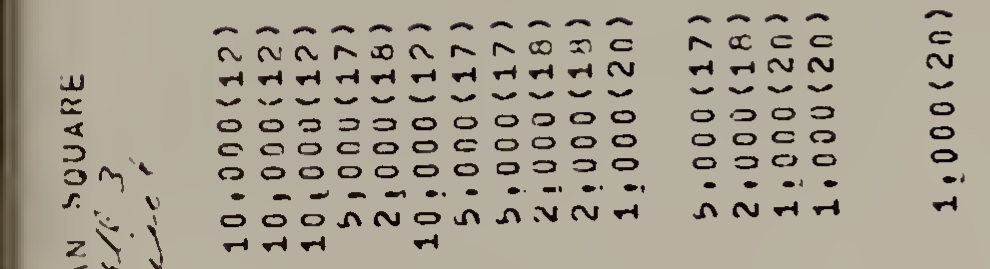

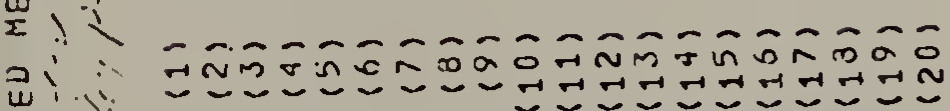

แ以

U

पर

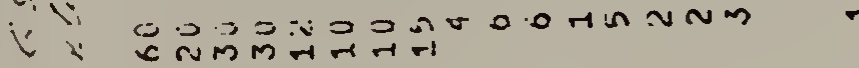

U.

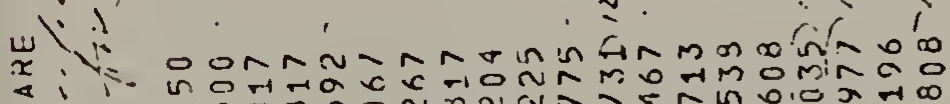<smiles>CCCCCC(C)C</smiles>

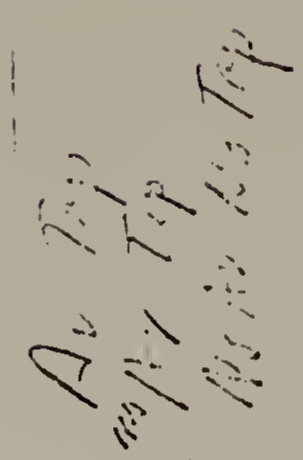

K.

$\begin{array}{ll}\searrow & 4 \\ \vdots & \vdots\end{array}$

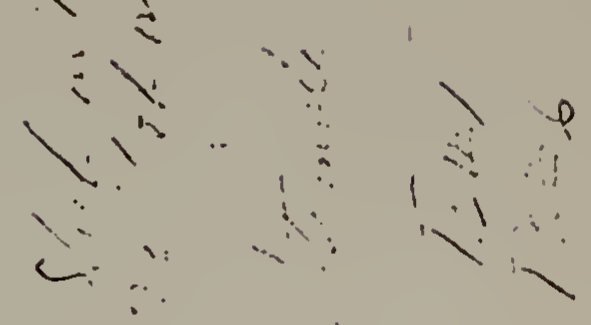
Uे $U^{N}$

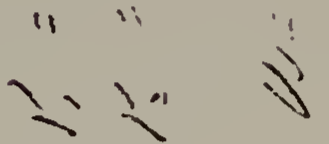

$2 \ln$

G toodoon

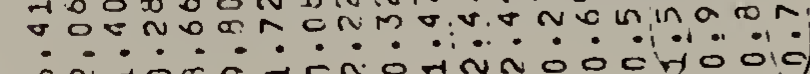

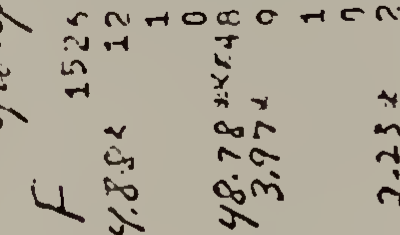

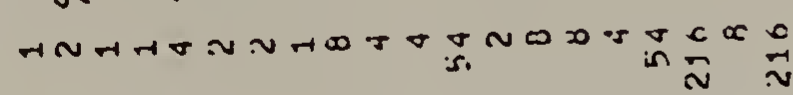
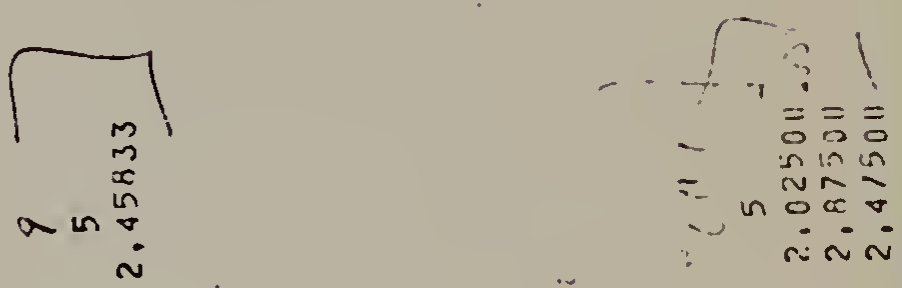

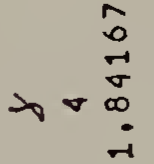

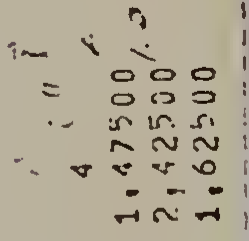

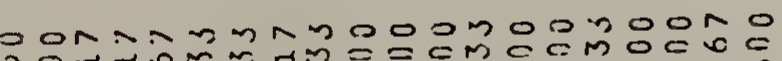

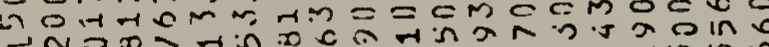
ง

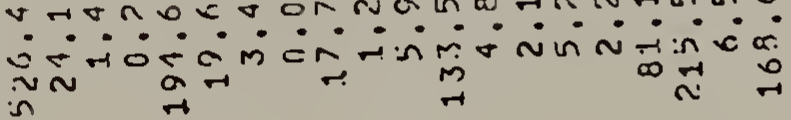

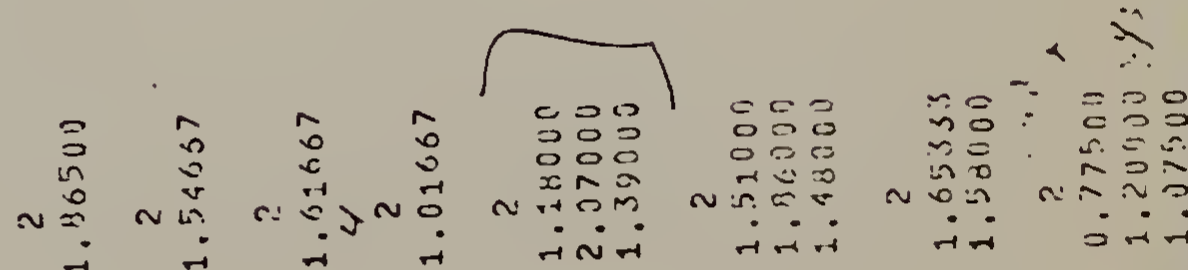

$\because 4$

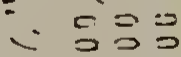

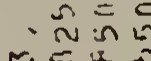

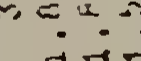

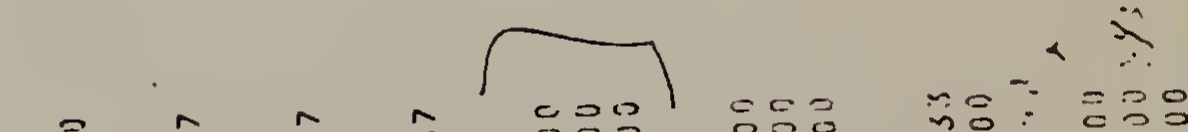

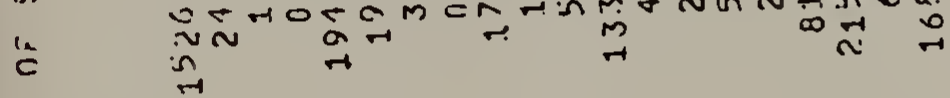
京<smiles>O=S(=O)(O)OC1CCCCC1</smiles>

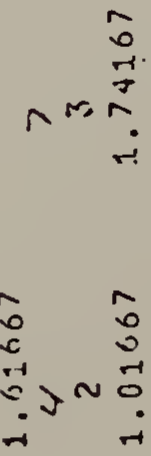
in nis 5 ori 


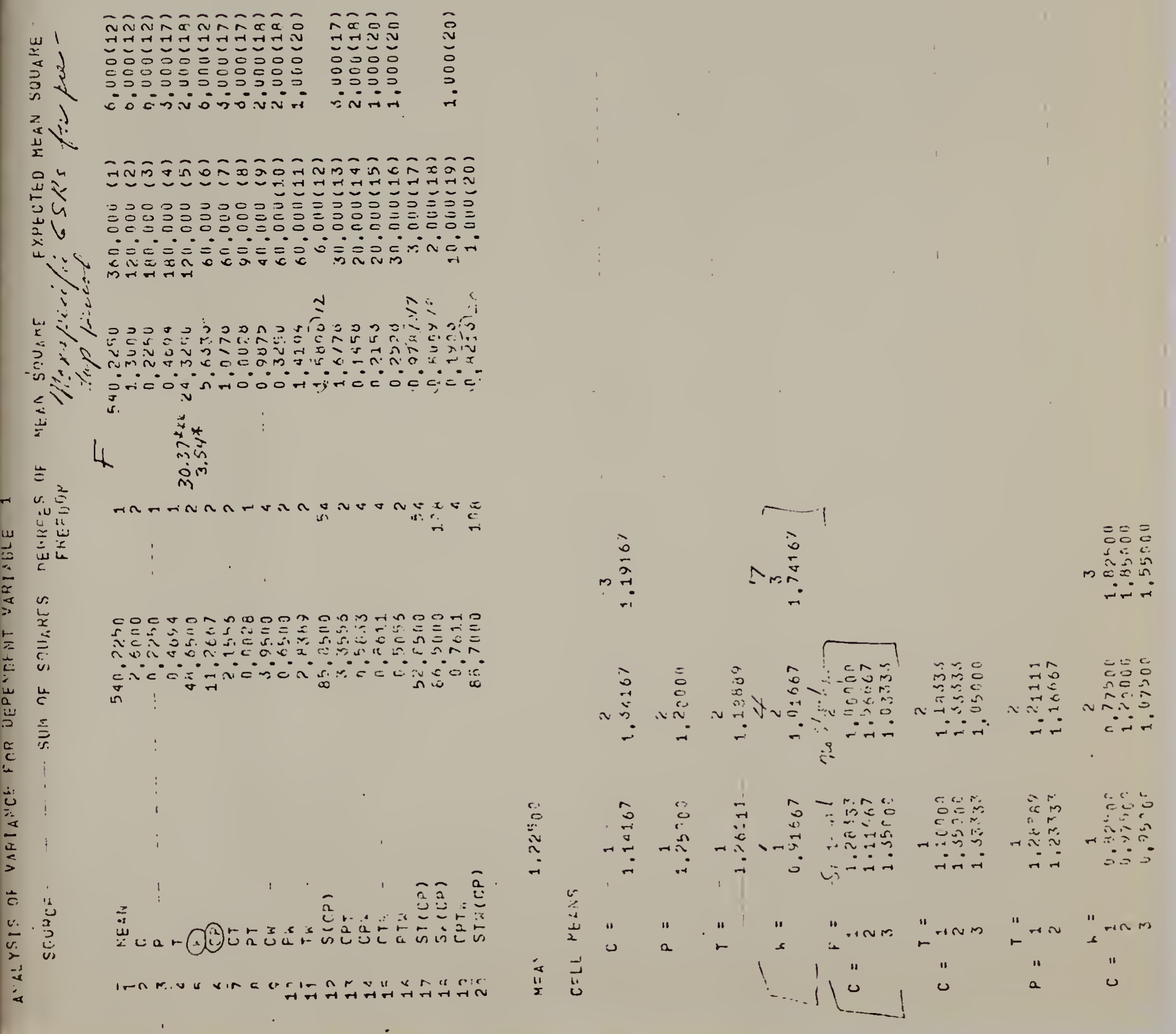




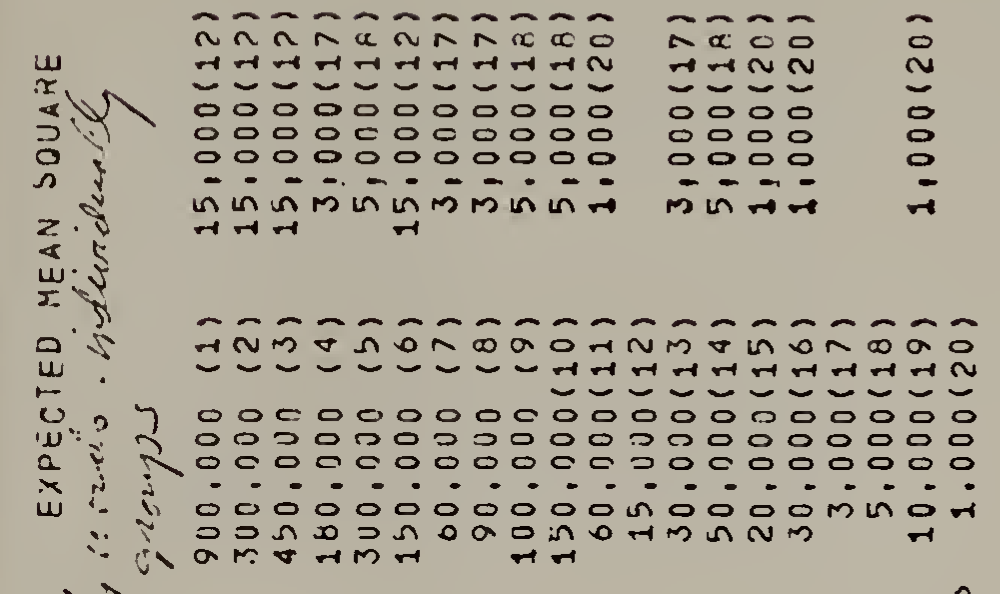

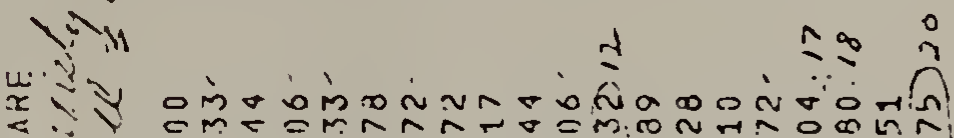

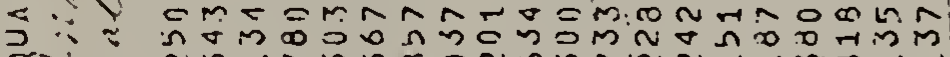

in $\Rightarrow$ ó

zMi $\stackrel{-1}{2}$.
3

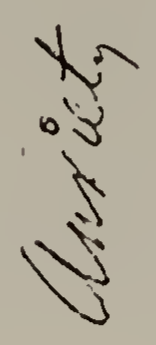

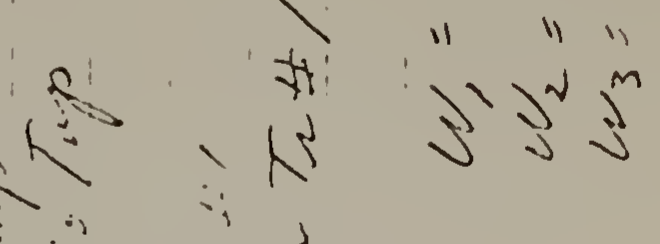

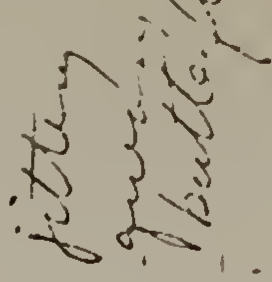




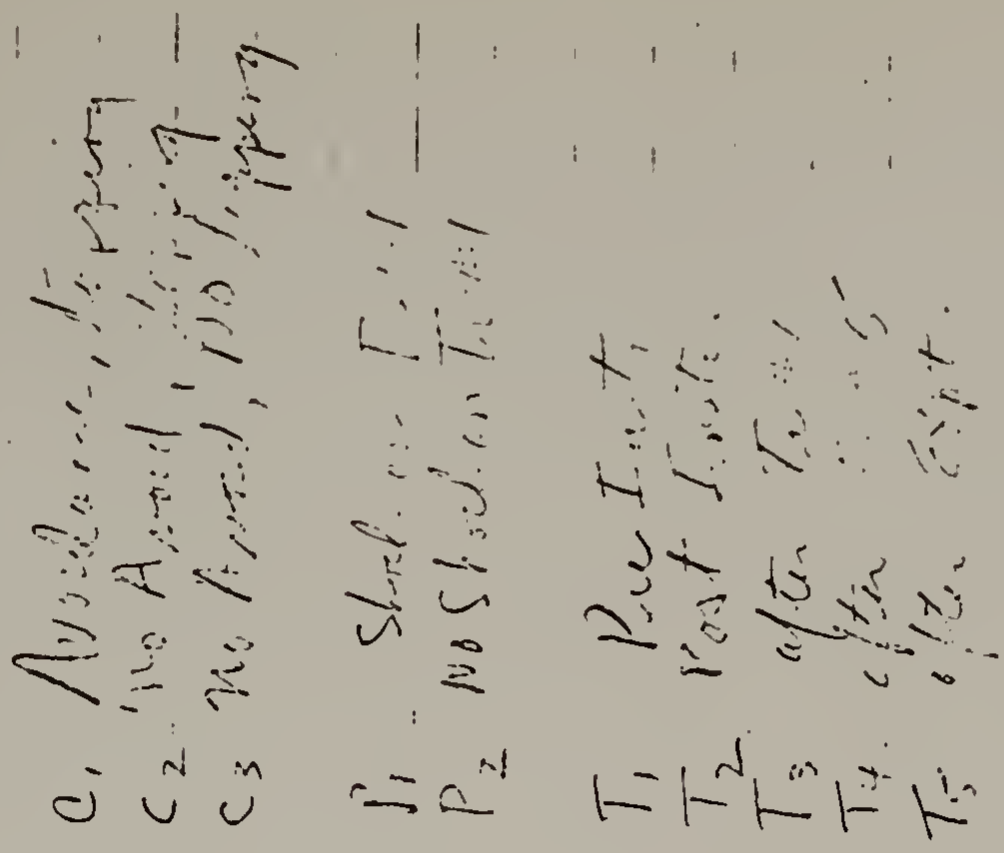

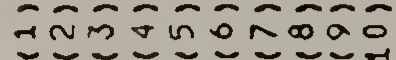
c000000000

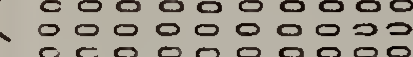

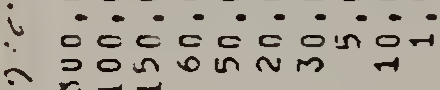
$\begin{aligned} i & \text { ! }\end{aligned}$

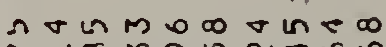

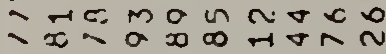

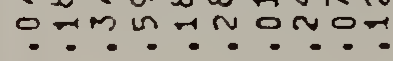

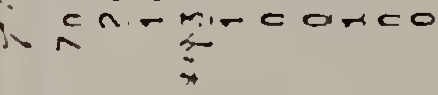
L $\vdots$

ranano

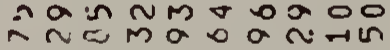

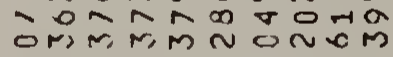
or
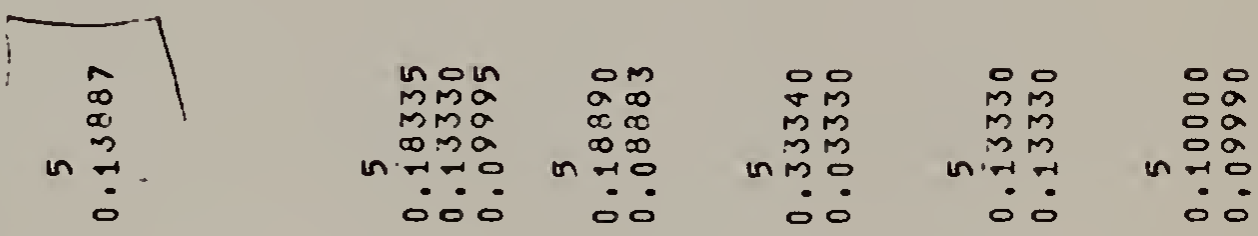

$n$
0
0
0
0
0
0
0

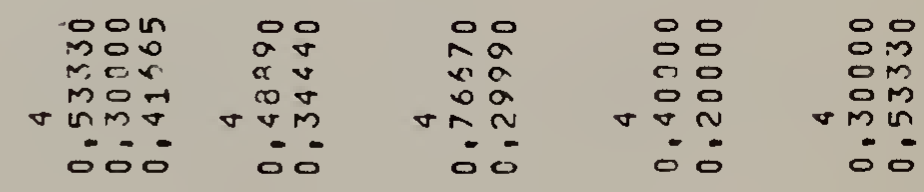

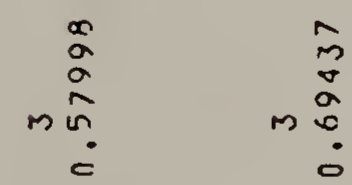

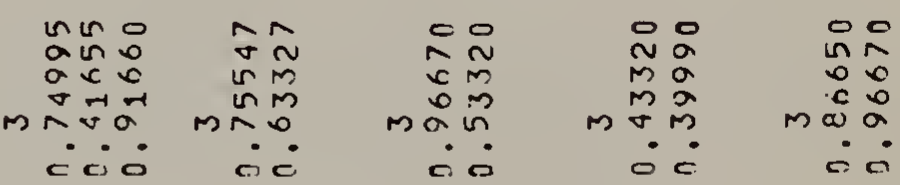

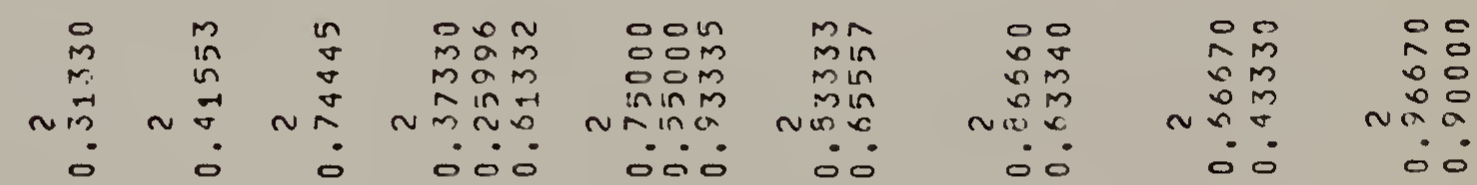

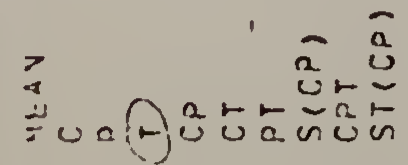

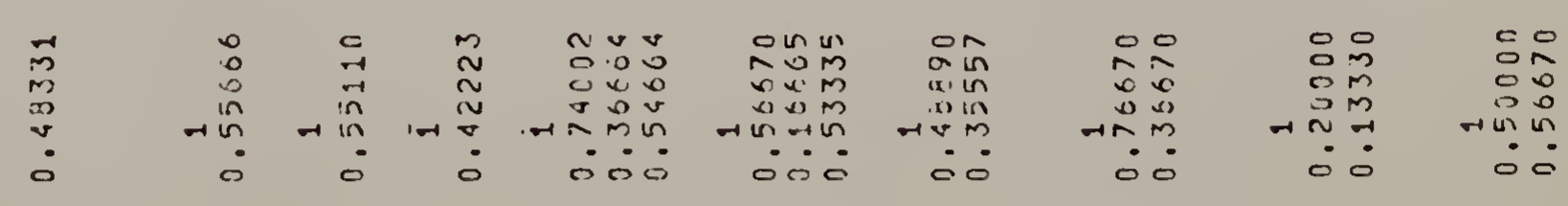

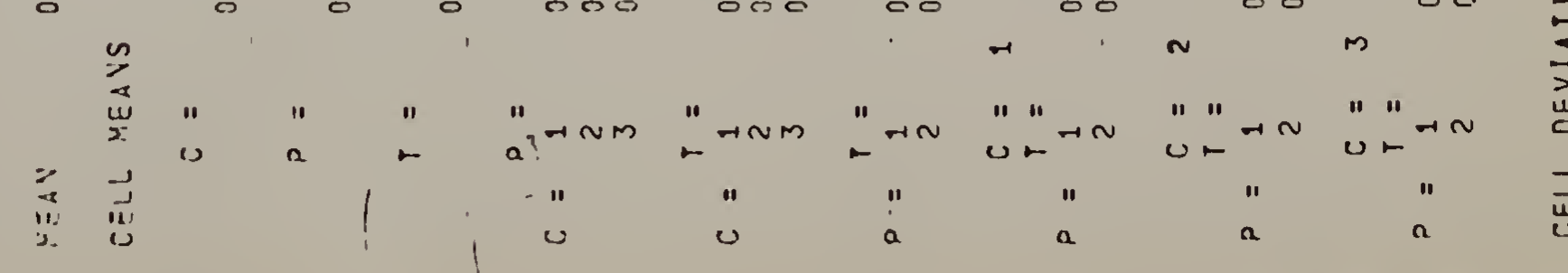
annunonomes 


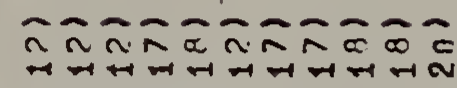

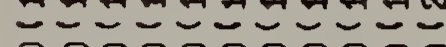
0
0000000000000
000000000000

뜰ำ

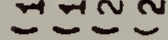
:

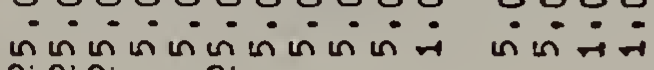

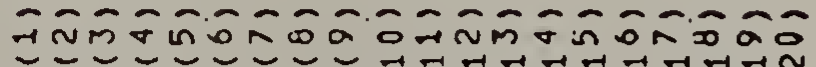

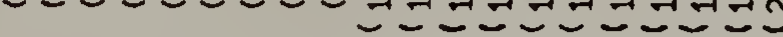

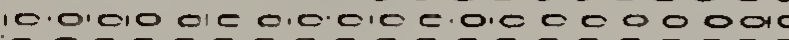
응ㅇㅇㅇㅇㅇㅇㅇㅇㅇㅇㅇㅇㅇㅇㅇㅇㅇㅇㅇㅇㅇㅇㅇㅇ영 - $0^{-}-0^{-}-0^{-}$

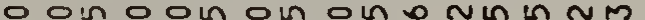
ininmmantan

$\pm \quad 2 \infty ?$

monnuatooud m नNOL iñon

$$
\begin{aligned}
& \begin{array}{ll}
\text { Na } & \text { xy } \\
\text { रक } &
\end{array}
\end{aligned}
$$

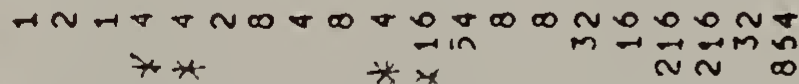

$$
\begin{aligned}
& \begin{array}{c}
* * \\
* * \\
* *
\end{array}
\end{aligned}
$$

थNก mNAO

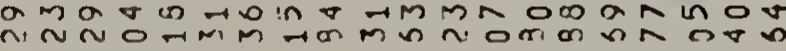

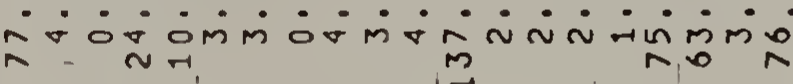

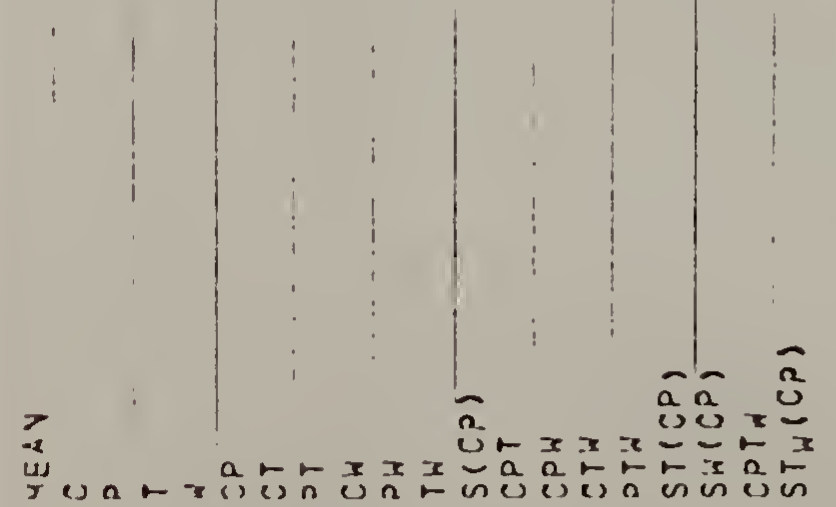

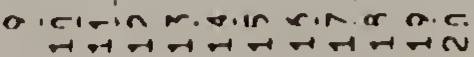

임

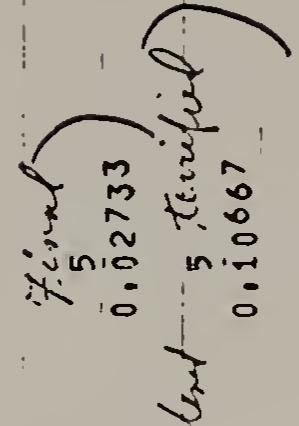

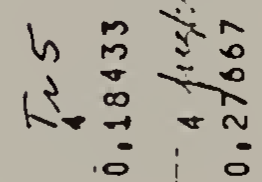

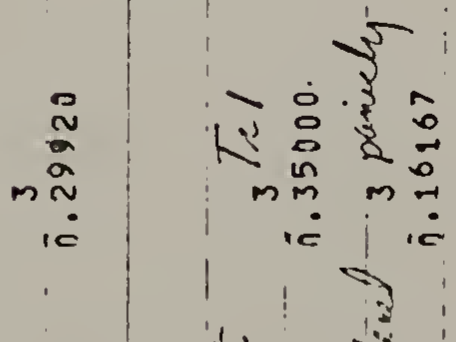

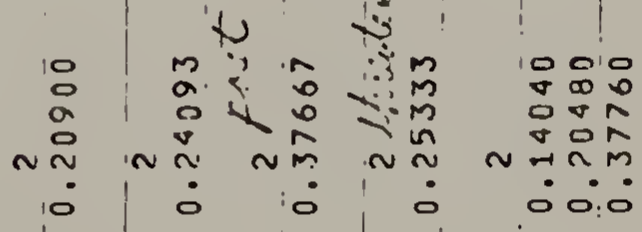

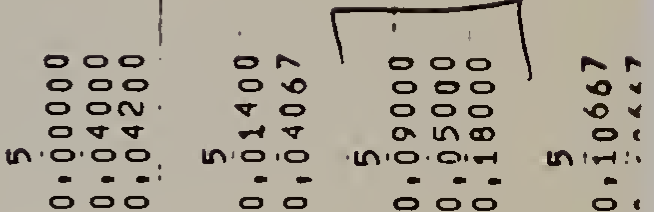

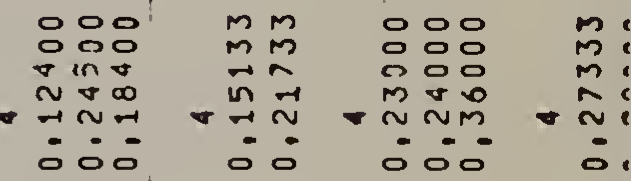

\section{응이}

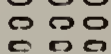

$\min \pi \infty$

icicic

$n m$
0
0
$m$
$m$

으이 Ấ iं

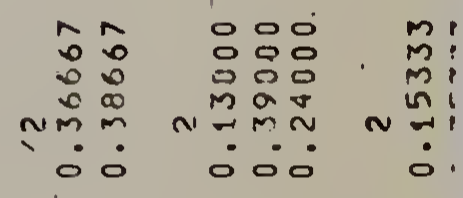

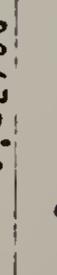
$\int_{\substack{x \\ z}}^{u}$

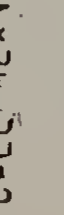




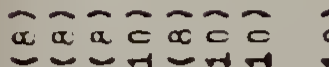
0000000

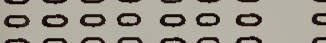
जा

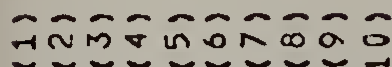
-

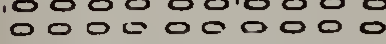
0000000000

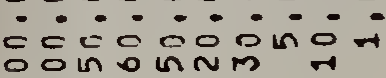
$m \rightarrow$

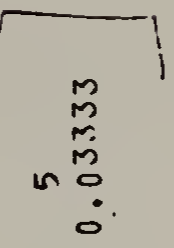

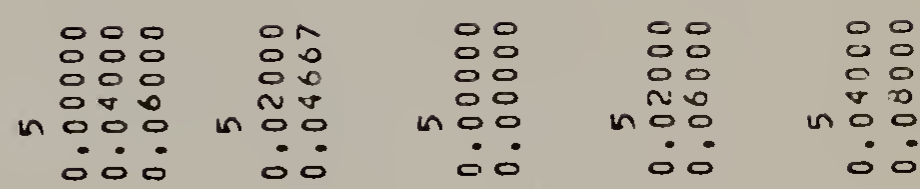

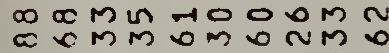
of in $m$ 舟 0.

L

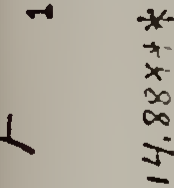

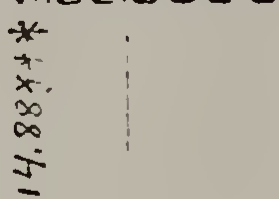

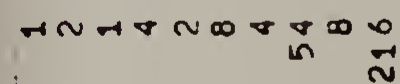

우ำ OMMM ०000 000000<smiles>C=CC=CCCC</smiles><smiles>CCCCCCCC</smiles>
h 


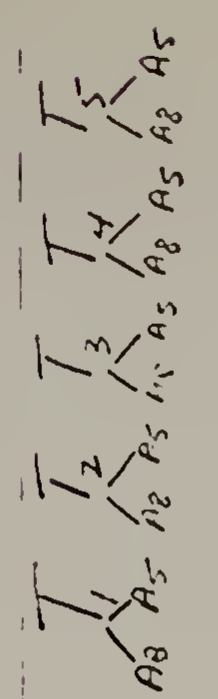

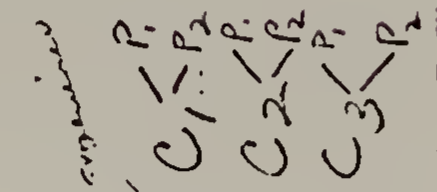

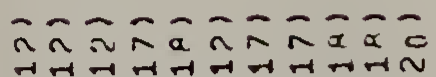

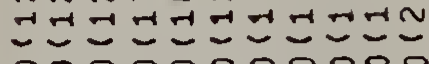

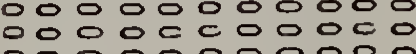

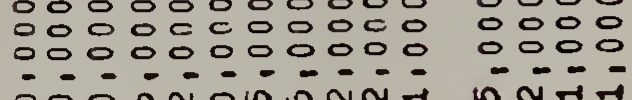

000

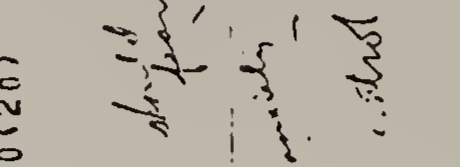

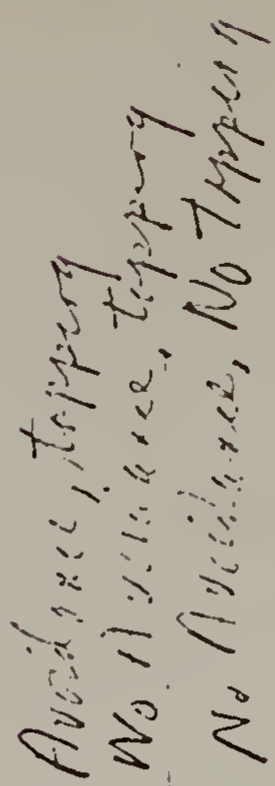

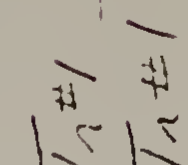

1512

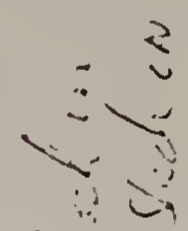

$\because$

"
0

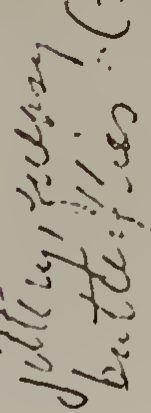

.4

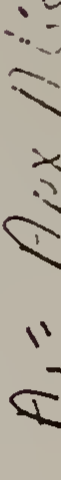

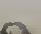

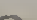
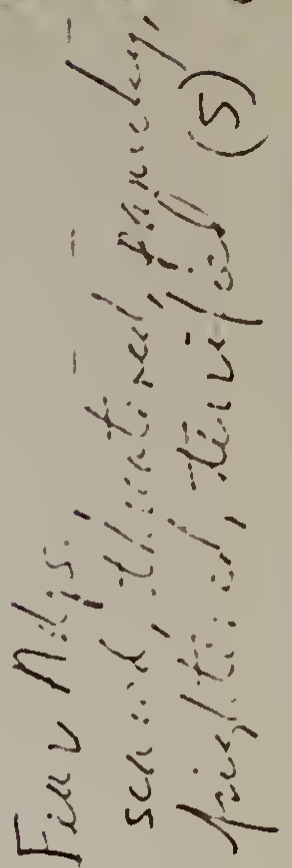

$e^{11}$

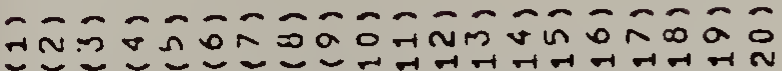

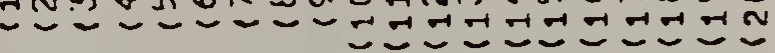
C0000000000000000000

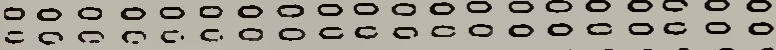

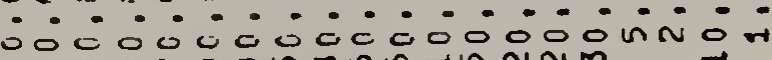

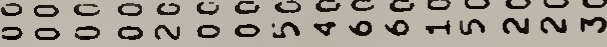

रागयननन ?

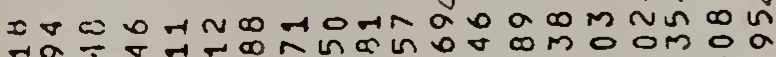
न

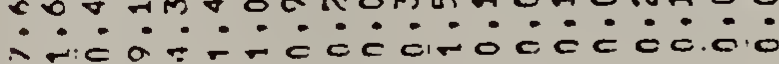

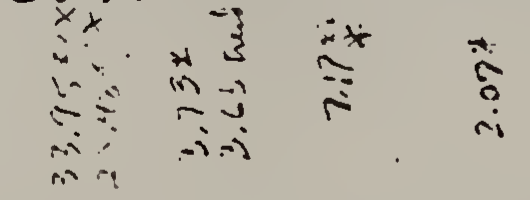
4

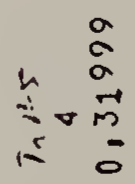

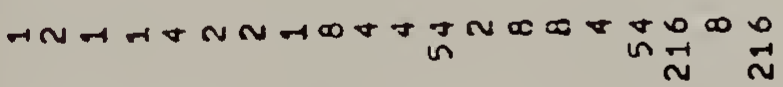

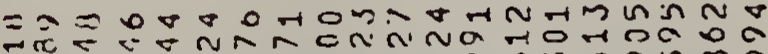

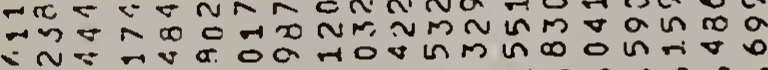

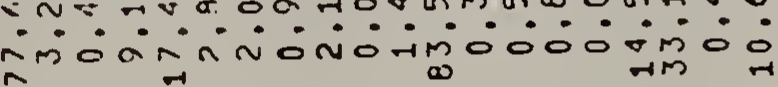

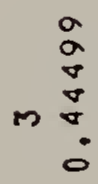

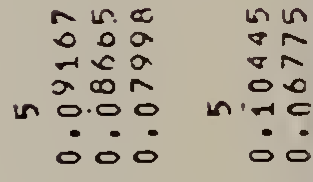

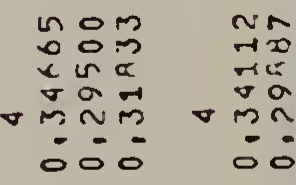

ईई

$c \leqslant$

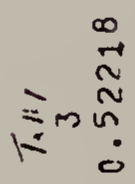<smiles>C=C[Tl]</smiles>
$\frac{1}{1}$

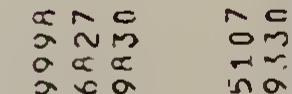
m 0ं0

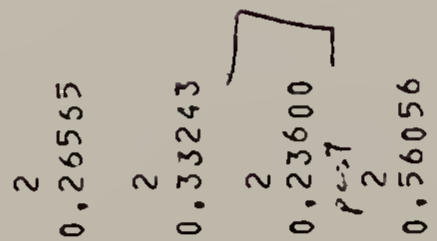

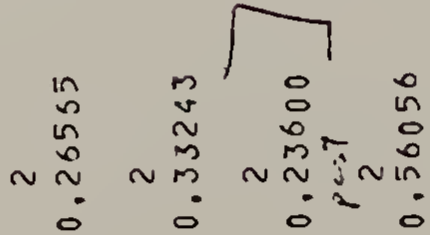
约成品:

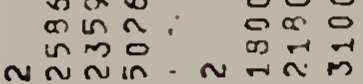
$000^{\circ}$ ñm $\sim \stackrel{n}{\sim}$ ¿०

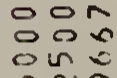
in $\approx$ in $\therefore \circ 0^{\circ}$

$2=$
$\therefore: 5$
$0 i n$
0.0
0.0

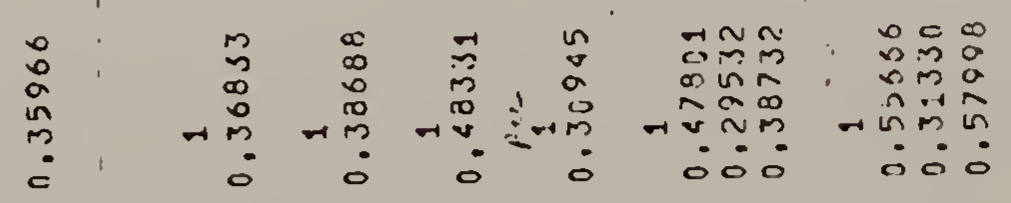
cm in $y$ min $\therefore$ व००

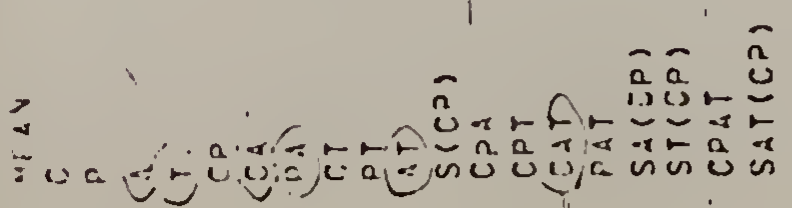
wa cut

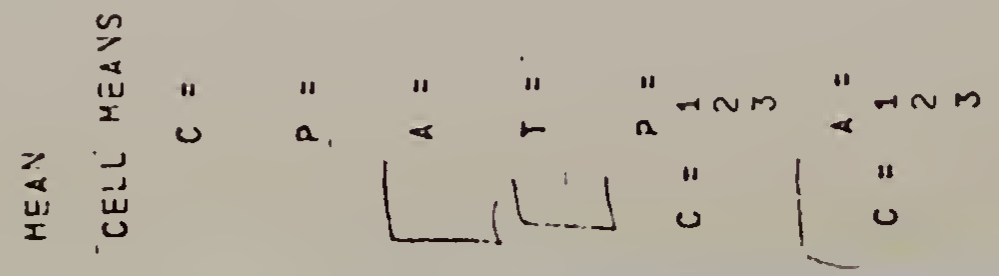


